RICARDO ANTONIO GUIMARÃES BARBOSA

\title{
Avaliação farmacocinética e farmacodinâmica do propofol em pacientes submetidos à revascularização do miocárdio, com ou sem utilização de circulação extracorpórea
}

Tese apresentada ao Departamento de Cirurgia da Faculdade de Medicina da Universidade de São Paulo para obtenção do título de Doutor em Ciências.

Área de concentração: Anestesiologia

Orientadora: Profa. Dra. Maria José Carvalho Carmona

São Paulo

2004 


\section{RICARDO ANTONIO GUIMARÃES BARBOSA}

\section{Avaliação farmacocinética e farmacodinâmica do propofol em pacientes submetidos à revascularização do miocárdio, com ou sem utilização de circulação extracorpórea}

Tese apresentada ao Departamento de Cirurgia da Faculdade de Medicina da Universidade de São Paulo para obtenção do título de Doutor em Ciências.

Área de concentração: Anestesiologia

Orientadora: Profa. Dra. Maria José Carvalho Carmona

São Paulo

2004 
Aos meus pais, OSCAR (in memoriam) e MARIA

JEANETE, com enorme amor e respeito,

Aos meus avós, ANTONIO (in memoriam) e

JEANNETTE, com carinho,

À minha esposa ROSANA, com muito amor. 


\section{AGRADECIMENTOS}

À minha orientadora, Profa. Dra. Maria José Carvalho Carmona, à qual devo grande parte de minha formação científica;

Ao Prof. Dr. José Otávio Costa Auler Júnior, pelo incentivo constante à pesquisa;

À Prof. Dra. Silvia Regina Cavani Jorge Santos, pela imensa ajuda na investigação da farmacologia clínica e colaboração na análise farmacocinética deste estudo;

À farmacêutica Valéria Adriana Pereira e aos funcionários do Laboratório de Farmacologia Terapêutica da Faculdade de Ciências Farmacêuticas da USP, pelo apoio na realização desta pesquisa;

À Dra. Marilde de Albuquerque Piccioni e à Dra. Paula Andréa Baptista Franco pela grande ajuda na coleta dos dados;

Aos colegas da Unidade de Recuperação Cardíaca do Instituto do Coração, com os quais tanto aprendi no convívio diário;

Ao gerente comercial da Berkeley, Jorge Bonsanto, que com dedicação ajudou na realização desta pesquisa, fornecendo os sensores para a medida do índice bispectral;

Aos pacientes e seus familiares, que entenderam os objetivos desta pesquisa e autorizaram sua realização. 


\section{LISTA DE ABREVIATURAS E UNIDADES}

\begin{tabular}{|c|c|c|}
\hline AIC & - & Anestesia intravenosa contínua \\
\hline ANOVA & - & Análise de variância para medidas repetidas \\
\hline AUC & - & Área sob a curva tempo versus concentração \\
\hline$\beta$ & - & Constante de velocidade de eliminação rápida \\
\hline BIS & - & Índice bispectral \\
\hline Bpm & - & Batimentos cardíacos por minuto \\
\hline CAM & - & Concentração alveolar mínima \\
\hline CAPPesq & - & Comissão de Ética para Análise de Projetos de Pesquisa \\
\hline CEC & - & Circulação extracorpórea \\
\hline $\mathrm{Cl}_{\mathrm{T}}$ & - & clearance ou depuração total \\
\hline $\mathrm{C}_{\mathrm{ss}}$ & - & Concentração do fármaco no estado de equilíbrio (steady state) \\
\hline Dl & - & Decilitro \\
\hline DP & - & Desvio-padrão da média \\
\hline DII & - & Derivação eletrocardiográfica \\
\hline $\mathrm{E}$ & - & Expiração \\
\hline EEG & - & Eletroencefalograma \\
\hline EP & - & Erro padrão da média \\
\hline FC & - & Freqüêencia cardíaca \\
\hline $\mathrm{FiO}_{2}$ & - & Fração inspirada de oxigênio \\
\hline GABA & - & Ácido gama amino butírico \\
\hline $\mathrm{H}$ & - & Hora \\
\hline HPLC & - & Cromatografia líquida de alta eficiência \\
\hline $\mathrm{Ht}$ & - & Hematócrito \\
\hline I & - & Inspiração \\
\hline IOT & - & Intubação orotraqueal \\
\hline IMC & - & Índice de massa corpórea \\
\hline $\mathrm{Kg}$ & - & Quilograma \\
\hline $\mathrm{L}$ & - & Litro \\
\hline $\mathrm{M}^{2}$ & - & Metro quadrado \\
\hline Min & - & Minuto \\
\hline
\end{tabular}




\begin{tabular}{|c|c|c|}
\hline $\mathrm{Mg}$ & - & Miligrama \\
\hline M1 & - & Mililitro \\
\hline $\mathrm{N}$ & - & Número \\
\hline $\mathrm{PaCO}_{2}$ & - & Pressão arterial de dióxido de carbono \\
\hline PAD & - & Pressão arterial diastólica \\
\hline PAM & - & Pressão arterial média \\
\hline PAS & - & Pressão arterial sistólica \\
\hline $\mathrm{PE}$ & - & Performance de erro ou percentual do erro de previsão \\
\hline P.O. & - & Pós-operatório \\
\hline P.O.I. & - & Pós-operatório imediato \\
\hline PVC & - & Pressão venosa central \\
\hline $\mathrm{RM}$ & - & Revascularização miocárdica \\
\hline $\mathrm{Rpm}$ & - & Rotações por minuto \\
\hline Sat $\mathrm{O}_{2}$ & - & Saturação de oxigênio \\
\hline $\mathrm{SC}$ & - & Superfície corpórea \\
\hline $\mathrm{SNC}$ & - & Sistema nervoso central \\
\hline S.O. & - & Sala de operações \\
\hline $\mathrm{T}_{1 / 2} \beta$ & - & Meia-vida de eliminação rápida \\
\hline $\mathrm{T}_{1 / 2} \gamma$ & - & Meia-vida terminal \\
\hline TCI & - & Target-controlled infusion \\
\hline $\mathrm{U}$ & - & Unidade \\
\hline USP & - & Universidade de São Paulo \\
\hline UTI & - & Unidade de terapia intensiva \\
\hline $\mathrm{V}_{1}$ & - & Volume de distribuição no compartimento central (fase alfa) \\
\hline $\mathrm{Vd}$ & - & Volume de distribuição \\
\hline $\operatorname{Vd} \beta$ & - & Volume aparente de distribuição fase beta \\
\hline $\mathrm{Vd} \gamma$ & - & Volume de distribuição residual fase gama \\
\hline VO & - & Via oral \\
\hline Vpp & - & Volume do perfusato da CEC \\
\hline$\mu g$ & - & Micrograma \\
\hline$\Gamma$ & - & Constante de velocidade de eliminação lenta \\
\hline
\end{tabular}


SUMÁRIO 


\section{SUMÁRIO}

\section{RESUMO}

SUMMARY

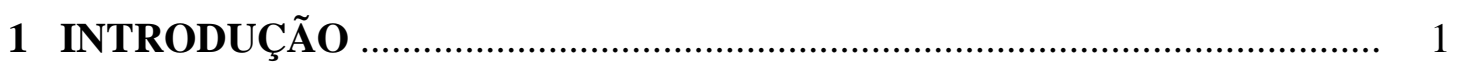

1.1 Objetivos.................................................................................. 4

2 REVISÃO DA LITERATURA ............................................................. 5

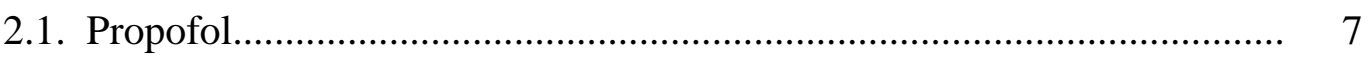

2.1.1 Farmacocinética do propofol.................................................... 9

2.1.2 Farmacodinâmica do propofol....................................................... 13

2.1.2.1 Índice bispectral (BIS) ....................................................... 13

2.2 Infusão alvo-controlada ............................................................. 16

$2.3 \mathrm{O}$ uso de propofol em anestesia para cirurgia cardíaca.......................... 21

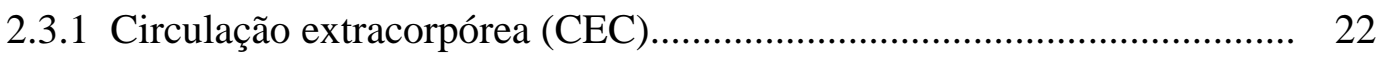

2.3.2 Aspectos fisiológicos e mecânicos da CEC......................................... 23

2.3.3 Efeitos da CEC sobre a farmacocinética dos agentes anestésicos

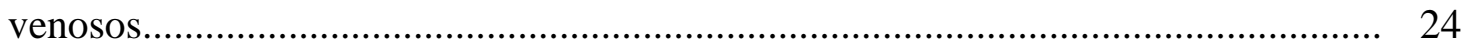

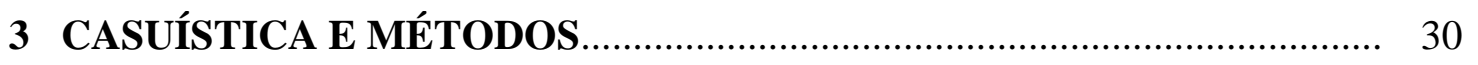

3.1 Projeto de pesquisa........................................................................ 31

3.1.1 Critério de seleção dos pacientes..................................................... 31

3.1.2 Termo de consentimento livre e esclarecido.................................... 32

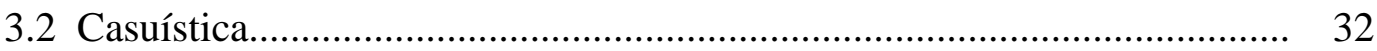

3.3 Métodos................................................................................ 33 
3.4 Análise das amostras sangüíneas............................................................ 39

3.5 Análise farmacocinética (procedimento analítico).................................... 40

3.5.1 Reagentes, padrões de referência e soluções............................................ 40

3.5.2 Validação da metodologia analítica........................................................ 43

3.5.3 Modelagem cinética do propofol......................................................... 44

3.6 Cálculo da percentagem do erro de previsão............................................. 46

3.7 Metodologia estatística.................................................................... 46

4 RESULTADOS

4.1 População estudada.................................................................................. 49

4.2 Infusão de propofol......................................................................... 50

4.2.1 Dose infundida de propofol............................................................ 50

4.2.2 Velocidade de infusão do propofol...................................................... 52

4.2.3 Tempo previsto de regressão............................................................... 54

4.3 Concentrações plasmáticas de propofol...................................................... 56

4.3.1 Cálculo da percentagem do erro de previsão.............................................. 60

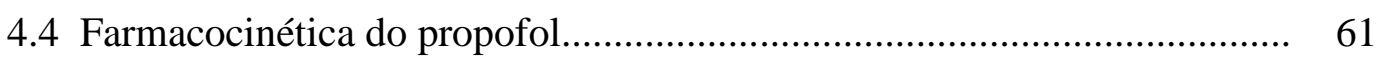

4.5 Farmacodinâmica do propofol................................................................ 62

4.5.1 Avaliação do grau de hipnose............................................................. 62

4.5.1.1 Índice bispectral (BIS) .................................................................. 62

4.5.2 Avaliação hemodinâmica......................................................................... 66

4.5.2.1 Pressão arterial média (PAM) ........................................................... 66

4.5.2.2 Freqüência cardíaca (FC)............................................................. 68 
5 DISCUSSÃO

5.1 Em relação à casuística e aos métodos.................................................... 72

5.2 Infusão de propofol............................................................................ 74

5.3 Concentrações plasmáticas de propofol....................................................... 77

5.4 Avaliação farmacocinética do propofol...................................................... 79

5.5 Avaliação farmacodinâmica................................................................... 82

5.5.1 Grau de hipnose...................................................................... 82

5.5.2 Avaliação hemodinâmica........................................................................ 83

5.6 Considerações finais................................................................................ 85

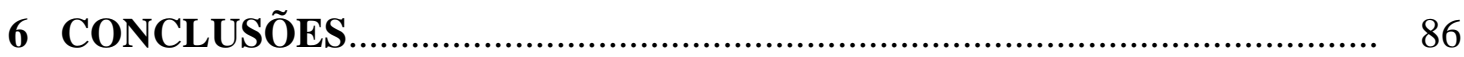

7 REFERÊNCIAS BIBLIOGRÁFICAS......................................................... 88 APÊNDICES 
RESUMO 


\section{RESUMO}

BARBOSA, R.A.G. - Avaliação farmacocinética e farmacodinâmica do propofol em pacientes submetidos à revascularização do miocárdio, com ou sem utilização de circulação extracorpórea. São Paulo, 2004. 120 p. Tese (Doutorado) - Faculdade de Medicina, Universidade de São Paulo.

A circulação extracorpórea (CEC) pode alterar a concentração plasmática prevista para fármacos administrados durante a anestesia. Os objetivos deste estudo foram avaliar os efeitos da CEC sobre a farmacocinética, farmacodinâmica e as concentrações plasmáticas do propofol em pacientes submetidos à cirurgia de revascularização miocárdica (RM) com ou sem utilização de CEC, correlacionando-se às concentrações plasmáticas obtidas com as previstas por infusão contínua alvo-controlada. Dez pacientes submetidos à RM com CEC (Grupo CEC) e dez sem CEC (Grupo sem CEC) foram comparados em relação à concentração plasmática obtida, utilizando-se cromatografia líquida de alta eficiência e aquela prevista por infusão alvo-controlada, em relação à farmacocinética $\left(\mathrm{t}_{1 / 2} ß\right.$, volume de distribuição e clearance plasmático), ao grau de hipnose (índice bispectral) e aos parâmetros hemodinâmicos (pressão arterial média e freqüência cardíaca), avaliados nos períodos intra-operatório e pós-operatório imediato. Os dados foram avaliados pela análise de variância para medidas repetidas, considerando-se significativo $p<0,05$. A concentração obtida de propofol foi maior no grupo sem CEC nos momentos 120 min $(3,32 \pm 1,76$ no grupo sem CEC e 2,48 $\pm 1,12$ no grupo CEC, $\mathrm{p}=0,005)$ e $240 \mathrm{~min}(3,24 \pm 2,71$ no grupo sem CEC e 2,23 $\pm 2,48$ no grupo CEC, $p=0,0212$ ) após o início da cirurgia. A concentração medida de propofol foi maior que a prevista nos 2 grupos, com valores superiores no grupo sem CEC ( $\mathrm{p}=0,02)$. $O \mathrm{t}_{1 / 2} \beta$ foi maior no grupo sem CEC $(3,67 \pm 1,15$ grupo sem CEC e $1,82 \pm 0,5$ no grupo $\mathrm{CEC}, \mathrm{p}=0,0005)$ e o clearance plasmático maior no grupo CEC (28,36 $\pm 11,40$ no grupo CEC e 18,29 $\pm 7,67$ no grupo sem CEC, $p=0,03)$. O grau de hipnose foi superior no grupo CEC. Os grupos não diferiram quanto à análise hemodinâmica. Conclui-se que a CEC promove alterações na farmacocinética e nas concentrações plasmáticas de propofol, com conseqüente diferença no grau de hipnose em relação aos pacientes submetidos à revascularização do miocárdio sem utilização de CEC. 
SUMMARY 


\section{SUMMARY}

BARBOSA, R.A.G. Evaluation of pharmacokinetics and pharmacodynamics of propofol in patients undergoing coronary artery bypass grafting, with or without cardiopulmonary bypass. São Paulo, 2004. 120 p. Tese de Doutorado - Faculdade de Medicina da Universidade de São Paulo.

Cardiopulmonary bypass $(\mathrm{CPB})$ can alter predicted plasmatic concentration of drugs administered during anesthesia. The aim of this study was evaluate the effects of cardiopulmonary bypass under pharmacokinetics, pharmacodynamics and plasmatic concentration of propofol in patients undergoing coronary artery bypass grafting surgery $(\mathrm{CABG})$ with or without $\mathrm{CPB}$, comparing measured plasmatic concentration with predicted concentration administered by target-controlled infusion. Ten patients undergoing coronary artery bypass grafting surgery with CPB (CPB Group, n=10) and ten without CPB (offpump Group, $\mathrm{n}=10$ ) were compared in relaction to measured plasmatic concentration using high performance liquid chromatography (HPLC) and predicted concentration administered by target-controlled infusion, pharmacokinetics $\left(\mathrm{t}_{1 / 2} \beta\right.$, volume of distribution and total clearance), hypnosis degree (bispectral index) and hemodynamics parameters (mean arterial pressure and heart rate) during and after surgery. Statistical analysis was done using analysis of variance for repeated measures $\left(*_{p}<0,05\right)$. Measured plasmatic concentration was higher in off-pump group in the moments $120 \mathrm{~min}(3,32 \pm 1,76$ in offpump group and 2,48 $\pm 1,12$ in CPB group, $\mathrm{p}=0,005)$ and 240 min $(3,24 \pm 2,71$ in off-pump group and 2,23 $\pm 2,48$ in CPB group, $p=0,0212$ ) after the beginning of surgery. Measured plasmatic concentration was higher than predicted in two groups, with superior values in off-pump group ( $\mathrm{p}=0,02) . \mathrm{T}_{1 / 2} \beta$ was greater in off-pump group $(3,67 \pm 1,15$ in off-pump group and 1,82 $\pm 0,5$ in $\mathrm{CPB}$ group, $\mathrm{p}=0,0005$ ) and total clearance was higher in CPB group (28,36 $\pm 11,40$ in CPB group and 18,29 $\pm 7,67$ in off-pump group, $p=0,03)$. Hypnosis degree was greater in CPB group. Hemodynamics parameters did not differ between the groups. In conclusion, $\mathrm{CPB}$ causes alterations on pharmacokinetics and under propofol plasmatic concentration with higher hypnosis degree when compared with patients undergoing coronary artery bypass grafting surgery without CPB (off-pump group). 
INTRODUČ̃̃ 


\section{INTRODUÇÃO}

Além de proporcionar hipnose, amnésia e analgesia, a anestesia para cirurgia cardíaca deve proporcionar estabilidade hemodinâmica com mínima depressão miocárdica e rápida recuperação pós-operatória (WHITE, 2001). A ausência de hipnose durante a anestesia geral, além de ser experiência desagradável, pode resultar em sérios distúrbios emocionais, pesadelos recorrentes e possíveis problemas médico-legais (SPACKMAN et al., 2002). A ocorrência deste episódio em cirurgias gerais é de 0,1 a 2\% (SEBEL, 2003) e em cirurgias cardíacas pode variar de 1,1 a 23\% (GOLDMAN et al., 1987; PHILLIPS et al., 1993). A utilização de doses menores de agentes anestésicos devido a alterações hemodinâmicas, a hemodiluição durante a circulação extracorpórea (CEC), a necessidade aumentada de anestésicos durante o reaquecimento ao final da CEC e o emprego de opióides sem a utilização de anestésicos gerais inalatórios (HELLER, 2002) podem contribuir para a ocorrência de hipnose insatisfatória em cirurgia cardíaca.

O propofol, agente sedativo hipnótico não barbitúrico, tem sido usado na indução e manutenção da anestesia geral, bem como para sedação em pacientes submetidos a procedimentos diagnósticos ou sob assistência ventilatória em unidades de terapia intensiva (REVES et al., 2000). O perfil farmacocinético do propofol favorece a recuperação rápida e o tempo de ação curta torna conveniente a administração em infusão contínua. O acoplamento de softwares farmacocinéticos à bomba de infusão permite a administração do fármaco em velocidade capaz de manter concentração 
plasmática constante, resultando na manutenção do efeito hipnótico pelo tempo desejado (BAILEY et $a l .$, 1996). Dentre as vantagens da utilização desta técnica anestésica, conhecida como infusão alvo-controlada, inclui-se indução anestésica em tempo adequado, manutenção do nível desejado de hipnose e rápida recuperação após a interrupção da infusão do propofol (WHITE, 2001). Embora o propofol possa ter vantagem em relação ao tempo de despertar, a sua segurança em pacientes com baixa reserva cardíaca tem sido tema de muitos debates na literatura médica (WHITE, 2001).

Em pacientes submetidos à cirurgia cardíaca, a circulação extracorpórea pode alterar a concentração plasmática prevista para os fármacos administrados durante a anestesia. A hemodiluição, a perda sangüínea, a mobilização de líquidos e os efeitos da hipotermia podem alterar a cinética dos fármacos (METS, 2000). A redução no fluxo sangüíneo hepático pode modificar a biotransformação de fármacos de alta extração pelo fígado, afetando a eliminação fluxo-sangüíneo dependente (GOUKE et al., 1982; BUYLAERT et al., 1989). Por outro lado, na cirurgia cardíaca sem CEC, a reposição volêmica com cristalóides promove hemodiluição e alterações nas concentrações de proteínas plasmáticas podendo alterar a ligação protéica (WOOD et al., 1979; WOOD et al., 1986; HIRAOKA et al., 2004), a concentração plasmática e o efeito dos fármacos.

Considerando-se que os efeitos da CEC, ou da hemodiluição durante a revascularização miocárdica sem CEC, sobre a farmacocinética e a farmacodinâmica do propofol são inconclusivos (MASSEY et al., 1990; LEE et al., 1995; BAILEY et al., 1996; HAMMAREN et al., 1996), justifica-se estudo comparativo destes parâmetros na revascularização do miocárdio, com ou sem utilização de CEC. 


\subsection{OBJETIVOS}

Os objetivos deste estudo foram a compararação dos efeitos da cirurgia de revascularização miocárdica, com ou sem utilização de circulação extracorpórea sobre a farmacocinética, as concentrações plasmáticas e a farmacodinâmica do propofol administrado por infusão alvo-controlada. 


\section{REVISÃO DA LITERATURA}




\section{REVISÃO DA LITERATURA}

A técnica ideal de anestesia geral deve produzir início rápido de ação e condições cirúrgicas estáveis, enquanto assegura recuperação rápida dos reflexos protetores, bem como das funções cognitivas e psicomotoras (WHITE, 2001). Ao avaliar a recuperação anestésica em pacientes internados e ambulatoriais, o processo de recuperação tem três fases distintas. A recuperação inicial geralmente se refere ao despertar, descrevendo tempo em que o paciente acorda da anestesia e obedece a comandos simples. A recuperação intermediária (ou simplesmente "recuperação") descreve o retorno suficiente das funções cognitivas e psicomotoras para receber alta da unidade de recuperação pós-anestésica (URPA). A recuperação tardia descreve o retorno ao estado pré-operatório e a retomada de atividades normais (WHITE, 2001).

Desde a sua introdução na clínica anestésica, o propofol tornou-se um anestésico venoso muito usado para procedimentos cirúrgicos ambulatoriais devido à recuperação previsível e perfil favorável quanto aos efeitos colaterais. A recuperação é rápida não somente após dose única em bolus, mas também após doses repetidas ou infusões contínuas tituladas, permitindo, assim, o uso eficaz do propofol para a manutenção anestésica (DING et al., 1993). O período “curto” de recuperação após o uso de propofol levou alguns autores a especular sobre a possível economia de custo que resultaria do uso de técnicas anestésicas em que o propofol é utilizado (SANDERS et al., 1989; SUNG et al., 1991). 


\subsection{Propofol}

Desde a introdução do propofol na prática clínica, no final da década de 80, muitos estudos sobre este agente foram realizados pela comunidade científica e publicados na literatura especializada (MACKENZIE et al., 1985; REVES, et al.,2000). Embora o propofol tenha sido inicialmente aprovado como agente hipnótico de indução e manutenção, seu uso clínico expandiu-se bastante, passando a ser indicado não apenas em diferentes tipos de cirurgias, como também para sedação em pacientes na unidade de terapia intensiva (UTI) (SEBEL et al., 1997). O propofol rapidamente se tornou o fármaco de escolha para indução anestésica em pacientes submetidos a procedimentos ambulatoriais e é cada vez mais usado na prática anestésica. As propriedades antieméticas e as modificadoras do humor peculiares ao propofol podem resultar em novas aplicações clínicas (ZACNY et al., 1992). Embora relatos individuais sugiram que o propofol possua propriedades euforizantes (dando a sensação de bem-estar), esse achado não foi comprovado em estudos duplos-cegos controlados. No entanto, por ter efeito agradável nos indivíduos, o propofol pode potencialmente conduzir ao abuso ou uso indevido (WHITE, 2001).

Durante a cirurgia as respostas dos pacientes ao propofol variam muito, e a dose e a velocidade de administração do propofol devem ser tituladas conforme as necessidades individuais dos pacientes. Os fatores que influenciam as doses necessárias de propofol incluem idade, peso, doenças prévias, tipos de procedimentos cirúrgicos e tratamentos clínicos concomitantes (SHAFER, 1993).

Quando o propofol for componente de técnica balanceada ou anestesia venosa total (AVT), velocidades de infusão de 75 a $300 \mu \mathrm{g} / \mathrm{kg} / \mathrm{min}$ geralmente serão 
necessárias e velocidades de infusão de 25 a $100 \mu \mathrm{g} / \mathrm{kg} / \mathrm{min}$ poderão manter uma sedação adequada (WHITE, 2001).

Podem ser definidas concentrações plasmáticas "alvo" para a hipnose (2 a 6 $\mu \mathrm{g} / \mathrm{ml})$ ou sedação $(0,5$ a $1,5 \mu \mathrm{g} / \mathrm{ml})$ durante uma variedade de condições clínicas. Os sistemas de administração baseados na farmacocinética podem atingir rapidamente concentrações plasmáticas alvo. Entretanto, é necessário fazer a titulação cuidadosa até a obtenção do efeito desejado, por causa da variabilidade interindividual na farmacocinética e farmacodinâmica deste agente. Além disso, a concentração terapêutica do propofol depende do estímulo cirúrgico (GLASS et al., 1989).

Os estudos a respeito do mecanismo molecular dos efeitos do propofol sobre o sistema nervoso central (SNC) sugerem que, assim como os outros depressores do SNC (barbitúricos, etomidato), ele ativa o complexo ionóforo do receptor GABA $\mathrm{A}$. Em concentrações clinicamente relevantes, o propofol aumenta a condutância ao cloro. No entanto, em altas concentrações de propofol, a dessensibilização do receptor GABA resulta na supressão do sistema inibitório (HARA et al., 1993).

O propofol pertence a uma série de di-ortofenóis substituídos desenvolvidos no início dos anos 70 que possuem moderada a elevada ação hipnótica (VUYK, 1993) e, sendo altamente lipofílico, distribui-se rapidamente do compartimento central para tecidos altamente vascularizados, incluindo o cérebro, e em seguida para tecidos de menor perfusão, sendo parcialmente captado pelos pulmões e novamente liberado para a circulação (MATOT et al., 1993).

A instalação do efeito hipnótico é bastante rápida, observando-se perda de consciência em de 1 a 2 minutos, que pode ser explicado pela rápida distribuição no 
compartimento central e rápido equilíbrio entre a concentração no sangue e no cérebro (2,9 minutos em média), que contribui para uma rápida elevação da concentração no sítio de ação (SCHUTTLER et al., 1985; VUYK, 1993). Desta forma, reporta-se para o fármaco elevado volume de distribuição, indicando extensa distribuição do propofol para os músculos, tecido adiposo e outros tecidos menos perfundidos. A rápida distribuição, associada a uma rápida eliminação, contribui para curta duração do efeito do propofol, da ordem de 5 a 8 minutos (SCHUTTLER et al., 1985; VUYK, 1993). Ele se liga à albumina plasmática e às hemácias na proporção de 97 a 98\%. As doses utilizadas na clínica usualmente não resultam em saturação dos sítios de ligação (SERVIN et al., 1988; VUYK, 1993). Sofre intenso metabolismo hepático, produzindo conjugado com ácido glicurônico e com sulfato, os quais são eliminados pela urina.

\subsubsection{Farmacocinética do propofol}

Vários pesquisadores têm examinado a farmacocinética do propofol em adultos e crianças saudáveis, assim como em diversos estados patológicos. De maior importância é o alto clearance metabólico, aproximadamente dez vezes mais rápido que o do tiopental. O clearance metabólico, do propofol ultrapassa o fluxo sangüíneo hepático, que resultou na sugestão de que o propofol também é metabolizado em locais extra-hepáticos. Comprovou-se essa hipótese pela detecção de metabólitos do propofol durante a fase do transplante hepático ortotópico (VEROLI et al., 1992).

Após um bolus inicial de propofol, os níveis plasmáticos caem rapidamente, em especial devido à distribuição do propofol do cérebro e de outros tecidos bem 
perfundidos para locais de menor perfusão como gorduras e músculos (WHITE, 2001).

Skipsey e colaboradores (SKIPSEY et al., 1993) mostraram que a dose de propofol necessária para produzir inconsciência foi de $6,2 \mu \mathrm{g} / \mathrm{kg} / \mathrm{h}$, e a concentração efetiva média $\left(\mathrm{ED}_{50}\right)$ para produzir o mesmo efeito foi de $2,3 \mu \mathrm{g} / \mathrm{ml}$. Para fazer sedações adequadas, usando um sistema de infusão alvo-controlada, foi necessária uma concentração de 0,9 $\mu \mathrm{g} / \mathrm{ml}$ (SKIPSEY et al., 1993). O volume de distribuição de propofol (3 a 4 1/kg) é semelhante ao do tiopental e, inicialmente, os níveis plasmáticos de tiopental e propofol diminuem de forma semelhante. Subseqüentemente, a diminuição da velocidade do propofol é muito mais rápida que a do tiopental em função de sua alta taxa de clearance metabólico. O propofol pode prejudicar o seu próprio clearance, reduzindo o fluxo sangüíneo hepático, efeito que aumenta na presença de hipotermia leve (LESLIE et al., 1995) .

A meia-vida de eliminação rápida do propofol $\left(\mathrm{t}_{1 / 2} \beta\right)$ é de 1,8 horas, porém a recuperação de seus efeitos clínicos é rápida, mesmo após administração prolongada. O motivo para tal discrepância aparente é que a meia-vida de eliminação lenta ( $\mathrm{t}_{1 / 2}$ gama) está relacionada com a eliminação lenta dos tecidos altamente lipofílicos (por exemplo, a gordura), o que geralmente é irrelevante na clínica (SHAFER et al., 1992).

Hughes e colaboradores introduziram o termo "meia-vida contextosensível" para descrever a recuperação após infusões anestésicas de duração variada (HUGHES et al., 1992). A meia-vida contexto-sensível é o tempo necessário para que a concentração do fármaco no compartimento central seja reduzida em $50 \%$ após o término da infusão (HUGHES et al., 1992). O contexto relaciona-se com a duração da infusão do fármaco antes de ser interrompido. O propofol tem uma meia-vida contexto- 
sensível menor que 25 minutos após infusões que duram até 3 horas e, após infusões prolongadas, a meia-vida ainda é de apenas 50 minutos após o término da infusão (HUGHES et al., 1992).

Se a infusão de propofol for titulada até a obtenção do efeito, de modo que a concentração plasmática do mesmo tenha que diminuir somente 10 a $20 \%$ para permitir o despertar, a recuperação será extremamente rápida. O uso de opióides adjuvantes (por exemplo, o alfentanil) diminuiu a concentração de propofol necessária para que os pacientes recuperem a consciência (VUYK et al., 1995).

Hughes e colaboradores forneceram uma descrição abrangente do modo pelo qual os parâmetros farmacocinéticos do propofol interagem para permitir recuperação rápida (HUGHES et al., 1992). O propofol apresenta grande volume de distribuição no estado de equilíbrio, indicando extensa distribuição do fármaco no músculo, nas gorduras e em outros tecidos de menor perfusão e de grande capacidade.

Entretanto, a velocidade de equilíbrio do compartimento central com os outros compartimentos é lenta. Ao término da infusão de propofol, a concentração no compartimento central é muito mais alta que nos compartimentos periféricos; portanto, a distribuição continua ocorrendo (WHITE, 2001). Conseqüentemente, a concentração no compartimento central diminui pelo metabolismo (eliminação) e pela distribuição contínua. Uma vez que a capacidade desses compartimentos periféricos é grande, a distribuição do compartimento central pode ocorrer mesmo após a administração prolongada do fármaco (WHITE, 2001).

O resultado final é a diminuição rápida da concentração para nível inferior ao necessário para produzir hipnose (ou sedação profunda), permitindo despertar rápido. 
Eventualmente a concentração do compartimento central torna-se mais baixa que nos sítios periféricos, e o fármaco começa a ser mobilizado para dentro do compartimento central. No entanto, a velocidade dessa transferência é lenta (resultando em meia-vida terminal longa), de modo que a concentração de propofol no compartimento central é mantida em níveis baixos por período prolongado. A eliminação do propofol do corpo pode levar muitas horas ou até mesmo dias, embora tenha pequeno efeito sobre a recuperação clínica (WHITE, 2001).

Do mesmo modo que acontece com os barbitúricos, o paciente idoso necessita de doses menores de propofol (WHITE, 2001).

O volume do compartimento central do propofol é maior em crianças que em adultos, com base em quilo de peso corporal, e a taxa de clearance do propofol também é mais alta em crianças. Portanto, elas necessitam de uma dose maior de indução e de uma maior velocidade de infusão para manutenção que os adultos (WHITE, 2001).

Embora seja evidente indicar o ajuste nas dosagens em pacientes graves e debilitados, a duração clínica do efeito do propofol não parece ser muito afetada pela obesidade ou pelas disfunções hepáticas ou renais moderadas (SERVIN et al., 1993).

Apesar de existir acúmulo de metabólitos do propofol em pacientes com falência renal, o fato de não ocorrerem diferenças nos tempos de despertar sugere que tais metabólitos não possuam efeitos clínicos significativos (NATHAN et al., 1993). Como existe uma variabilidade considerável entre voluntários sadios e pacientes, a titulação cuidadosa da dose de propofol até a obtenção do efeito minimiza efeitos adversos, como a hipotensão, enquanto permite a recuperação rápida dos efeitos centrais do fármaco (SEAR et al., 1995). 


\subsubsection{Farmacodinâmica do propofol}

O propofol tem ação sobre os diversos órgãos e sistemas do organismo. Sobre o sistema nervoso central ele reduz o consumo de oxigênio, o fluxo sangüíneo cerebral e as pressões intracraniana e intra-ocular da mesma maneira que o tiopental (VANDESTEENE et al., 1988). Sobre o sistema cardiovascular o propofol promove uma redução dependente da dose na pressão arterial significativamente maior que o tiopental (GROUNDS et al., 1985). A diminuição da pressão arterial pode ser explicada pela vasodilatação e por depressão leve da contratilidade miocárdica (GROUNDS et al., 1985). O propofol parece minimizar o reflexo barorreceptor e/ou é diretamente vagotônico, pois são observados aumentos menores na frequiência cardíaca para qualquer diminuição na pressão arterial após a administração de doses de propofol (CLAEYS et al., 1988). Da mesma forma que na administração de tiopental, o propofol deve ser utilizado com cuidado nos pacientes com risco ou intolerantes às reduções na pressão arterial. Sobre o aparelho respiratório o propofol causa um grau de depressão respiratória maior que o tiopental (BLOUIN et al., 1991). Os pacientes que recebem propofol devem ser monitorados para que oxigenação e ventilação adequada sejam garantidas.

\subsubsection{1 Índice Bispectral (BIS)}

Até recentemente, os anestesiologistas não possuíam uma maneira adequada de monitorizar a ação dos anestésicos sobre o sistema nervoso central em relação à profundidade da anestesia. Esta monitorização era realizada pela observação das respostas autonômicas como o aumento da frequêencia cardíaca e da pressão arterial que se relacionam com um adequado grau de anestesia. 
Como se acreditava que os anestésicos gerais levavam à inconsciência por causarem depressão do sistema nervoso central, e a atividade do córtex cerebral poderia ser medida pelo eletroencefalograma (EEG), era esperado que algum componente do EEG se relacionasse com um grau adequado de anestesia (FISHER et al., 2000; RAMPIL, 1998). Tal relação foi descrita pela primeira vez, em 1937 (GIBBS et.al., 1987).

Para a avaliação da intensidade de hipnose, uma opção seria o traçado do EEG, que implica a obtenção de registro complexo com numerosos sinais que consomem dezenas de metros de papel, o que dificulta a sua interpretação em sala de cirurgia, além de os fármacos administrados em anestesia causarem diferentes padrões no traçado do EEG, impedindo a criação de um monitor universal. Para minimizar estes inconvenientes, tem sido proposto o EEG processado pelo computador (BIS), que foi obtido da experiência acumulada em mais de dois mil traçados de EEG de pacientes em estado de vigília e anestesiado com diversos hipnóticos (inalatórios e venosos) (VIANNA et al., 1995).

Depois da eliminação dos artefatos, os traçados do EEG foram submetidos ao cálculo espectral, chegando-se a vários parâmetros que foram, então, submetidos à análise estatística para se obterem os melhores parâmetros (por exemplo, a frequiência mediana e o $\mathrm{SEF}_{95}$ ), resultando no índice bispectral (VIANNA et al., 1995).

Este equipamento utiliza sinais originários da região frontal, os quais são digitalizados e, em seguida, filtrados para evitar a interferência de artefatos. Estes sinais sofrem a transformação rápida de Fourier para atingir o Bispectrum (VIANNA, 1995). A soma destes parâmetros dá origem ao Índice Bispectral ou simplesmente BIS. Este é 
constituído de escala de 100 a 0 . O valor próximo de 100 mostra um indivíduo acordado, ou seja, que não sofreu a influência de qualquer fármaco hipnótico. À medida que o valor é reduzido, aumentam os níveis de sedação, sendo 70 considerado como sedação leve e, abaixo de 60, níveis profundos de hipnose. Isto é válido tanto para a indução quanto para a recuperação anestésica (VIANNA et al., 1995).

Com o surgimento da tecnologia dos microcomputadores foi possível reduzir a quantidade de dados obtidos do EEG para diversos processos derivados (RAMPIL, 1998). Tais processos derivados como margem (limite) do poder spectral, freqüência mediana e frequiência de zero-crossing, além de outros, têm sido descritos para medir os efeitos dos anestésicos sobre o sistema nervoso central (SNC) (SCHWILDEN, 1985).

A primeira e única tecnologia aprovada pela U.S. Food and Drug Administration (outubro de 1996) para a venda como monitor dos efeitos dos anestésicos sobre o EEG é a análise bispectral derivada, conhecida como índice bispectral (BIS, Aspect Medical Systems, Natick, MA) (FISHER et al., 2000).

A análise bispectral é uma técnica estatística que permite o estudo dos fenômenos com características não lineares. Ela proporciona descrição de uma contínua variação de sinal pseudo-aleatória do EEG, que é uma alternativa em relação a outras técnicas convencionais de análise do poder bispectral, derivada da transformação rápida de Fourier (ROSENBLATT et al., 1972). A análise bispectral só pôde ser utilizada quando os microcomputadores com processadores de ação rápida surgiram, pois estes permitiram que a análise bispectral do EEG, durante o procedimento cirúrgico, fosse realizada rapidamente (FISHER et al., 2000).

Os dados contendo a análise bispectral e a convencional análise do poder de 
freqüência do EEG são usados para criar o índice bispectral ou BIS. BIS é uma escala numérica que varia de 100 a 0 , na qual 100 representa o EEG de um paciente acordado; e 0, silêncio elétrico completo no EEG (que representa supressão cortical). Valores de BIS de 65 a 85 são recomendáveis para sedação, de 40 a 65 são utilizados para anestesia geral e valores menores que 40 representam supressão cortical. (SIGL et al., 1994). BIS relaciona-se com o componente hipnótico da anestesia e a concentração anestésica da droga. Ele indica o potencial de despertar e a sobredose de fármacos anestésicos, porém não prevê movimentos dos pacientes nem a resposta hemodinâmica à estimulação dolorosa. Também não antecipa o exato momento em que a consciência retorna (FISHER et al., 2000). Existem algumas limitações para se utilizar o BIS. Não deve ser empregado em pacientes que estão em uso de cetamina (MORIOKA et al., 1997) bem como em pacientes que tenham lesões neurológicas (O’CONNOR et al., 1998).

\subsection{Infusão alvo-controlada}

Com o aperfeiçoamento da tecnologia computadorizada houve interesse crescente nos sistemas automáticos de administração venosa. As infusões alvocontroladas por computador podem facilitar a manutenção anestésica e a sedação com propofol. Embora a relação entre a concentração-alvo e a concentração sangüínea real dependa das variáveis farmacocinéticas usadas para programar o sistema de administração, a escolha do modelo farmacocinético não parece fazer diferença clínica (COETZEE et al., 1995; VUYK et al., 1995).

A validação desses modelos para administração alvo-controlada pode ser feita pela comparação entre a concentração plasmática do fármaco obtido das amostras 
de sangue coletadas do paciente durante o procedimento cirúrgico e a concentração plasmática prevista pelo modelo e sistema de administração utilizada (KENNY et al., 1997; GLEN, 1998; GLASS et al., 2000).

Não obstante a administração alvo-controlada fosse mais conveniente que o uso de injeções em bolus intermitentes, ela não ofereceu vantagens óbvias em relação a um sistema de infusão de velocidade variada (NEWSON et al., 1995). Para que a infusão alvo-controlada seja comumente aceita como sistema de administração do propofol, o aparelho deverá ser de fácil utilização, de fácil montagem e ter baixo custo (WHITE, 1996).

Atualmente existe um crescente interesse entre os anestesiologistas em utilizar infusão contínua intravenosa de hipnóticos, evitando flutuações que definem picos e vales no efeito terapêutico, que é função da concentração na biofase, determinada pela concentração sangüínea. Esta pode ser mantida por bombas de infusão controladas por computador, que utilizam a proposta feita por Kruger-Thiemer et al. (1968). Estes autores sugeriram um esquema de infusão do anestésico intravenoso denominado BET, ou seja, um "bolus" (B) que preenche todo o compartimento central em nível desejado de concentração, seguido de infusão constante para substituir a droga que está sendo eliminada (E) do compartimento central por excreção ou metabolismo. Superposto a isto, uma infusão que declina exponencialmente para substituir a droga, sendo (T) transferência para os compartimentos periféricos (KRUGER-THIEMER, 1968).

O método para evitar acúmulo é baseado no regime guiado pelo algoritmo BET (Bolus + Eliminação + Transferência), descrito por Kruger-Tiemer (KRUGER- 
THIEMER, 1968). Ao propormos um alvo inicial, segue-se um bolus e uma infusão contínua para repor o fármaco que está sendo eliminado, e exponencialmente é diminuída a infusão para que não haja acúmulo por causa da transferência de compartimentos. A infusão alvo-controlada propicia a manutenção da adequação anestésica e os ajustes necessários de acordo com as necessidades requeridas pelo paciente. O desenvolvimento da infusão alvo-controlada coincidiu com conceitos farmacocinéticos mais recentes aplicados aos fármacos anestésicos, como o compartimento de efeito associado a constante de equilíbrio, tempo de pico de efeito, tempo de meia-vida contexto-dependente e tempo de meia-vida decréscimo-dependente.

Em 1993, Bailey descreveu a possibilidade teórica de se obter nível aproximadamente constante da concentração do fármaco no sangue, utilizando as formas convencionais de infusão (BAILEY, 1993). A partir dessas considerações, foram desenvolvidos variados softwares para serem utilizados com diversos fármacos empregados em anestesiologia. Estes programas foram criados para capacitar o anestesiologista a manter aproximadamente constante a concentração sangüínea alvodesejada. Após doses arbitrárias, calculam-se taxas de infusão decrescentes para manter nível sangüíneo estável. Estas são obtidas pelas equações que calculam o esquema das taxas de infusões seqüenciais (VIANNA et al., 1996).

É bastante atrativo o conceito do programa de infusão contínua, controlada pelo computador para administrar fármacos por via venosa, de acordo com o modelo farmacocinético guiado por algoritmos. Os fármacos devem ser administrados por uma concentração sangüínea alvo-calculada pelo algoritmo. Todas as informações farmacocinéticas de importância estão contidas no algoritmo, o que significa que a 
administração da infusão é simplificada e não existe a necessidade de se lembrar de fórmulas ou realizar cálculos para a administração venosa dos fármacos por ajuste manual. Além disso, a curva de concentração sangüínea relacionada ao tempo dá a indicação do provável tempo de despertar após o término da infusão (SHORT et al., 1994).

Para se obter a concentração plasmática previsível com níveis aproximadamente constantes, é utilizada a técnica denominada "anestesia intravenosa controlada por computador" (AICC); que consiste na utilização de programas farmacocinéticos instalados em microcomputadores que estarão ligados à bomba de infusão pela interface; desse modo, a velocidade da bomba de infusão será comandada pelo computador; este é o sistema mais evoluído para se realizar anestesia venosa contínua (VIANNA et al., 1995).

O grande inconveniente da AICC é o elevado custo dos equipamentos (BRUHN et al., 2002). Com o objetivo de minimizar esta dificuldade, Bailey sugeriu o cálculo prévio da infusão venosa de determinado fármaco, baseado também nos seus parâmetros farmacocinéticos, de modo que seja possível manter a concentração do fármaco em níveis plasmáticos aproximadamente constantes (TACKLEY et al., 1989; BAILEY, 1993; BRUHN et al., 2002).

Para a realização de anestesia intravenosa foi desenvolvido um sistema de infusão alvo-controlada padronizado para administração de propofol chamado de “diprifusor” (Astra Zeneca, London, UK) (GLEN, 1998).

A tecnologia do "diprifusor" utiliza modelos farmacocinéticos que controlam o ritmo de infusão da bomba, proporcionando ao anestesiologista o controle 
direto da concentração plasmática de propofol que deseja utilizar nos pacientes submetidos à anestesia. O módulo eletrônico do "diprifusor" é composto por dois microprocessadores que podem ser incorporados à bomba de infusão, proporcionando um modo de infusão alvo-controlada com concentrações de propofol que podem ser atingidas conforme a necessidade, mantidas ou alteradas, dependendo do grau de profundidade de anestesia necessária para a realização do procedimento (GRAY et al., 1998).

O módulo do "diprifusor" é um pequeno componente eletrônico e contém um software. Este software consiste na combinação particular de infusão controlada pelo algoritmo conectada a um programa de simulação farmacocinética (University of Glasgow). Este programa inclui um modelo farmacocinético de três compartimentos e incorpora os parâmetros farmacocinéticos descritos por Marsh (GLEN, 1998).

Com a disponibilidade do "diprifusor", os anestesiologistas têm a oportunidade de ganhar experiência no cálculo de concentrações de propofol adequadas para a realização dos diversos procedimentos anestésicos (GLEN, 1998).

A modelagem cinética do propofol tem sido descrita, utilizando modelos farmacocinéticos de dois (ADAM et al., 1983; SCHUTTLER et al., 1988; COCKSHOTT et al., 1992) ou de três compartimentos (GEPTS et al., 1987, SHAFER et al., 1992).

A avaliação da diferença entre as concentrações plasmáticas obtidas experimentalmente e o alvo previsto é denominada Performance de Erro (PE) ou Percentagem do erro de previsão, sendo expressa na forma percentual (KENNY et al., 1997; GLASS et al., 2000). O percentual de erro de previsão é calculado pela seguinte 
fórmula e expresso em percentagem:

Percentagem do erro de previsão $=$ Concentração plasmática - Concentração prevista $X 100$

Concentração prevista

\subsection{O uso de propofol em anestesia para cirurgia cardíaca}

Estudos clínicos iniciais a respeito do uso de propofol durante a cirurgia cardíaca salientaram seus efeitos hemodinâmicos agudos quando utilizado na indução anestésica em pacientes com boa função ventricular esquerda, que eram submetidos à cirurgia eletiva de revascularização miocárdica (MERIN, 1990; VARRO et al., 2001). Os pesquisadores avaliaram o uso de propofol para manutenção anestésica em pacientes hígidos e naqueles com função ventricular esquerda prejudicada (HALL et al., 1993; LEHMANN et al., 2001; MCQUAIRE et al., 2002).

Comparado com o tiopental ou com o etomidato, o propofol parece possuir maior efeito inotrópico negativo direto sobre o músculo papilar (BOYLE et al., 1989). A redução da pressão arterial durante as infusões de propofol resulta de suas ações inotrópicas negativas, assim como de seus efeitos sobre os tônus vascular venoso e arterial. Portanto, o propofol deve ser usado com cuidado em pacientes portadores de cardiopatia (PAGEL et al., 1993).

O uso de propofol para a indução anestésica em pacientes submetidos à cirurgia cardíaca pode produzir hipotensão significativa antes da laringoscopia e da intubação traqueal (WHITE, 2001). Além disso, o fator em comum com outros hipnóticos é que a interação com opióides exacerbam esses efeitos hipotensores (VUYK, 2001). 
A indução anestésica com opióide associado ao benzodiazepínico seguida pela infusão de propofol, suplementada com agente inalatório ou analgésico opióide, conforme necessário para controlar a pressão arterial e a freqüência cardíaca, parece proporcionar condições anestésicas aceitáveis em pacientes submetidos à cirurgia cardíaca e está associada ao despertar rápido e à extubação precoce. O uso de infusão titulada de propofol para a manutenção anestésica não está associado com o aumento da necessidade de suporte inotrópico após a cirurgia cardíaca (WHITE, 2001).

\subsubsection{Circulação extracorpórea (CEC)}

Os estudos farmacocinéticos sobre o propofol utilizado em infusão contínua revelaram o rápido declínio transitório das concentrações após o início da CEC causado pela hemodiluição aguda, seguida por um aumento gradativo da concentração sangüínea durante a fase de hipotermia (WHITE, 2001). A manutenção da velocidade de infusão permite obtenção de altas concentrações de propofol durante a esternotomia e manutenção de concentrações hipnóticas do fármaco durante a CEC (WHITE, 2001). O reaquecimento na CEC resulta em redução da concentração de propofol aos níveis préCEC, sugerindo que a hipotermia esteja associada a alterações da atividade das enzimas hepáticas e do fluxo sangüíneo hepático (MATHIE, 1993). Entretanto, níveis hipnóticos são mantidos durante toda a cirurgia (WHITE, 2001).

Massey e colaboradores (1990) não descobriram alterações significativas da concentração sangüínea do propofol durante a CEC, quando uma infusão de ordem zero igual a $67 \mu \mathrm{g} / \mathrm{kg} / \mathrm{min}$ de propofol foi administrada durante a cirurgia cardíaca (MASSEY et al., 1990). 
Comprovou-se que o propofol é vasodilatador durante a CEC (PENSADO et al., 1993) e a infusão de altas doses $(2,5 \mathrm{mg} / \mathrm{kg}$ seguidos por $333 \mu \mathrm{g} / \mathrm{kg} / \mathrm{min})$ pode reduzir mais ainda o consumo de oxigênio durante a hipotermia da CEC (LAYCOCK et al., 1992). O propofol também inibe a vasoconstrição termorreguladora, mas só altera ligeiramente o limiar aos tremores (MATSUKAWA et al., 1995). Quando o propofol é usado, a combinação de vasodilatação e o consumo diminuído de oxigênio podem conferir proteção adicional contra os efeitos adversos da CEC (WHITE, 2001).

Em estudos comparativos em anestesia para cirurgia cardíaca, envolvendo técnicas cujo agente principal era o propofol ou técnicas balanceadas padronizadas de opióides e inalatórios não foram encontradas diferenças quanto à necessidade de suporte inotrópico após término da CEC (HALL et al., 1993).

\subsubsection{Aspectos Fisiológicos e Mecânicos da Circulação Extracorpórea (CEC)}

Em pacientes adultos, o circuito de circulação extracorpórea (CEC) é habitualmente preenchido com um perfusato de cerca de 1500 a $2000 \mathrm{ml}$ de solução cristalóide. Após a heparinização sistêmica, a aorta é canulada para permitir a administração do sangue oxigenado proveniente do circuito de CEC, sendo a drenagem sangüínea proveniente da canulação das veias cavas superior e inferior. Quando se inicia a CEC, o perfusato é administrado ao paciente pela cânula aórtica, enquanto o sangue venoso é drenado para o circuito de CEC, onde será oxigenado e esfriado até a obtenção de uma temperatura corporal pré-determinada.

A hemodiluição do sangue com o perfusato resulta em gradual estabilização da mistura sangue/perfusato pela contínua circulação para o paciente. Atingindo um 
fluxo indexado de cerca de $70 \mathrm{ml} / \mathrm{kg} / \mathrm{min}$ no paciente adulto, a ventilação pulmonar é interrompida, a aorta é clampeada, sendo então os pulmões efetivamente isolados da circulação. Geralmente, durante a hipotermia, o fluxo da CEC é substancialmente reduzido, e o ajuste do fluxo de oxigênio permite o ajuste da $\mathrm{PaCO}_{2}(\mathrm{METS}, 2000)$.

Anestésicos gerais inalatórios podem ser administrados no fluxo de gás fresco do oxigenador, e fármacos de ação venosa podem ser administrados diretamente no circuito de CEC. Isto se deve ao fato da comprovação, utilizando-se marcadores radioativos, que $95 \%$ da dose administrada no oxigenador é liberada na cânula arterial na primeira circulação e a totalidade, em cerca de 2 minutos. Em contraste, a administração através do cateter central resulta em uma liberação imprevisível no mesmo período de tempo (KAMATH et al., 1980). Ao final do procedimento cirúrgico principal o paciente é reaquecido, quando foi utilizada a hipotermia, a ventilação pulmonar é reiniciada, permitindo que a CEC seja finalizada. Após a retirada das cânulas vasculares, procede-se à reversão da anticoagulação que foi feita com a heparina, utilizando-se a protamina.

\subsubsection{Efeitos da circulação extracorpórea (CEC) sobre a farmacocinética dos agentes anestésicos venosos}

A instituição da CEC tem efeitos importantes na concentração plasmática dos fármacos, em sua distribuição e, também, na sua eliminação.

Os principais fatores relacionados a estas alterações e que afetam a farmacocinética dos fármacos durante a CEC são:

A-) Hemodiluição e ligação protéica plasmática: o efeito imediato da 
hemodiluição aguda durante a CEC é a diminuição na concentração sangüínea total de qualquer fármaco presente no sangue. A concentração final do fármaco depende de sua ligação protéica plasmática, de seu volume de distribuição original, bem como do extenso equilíbrio entre a concentração tecidual e a concentração plasmática no início da CEC (ROSEN et al., 1997).

Uma importante consideração que deve ser feita é a distinção entre a concentração plasmática total do agente (ligada a proteínas + fração livre) e sua fração livre ou fármaco livre. A fração livre é somente o fármaco que tem efeitos ou pode se difundir para os tecidos. Se o agente em questão tem alta ligação protéica plasmática, então a hemodiluição resultará num grande aumento da fração livre do fármaco, pois a hemodiluição causa diminuição nos níveis de albumina e alfa-1-ácido glicoproteína com aumento na sua fração livre. Este fato induz a uma maior transferência do agente para fora do sangue e a uma menor concentração sangüínea final do mesmo (BUYLAERT et al., 1989).

O volume de distribuição $(\mathrm{Vd})$ do fármaco é outro fator que determina a concentração final do mesmo durante a CEC. Um grande aumento no Vd tenderia a contrabalançar a diminuição da concentração sangüínea causada pela hemodiluição, pois seria um grande reservatório disponível para a difusão de retorno para o plasma (BUYLAERT et al., 1989).

É importante também a consideração sobre o efeito da administração da heparina imediatamente antes da CEC sobre a ligação às proteínas plasmáticas. A heparina produz liberação de lipase lipoproteica e lipase hepática, as quais hidrolisam triglicérides plasmáticas em ácidos graxos não esterificados. Estes podem se ligar 
competitivamente a proteínas plasmáticas e promover um deslocamento de fármacos, aumentando sua concentração plasmática (WOOD, 1986).

Desconsiderando-se os efeitos das alterações distribucionais causadas pela alteração da ligação às proteínas plasmáticas e possíveis elevações na fração livre dos fármacos, o efeito agudo da hemodiluição isolada promovida pela CEC pode ser estabelecido pela fórmula abaixo (WOOD, 1986):

$$
\Delta \text { Css }=\text { Css } \quad x \quad \frac{V p}{V_{1}+V p}
$$

Sendo:

$\Delta$ Css = alteração na concentração do fármaco

Css = concentração do fármaco antes da hemodiluição

$\mathrm{Vp}=$ volume do perfusato da CEC

$\mathrm{V}_{1}=$ volume de distribuição no compartimento central (fase $\alpha$ )

Se um fármaco foi administrado durante a CEC, o efeito da hemodiluição causaria menor ligação às proteínas plasmáticas, a concentração efetiva imediata do mesmo se tornaria maior e seu volume de distribuição estaria aumentado (MORRELL et al., 1983).

B-) Hipotensão e alteração do fluxo sangüíneo hepático: a circulação extracorpórea é associada com hipotensão, inicialmente, pela redução do fluxo sangüíneo em torno de 2,0 a 2,2 1/min/ $/ \mathrm{m}^{2}$, pela hemodiluição que diminui a resistência vascular sistêmica. A hipotensão pode ser compensada pela liberação de catecolaminas com o prolongamento da CEC (MORI et al., 1988). O fluxo sangüíneo para o fígado, 
rim e pâncreas podem ser alterados pela CEC e mantém-se melhor por fluxo pulsátil do que pelo fluxo não pulsátil (MORI et al., 1988).

Existem poucos estudos referentes à hipotensão em humanos, contudo, um estudo clássico realizado por Stenson e colaboradores mostrou que a concentração de lidocaína durante uma infusão contínua era inversamente proporcional ao fluxo sangüíneo hepático (STENSON et al, 1971). Isto é muito importante para agentes que possuem alta eliminação hepática.

Devemos ressaltar também que o fluxo não pulsátil e a diminuição da perfusão periférica durante a CEC e a hipotermia podem causar hipóxia celular e provável acidose intracelular (STANLEY, 1978). Este evento é esperado especialmente com fármacos básicos, como o tiopental, que podem ser seqüestrados nos tecidos acidóticos (METS, 2000)

C-) Hipotermia: a hipotermia induzida pela CEC pode afetar a eliminação dos fármacos pela via hepática de três maneiras: 1- efeito direto sobre o metabolismo (McALLISTER et al., 1980) ; 2- alteração da circulação intra-hepática provocada pela hipotermia (LARSEN, 1971); 3- a hipotermia por si só pode diminuir o fluxo sangüíneo hepático e renal, embora esta alteração seja menor quando se utiliza um fluxo pulsátil durante a CEC (MORI et al., 1988).

À semelhança do que acontece no fígado, é possível que as enzimas tubulares renais que atuam na eliminação dos fármacos sejam também sensíveis à alteração de temperatura (HOLLEY et al., 1982). A hipotermia também pode ter dois efeitos farmacodinâmicos importantes como a diminuição da afinidade dos receptores opióides (PUIG et al., 1987) e da concentração alveolar mínima (CAM) de agentes 
inalatórios (ANTOGNINI, 1993).

D-) Isolamento dos pulmões: durante a CEC os pulmões são isolados da circulação de maneira que o fluxo sangüíneo arterial pulmonar seja interrompido, embora o fluxo sanguiíneo das artérias brônquicas mantenha-se intacto. Os pulmões podem atuar como reservatórios para alguns agentes de caráter básico (lidocaína, propanolol e fentanil) (ROTH et al., 1979; HALL et al., 1991), se esses agentes forem administrados diretamente na CEC, altas concentrações sangüíneas serão obtidas.

Além disso, depois de restabelecida a circulação pulmonar, os fármacos sequiestrados antes do isolamento dos pulmões poderão retornar para a circulação sangüínea. Isto acarretará um aumento na concentração dos mesmos em valores maiores que os anteriores, podendo exercer efeitos farmacológicos. Este efeito foi demonstrado pelo fentanil (BENTLEY et al., 1983) e pelo sufentanil (OKUTANI et al., 1988), quando a circulação foi restabelecida após a CEC.

E-) Retirada dos agentes anestésicos realizada pelo circuito da CEC: experimentos in vitro têm demonstrado que quantidades significantes de fentanil (KOREN et al., 1984; SKACEL et al., 1986; ROSEN et al., 1990) e de alfentanil (SKACEL et al., 1986; HYNYNEM et al., 1987; ROSEN et al., 1990) podem ser retiradas do circuito da CEC, enquanto o sufentanil pode ser seqüestrado pelo oxigenador (DURKAN et al., 1988).

F-) Efeitos da circulação extracorpórea sobre a farmacocinética de outros fármacos: McAllister et al. observaram diminuição na concentração plasmática de propranolol no início da CEC (McALLISTER et al., 1980; CARMONA et al., 2003). No entanto, quando estes autores ajustaram esta concentração para diluição do volume 
plasmático, na tentativa de estabelecer se a CEC prejudicava a eliminação de propranolol, observaram aumento da concentração de propranolol durante a hipotermia. No período pré-operatório, houve redução da concentração de propranolol para valores de controle ou abaixo dele, após o reaquecimento.

O mesmo grupo de pesquisadores investigou os efeitos da hipotermia num estudo experimental in vitro e determinou que ela diminui o metabolismo do propranolol (McALLSTER et al., 1980); pois, no período após a CEC, o nível plasmático avaliado até 4 horas aumentou acima do último valor da CEC. (PLACHETKA et al., 1981). 
CASUÍSTICA E MÉTODOS 


\section{CASUÍSTICA E MÉTODOS}

\subsection{Projeto de pesquisa}

O protocolo do estudo foi aprovado pela Comissão Científica do Instituto do Coração e pela Comissão de Ética Médica do Hospital das Clínicas da Faculdade de Medicina da Universidade de São Paulo (CAPPesq - projeto de pesquisa número 802/01).

\subsubsection{Critério de seleção dos pacientes}

Foram selecionados pacientes portadores de insuficiência coronária crônica e candidatos à cirurgia eletiva de revascularização miocárdica, internados na enfermaria clínica do Instituto do Coração do Hospital das Clínicas da Faculdade de Medicina da Universidade de São Paulo. Foram estudados 20 pacientes, adultos, de ambos os sexos, selecionados de acordo com os critérios de inclusão e exclusão listados a seguir:

\section{Critérios de Inclusão}

- A aceitação voluntária do paciente e capacidade e vontade de ler, entender e assinar termo de consentimento livre e esclarecido;

- Idade entre 18 e 75 anos;

- Portador de função renal e hepática dentro dos limites de normalidade, avaliado pelo perfil bioquímico (sangue e urina) e hematológico;

- função ventricular dentro dos parâmetros normais (fração de ejeção maior ou igual a $50 \%$ ) avaliadas pelo ecocardiograma. 


\section{Critérios de Exclusão}

- Recusa em participar do estudo;

- Idade superior a 75 anos;

- Com histórico de abuso de álcool ou drogas;

- Creatinina sérica igual ou superior a 1,4 mg/dl;

- Atividade de protrombina inferior a $80 \%$;

- Sorologia positiva para hepatites;

- Uso de anticoagulantes orais;

- Fração de ejeção do ventrículo esquerdo inferior a 50\%;

- Obeso com índice de massa corpórea maior que $35 \mathrm{~kg} / \mathrm{m}^{2}$, calculado pela razão entre o peso $(\mathrm{kg})$ e o quadrado da altura $\left(\mathrm{m}^{2}\right)$;

- Histórico de alergia ao propofol.

\subsubsection{Termo de consentimento livre e esclarecido}

Após definição da indicação cirúrgica e avaliação dos critérios de inclusão e exclusão, os pacientes foram convidados a participar do estudo. Após esclarecimentos em relação aos objetivos gerais do estudo, assinaram o termo por escrito, de consentimento livre e esclarecido (apêndice).

\subsection{Casuística}

A coleta de dados realizou-se entre setembro de 2002 e agosto de 2003. Foram estudados 20 pacientes (quadro 1 do apêndice), divididos em 2 grupos, conforme decisão da equipe cirúrgica: 


\section{Grupo Revascularização Miocárdica com Circulação extracorpórea (CEC) (Grupo}

CEC) (n=10): pacientes submetidos à cirurgia de revascularização miocárdica com utilização de circulação extracorpórea.

Grupo Revascularização Miocárdica sem Circulação extracorpórea (CEC) (Grupo sem CEC) (n=10): pacientes submetidos à cirurgia de revascularização miocárdica sem utilização de circulação extracorpórea.

\subsection{Métodos}

O estudo foi iniciado na entrevista com os pacientes no dia anterior à cirurgia, quando se obteve a autorização para a realização do mesmo. Nessa ocasião procedeu-se à avaliação dos exames pré-operatórios, idade, sexo, peso, altura, superfície corpórea e do risco cirúrgico pelos critérios de avaliação de Higgins (HIGGINS et al., 1992), considerando-se (quadro 1):

- 0-1 pontos: risco mínimo

- 2-3 pontos: risco baixo

- 4-6 pontos: risco moderado

- 7-9 pontos: risco alto

- $>10$ pontos: risco extremo 
Quadro 1. Critérios de avaliação do risco cirúrgico

\begin{tabular}{|lc|}
\hline \multicolumn{1}{|c|}{ Atributo } & Pontuação \\
\hline Cirurgia de Emergência & 6 \\
Creatinina sérica > 1,9 & 4 \\
Creatinina sérica entre 1,4-1,9 & 1 \\
Disfunção de VE (FE<.50) & 3 \\
Reoperação & 3 \\
Insuficiência Mitral & 3 \\
Idade > 75 anos & 2 \\
Idade entre 64 e 75 anos & 1 \\
Cirurgia vascular prévia & 2 \\
Doença pulmonar obstrutiva crônica & 2 \\
Ht < 34\% & 2 \\
Estenose aórtica & 1 \\
Diabetes com medicação & 1 \\
Coagulopatia & 1 \\
Doença cerebrovascular & 1 \\
Peso < 65 kg & 1 \\
\hline
\end{tabular}

A medicação pré-anestésica consistiu de midazolam na dose de 0,1 a 0,2 mg/kg por via oral (VO), 30 minutos antes da operação, até a dose máxima de 15 mg.

Ao serem admitidos na sala de cirurgia, os pacientes foram monitorizados com eletrocardiografia contínua na derivação DII e V5 e oximetria de pulso.

Após venóclise periférica com cateter número 16, a monitorização invasiva da pressão arterial foi realizada pela punção da artéria radial com cateter número 20, utilizando-se transdutor de pressão e passagem de cateter venoso central pela punção da jugular interna direita.

Monitorizou-se o grau de hipnose pelo índice bispectral (BIS, Aspect Medical Systems, Natick, MA), adotando-se: 
- BIS de 85-100 - indivíduo acordado;

- BIS de 65-85 - sedação;

- BIS de 40-65 - anestesia geral;

- BIS < 40 - supressão cortical (SIGL et al., 1994).

Após a pré-oxigenação, a indução da anestesia foi realizada com sufentanil na dose de $0,5 \mu \mathrm{g} / \mathrm{Kg}$, seguido de infusão contínua de $0,5 \mu \mathrm{g} / \mathrm{kg} / \mathrm{hora}$, pela bomba de infusão (Anne, Abott, USA) especialmente programada com o peso do paciente e o fármaco específico. Para hipnose, administrou-se propofol pela técnica de infusão alvocontrolada infundido pela bomba de infusão específica (Diprifusor, Astra-Zeneca, USA), adotando-se 2,0 $\mu \mathrm{g} / \mathrm{ml}$ como concentração alvo-desejada, durante toda a cirurgia e com tempo de infusão inicial de 30 segundos. Os dados dos pacientes inseridos no diprifusor foram sexo, peso e idade. Todos os pacientes utilizaram o mesmo aparelho de diprifusor durante todo o estudo.

O relaxamento muscular foi obtido com brometo de pancurônio na dose de 0,1 a $0,2 \mathrm{mg} / \mathrm{kg}$. Aplicou-se ventilação manual sob máscara e intubação traqueal com tubo de diâmetro adequado, instalando-se a seguir ventilação controlada mecânica (respirador Cícero EM-Dragger) com volume corrente de $8 \mathrm{ml} / \mathrm{kg}$, freqüência respiratória de 10 por minuto, relação $\mathrm{I}: \mathrm{E}=1: 2$ e $\mathrm{FiO}_{2}=0,6$ (oxigênio e ar comprimido). Após monitorização do $\mathrm{ETCO}_{2}$, o posicionamento correto da cânula traqueal foi verificado pela ausculta pulmonar bilateral. Após a indução anestésica, realizou-se sondagem vesical para avaliação de diurese e colocação de sensor de temperatura na nasofaringe. 
Os pacientes foram hidratados com solução de ringer lactato para ajuste volêmico e quando necessário foi utilizado norepinefrina em bolus de $2 \mu$ ou em infusão contínua de $0,01 \mu / \mathrm{kg} / \mathrm{min}$.

No Grupo CEC, após anticoagulação com 500 u/kg de heparina sódica, a CEC foi iniciada utilizando-se bomba de rolete ou bomba centrífuga, com oxigenador de membranas (Braile, Brasil) e perfusato inicial de $1600 \mathrm{ml}$ de solução de ringer lactato. O fluxo de perfusão foi de 60 a $80 \mathrm{ml} / \mathrm{kg} / \mathrm{min}$, utilizando-se fluxo não pulsátil e hipotermia moderada com controle gasométrico seriado. Durante a CEC a hipnose foi mantida com infusão contínua de propofol em sistema de infusão alvo-controlada, mantendo-se a concentração alvo de $2 \mu \mathrm{g} / \mathrm{ml}$.

Nos dois grupos foram colhidas amostras de $3 \mathrm{ml}$ de sangue arterial para dosagem de concentração sangüínea de propofol nos momentos:

1) Antes da indução anestésica (medida basal)

2) 5 minutos após a indução

3) 15 minutos após a indução

4) 30 minutos após a indução

5) 60 minutos após a indução

6) 120 minutos após a indução

7) 240 minutos após a indução

8) Ao final da cirurgia

No grupo CEC também foram colhidas amostras sangüíneas nos seguintes momentos: 
1) Imediatamente antes da CEC, anotando-se o tempo desde o início da infusão

2) 5 minutos após o início da CEC

3) 15 minutos após o início da CEC

4) 30 minutos após o início da CEC

5) 60 minutos após o início da CEC

6) Ao final da CEC, anotando-se o tempo desde o ínício da CEC

Durante todo o estudo, concomitantemente às coletas das amostras sangüíneas, foram registrados os parâmetros:

- monitorização do grau de hipnose no período pelo índice bispectral (BIS)

- dados hemodinâmicos: pressão arterial média (PAM) e frequiência cardíaca (FC)

- dados do diprifusor: - dose infundida de propofol (mg)

- velocidade de infusão do propofol (mg/kg/h)

- tempo previsto para regressão (min)

Avaliou-se também o tempo de CEC, hematócrito (inicial e mínimo durante a CEC) e temperatura corporal.

Ao final da cirurgia, a concentração alvo-desejada do propofol foi alterada para $1,0 \mu \mathrm{g} / \mathrm{ml}$ e os pacientes foram transportados para a Unidade de Terapia Intensiva (UTI) ainda intubados e sob efeito anestésico. Os pacientes foram mantidos com o mesmo tipo de monitorização utilizada no período intra-operatório e ventilados com o respirador Veolar (Hamilton-Veolar-Hamilton Medical; Rhazuns, Switzerland), com volume corrente de $8 \mathrm{ml} / \mathrm{kg}$ em ventilação controlada a volume, com freqüência respiratória de 10 respirações por minuto. Foi utilizada a pressão positiva expiratória 
final (PEEP) com valor inicial de $5 \mathrm{~cm}$ de $\mathrm{H}_{2} \mathrm{O}$.

Nesta fase realizou-se coleta de $3 \mathrm{ml}$ de sangue arterial nos momentos destacados a seguir, nos 2 grupos:

1) 5 minutos após o final da cirurgia

2) 15 minutos após o final da cirurgia

3) 30 minutos após o final da cirurgia

4) 60 minutos após o final da cirurgia

5) 120 minutos após o final da cirurgia

6) Ao final da infusão do propofol

Quando foi indicada a extubação traqueal, a infusão de propofol foi interrompida, realizando-se as coletas de amostras sangüíneas arteriais nos 2 grupos nos seguintes momentos:

1) 5 minutos após o término da infusão de propofol

2) 15 minutos após o término da infusão de propofol

3) 30 minutos após o término da infusão de propofol

4) 60 minutos após o término da infusão de propofol

5) 120 minutos após o término da infusão de propofol

6) 240 minutos após o término da infusão de propofol

7) 360 minutos após o término da infusão de propofol

8) 480 minutos após o término da infusão de propofol

9) 720 minutos após o término da infusão de propofol

As etapas do estudo citadas anteriormente estão descritas no quadro 2, a seguir: 
Quadro 2: Etapas do estudo

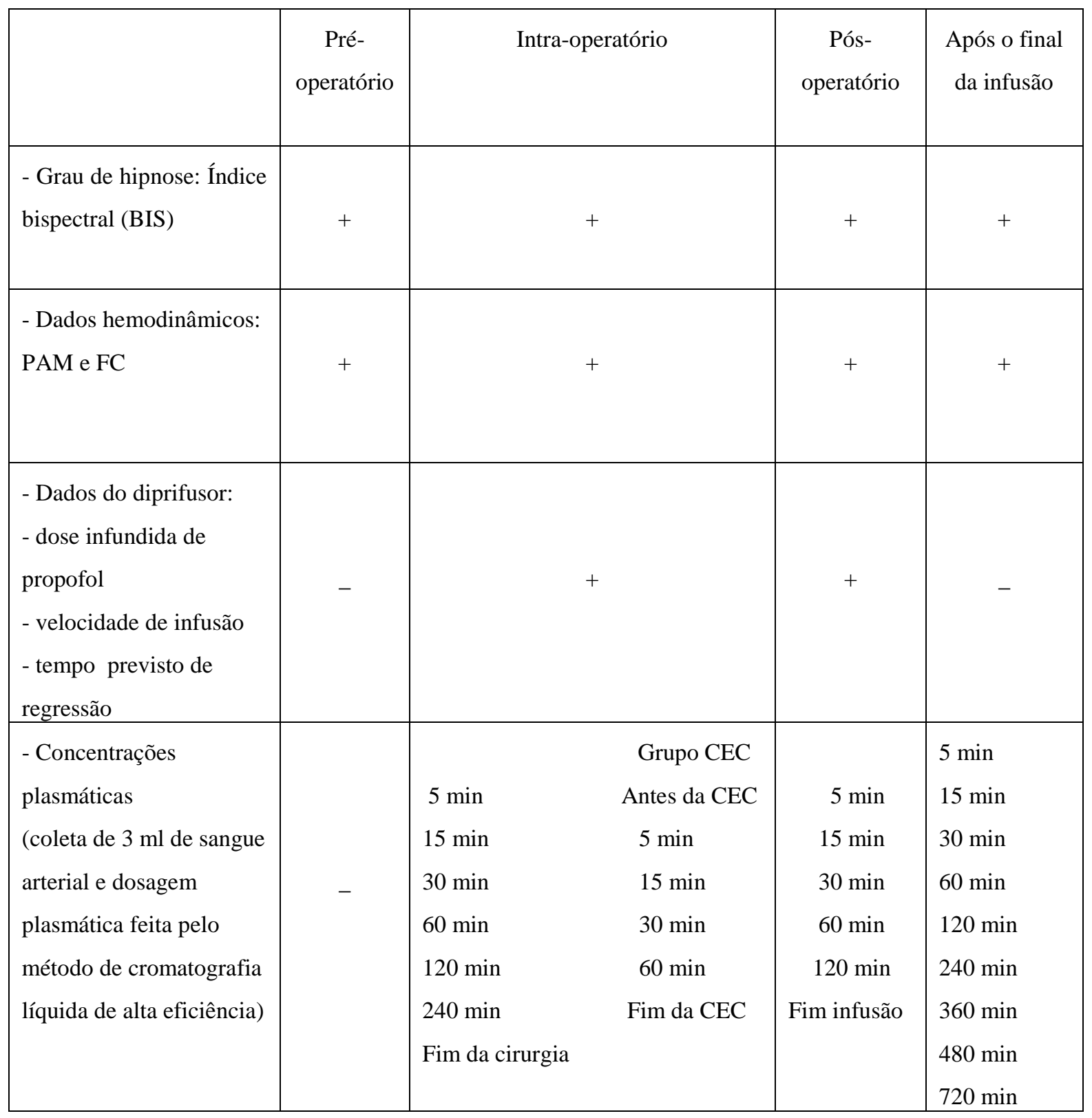

\subsection{Análise das amostras sangüíneas}

A análise das amostras sangüíneas foi realizada seguindo procedimentos padronizados no Laboratório de Farmacologia Terapêutica - Unidade de Pesquisa 
Clínica da Faculdade de Ciências Farmacêuticas da Universidade de São Paulo.

\subsection{Análise farmacocinética (Procedimento analítico)}

Após a coleta, as amostras sangüíneas foram centrifugadas e o plasma congelado a $-20^{\circ} \mathrm{C}$ até o ensaio. O valor mínimo de hematócrito durante a CEC foi considerado para avaliação da hemodiluição ocorrida durante a CEC e correção das concentrações plasmáticas de fármacos.

Foram determinadas as concentrações do propofol nas amostras de sangue coletadas através do método de cromatografia líquida de alta eficiência com detecção por fluorescência, de acordo com procedimentos que foram desenvolvidos e validados no Laboratório de Farmacologia Terapêutica da Unidade de Pesquisa Clínica do Departamento de Farmácia da USP, tendo como base as publicações de Yeganeh e colaboradores, em 1997, e Knibbe e colaboradores, em 1998 (YEGANEH et al., 1997; KNIBBE et al., 1998).

\subsubsection{Reagentes, padrões de referência e soluções}

Os reagentes utilizados no procedimento analítico apresentaram grau de “cromatografia”, procedência Merck. O nitrogênio utilizado na evaporação do solvente dos extratos orgânicos, e o hélio destinado à desgaseificação da fase móvel da cromatografia apresentaram grau de pureza 99,99\%, procedência Air Products Gases Industriais LTDA. Na filtração do tampão empregou-se membrana Millipore tipo HA e, na filtração da fase móvel e extratos orgânicos, utilizou-se membrana de mesma 
procedência, tipo FH. Inicialmente, ao tubo de extração limpo e seco foi adicionado volume fixo de padrão interno. Diariamente, utilizaram-se alíquotas de $500 \mu \mathrm{l}$ de plasma para os padrões de referência, controle e para as amostras; as análises foram realizadas em duplicata. A amostra biológica foi purificada pela técnica da precipitação de proteínas com adição de $1000 \mu \mathrm{l}$ de acetonitrila e agitação em agitador de tubos tipo Vortex, durante $1 \mathrm{~min}$, conforme detalhado no fluxograma. Após a precipitação e centrifugação a $3000 \mathrm{rpm}$ por $20 \mathrm{~min}$, a fase orgânica remanescente (100 $\mu \mathrm{l}$ ) foi transferida para tubo cônico limpo e seco Os extratos foram concentrados até resíduo, isto é, até a secura, utilizando banho-maria a $37^{\circ} \mathrm{C}$, sob corrente de nitrogênio purificado. Dissolveu-se o extrato seco purificado com $100 \mu$ de fase móvel (metanol : água $7: 3$, v/v) e $25 \mu \mathrm{l}$ foram injetados no cromatógrafo líquido, nas condições instrumentais referidas anteriormente, constantes no fluxograma descrito, a seguir, no quadro 3: 
Quadro 3: Fluxograma 1

\section{DETERMINAÇÃO DE PROPOFOL EM PLASMA}

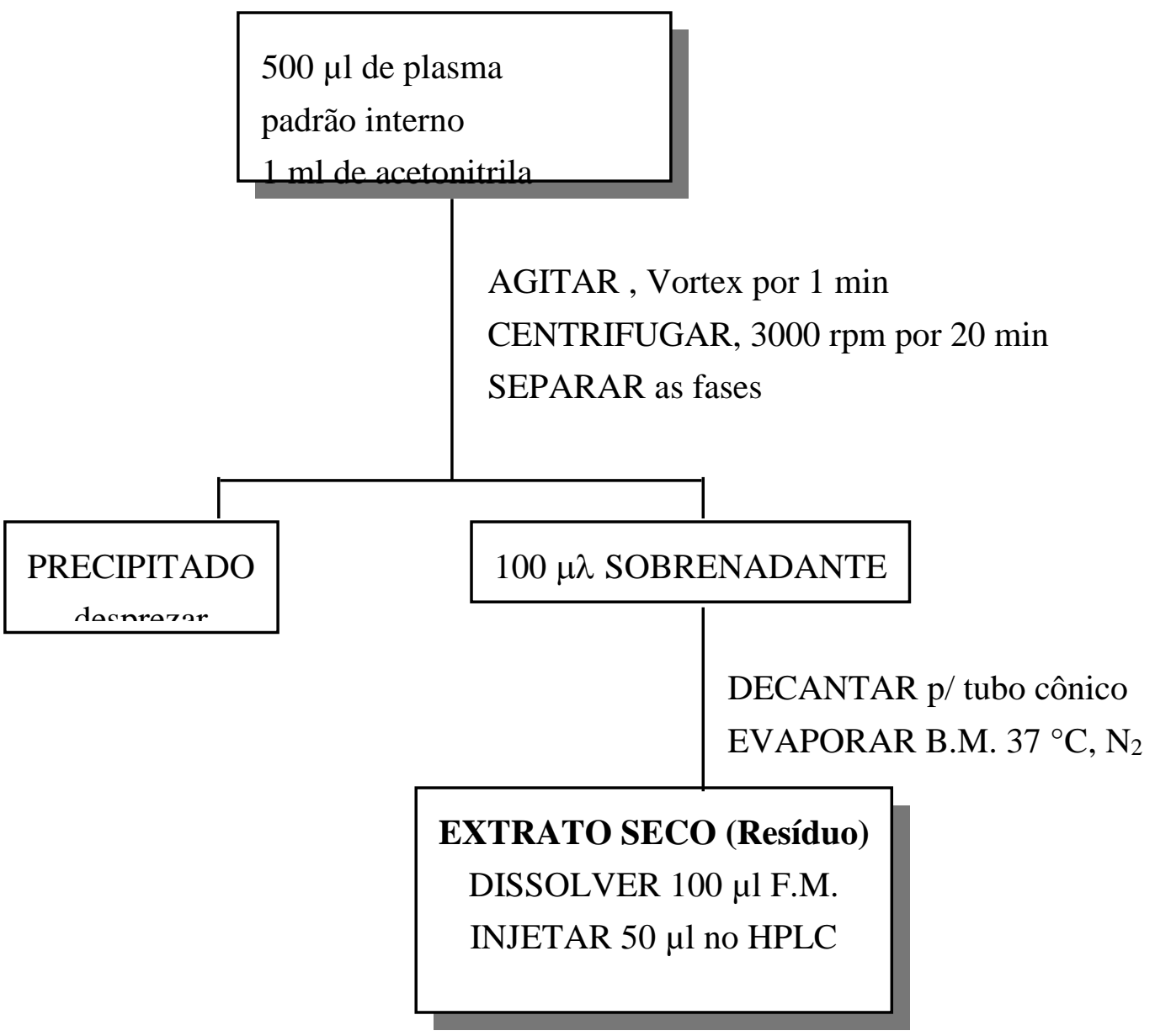

\section{Condições Instrumentais}

Coluna NovaPak C18 ${ }^{\circledR}$ Waters 150 x 3,9 mm, $4 \mu \mathrm{m}$

Fase Móvel: Metanol : Água (7;3, v/v)

Fluxo:0,7 ml/min 
A análise cromatográfica utilizou coluna de fase reversa tipo C18, em sistema isocrático de eluição, fluxo de $0,7 \mathrm{ml} / \mathrm{min}$. A monitorização dos picos referentes ao propofol bem como o padrão interno utilizado foram efetuados com o detetor de fluorescência [276 nm $\left(\lambda_{\text {exc }}\right)$ e $\left.310 \mathrm{~nm}\left(\lambda_{\text {em }}\right)\right]$

Vários métodos têm sido descritos na literatura para a análise das concentrações plasmáticas de propofol utilizando cromatografia líquida de alta eficiência com detecção ultravioleta (UV) (KNIBBE et al., 1998; ZHANG et al., 1998; EMARA et al., 1999), fluorescência (CHAN et al., 1990; EL-YAZIGI et al., 1996; YEGANCH et al., 1997) ou eletroquímico (DOWRIE et al., 1996), e também utilizando cromatografia a gás com detector de massas (STETSON et al., 1993).

\subsubsection{Validação da metodologia analítica}

A metodologia analítica foi validada, após otimização dos procedimentos e adaptações às condições do laboratório, pela fixação dos limites de confiança da técnica utilizada no estudo e pela aplicação na análise dos produtos em estudo em plasma.

$\mathrm{Na}$ análise quantitativa, foram considerados os parâmetros: linearidade, sensibilidade, limite de quantificação, reprodutibilidade, precisão intra e interdias, robustez, estabilidade e exatidão, bem como recuperação absoluta e relativa da extração de para o composto em estudo. Os resultados obtidos foram expressos através da: média, desvio-padrão, faixa de variação IC95 para a padronização cromatográfica. 


\subsubsection{Modelagem cinética do Propofol}

O modelo de três compartimentos permite prever a distribuição e a eliminação bifásica (descaimento triexponencial) a partir da coleta de, no mínimo, seis amostras sangüíneas, bem como estimar os parâmetros modelos-dependentes (constante de velocidade e a respectiva meia-vida) para a distribuição (fase alfa) e eliminação (fases beta e gama) bem como os modelos-independentes anteriormente referidos.

Entretanto cumpre ressaltar a ocorrência, bem como diferenciar a eliminação bifásica caracterizada por eliminação rápida (processo beta: meia-vida biológica) e eliminação lenta (processo gama: meia-vida terminal). Justifica-se o aparecimento de fase gama pela recirculação do fármaco mobilizado em quantidade significativa de compartimentos profundos ou sítios de alta afinidade (fármaco-tecido) também denominados sítio de acúmulo, enquanto a fase beta é definida pela retirada irreversível do fármaco por meio dos órgãos depuradores, gerando a meia-vida biológica. Finalmente, define-se ainda o volume de distribuição residual ou seja o volume em que o fármaco se encontra distribuído após o equilíbrio steady state sangue-tecidos, sendo denominado por Vdss. Tal parâmetro sempre representado por valor numérico superior ao Vdi, está associado à fase gama ou seja, dependente da situação de acúmulo do fármaco. Assim sendo, o Vdss deve ser estimado a partir da razão entre a depuração plasmática e gama, constante de velocidade associada ao processo de eliminação lenta.

Em relação ao modelo farmacocinético, efetuou-se a modelagem farmacocinética pela escolha do modelo de 3 compartimentos (tricompartimental), que melhor se adaptou ao delineamento experimental previsto no protocolo de coleta, nos períodos intra e pós-operatórios. 
O quadro 4 a seguir mostra os parâmetros farmacocinéticos analisados.

\section{Quadro 4. parâmetros farmacocinéticos}

\begin{tabular}{|c|c|c|c|}
\hline \multicolumn{4}{|c|}{ MODELAGEM CINÉTICA DO PROPOFOL } \\
\hline$t_{(1 / 2) \beta}$ & Meia-vida biológica & $\mathrm{h}$ & $0.693 / \beta$ \\
\hline$\beta$ & $\begin{array}{l}\text { Constante de velocidade de } \\
\text { eliminação rápida }\end{array}$ & $\mathrm{h}^{-1}$ & $(\ln C 1-\ln C 2) / \Delta \mathrm{T}$ \\
\hline $\mathbf{t}_{(1 / 2) \gamma}$ & Meia-vida terminal & $\mathrm{h}$ & $0.693 / \gamma$ \\
\hline$\gamma$ & $\begin{array}{l}\text { Constante de velocidade de } \\
\text { eliminação lenta }\end{array}$ & $h^{-1}$ & $(\operatorname{lnC} 1-\ln C 2) / \Delta \mathrm{T}$ \\
\hline AUCintervalo & $\begin{array}{l}\text { Área sob a curva } \\
\text { Período }\end{array}$ & $\mathrm{ng} / \mathrm{ml} . \mathrm{h}$ & $\begin{array}{l}\text { Trapezóides }(\tau) \\
\text { intervalo : período }\end{array}$ \\
\hline$\overline{\mathbf{A U} \mathbf{C}_{\mathbf{T}}}$ & $\begin{array}{c}\text { Área sob a curva, integração ponto a } \\
\text { ponto }\end{array}$ & $\mathrm{ng} / \mathrm{ml} . \mathrm{h}$ & $\begin{array}{c}\text { Trapezóides }(\tau) \\
\text { intervalo entre doses }\end{array}$ \\
\hline $\mathbf{C L}_{\mathrm{T}}$ & Depuração plasmática & $\mathrm{ml} / \mathrm{min} / \mathrm{kg}$ & Dose/AUC \\
\hline $\mathbf{V d} \beta$ & $\begin{array}{l}\text { Volume aparente de Distribuição fase } \\
\text { beta }\end{array}$ & $1 / \mathrm{kg}$ & $\mathrm{CLT}_{\mathrm{T}} / \beta$ \\
\hline $\mathbf{V d} \gamma$ & $\begin{array}{l}\text { Volume de distribuição residual } \\
\text { Fase gama }\end{array}$ & $1 / \mathrm{kg}$ & $\mathrm{CL}_{\mathrm{T}} / \gamma$ \\
\hline
\end{tabular}

Os valores normais de referência encontrados na literatura para a farmacocinética do propofol são: $\mathrm{t}_{1 / 2} \beta$ (meia-vida de eliminação) de 3,5 horas, volume

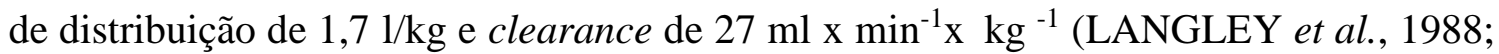
WILKINSON, 2001). 


\subsection{Cálculo da percentagem do erro de previsão}

O cálculo da percentagem do erro de previsão foi avaliado pela relação entre a concentração plasmática de propofol feita pela dosagem plasmática do fármaco, realizada pela cromatografia líquida de alta eficiência a partir das amostras sangüíneas, e a concentração prevista de propofol administrado por infusão alvo-controlada, efetuada pelo diprifusor. O percentual do erro de previsão foi calculado pela seguinte fórmula e expresso em percentagem:

Percentagem do erro de previsão $=\underline{\text { Concentração plasmática }- \text { Concentração prevista }}$ X 100

Concentração prevista

\subsection{Metodologia estatística}

Todos os dados foram resumidos pelos dos valores mínimo e máximo, mediana, média, desvio-padrão e erro-padrão e gráficos de perfis médios e individuais.

A análise dos dados constou inicialmente da avaliação da homogeneidade dos grupos com e sem CEC, quanto às informações demográficas e aos tempos de interesse. Nessa etapa da análise, utilizou-se o teste t-Student (ROSNER, 1986) empregado para comparar os dois grupos quanto às médias referentes aos dados quantitativos.

Para comparar os grupos com e sem CEC, quanto às variáveis da farmacodinâmica ao longo das várias avaliações, utilizou-se a metodologia de Análise de Variância para Medidas Repetidas (ANOVA) (WINER, 1971). As comparações 
das avaliações durante a CEC, no grupo CEC, também foram feitas utilizando-se a Análise de Variância para Medidas Repetidas (WINER, 1971) para um grupo.

Para avaliar a correlação entre a concentração prevista e a concentração medida, construiu-se um gráfico de dispersão e empregou-se o coeficiente de correlação de Pearson (ROSNER, 1986).

Adotou-se *p<0,05 como significativo de diferença entre os grupos. 


\section{RESULTADOS}




\section{RESULTADOS}

Os resultados estão expressos por meio de tabelas com valores de média aritmética e desvio-padrão com a respectiva análise estatística. Gráficos referentes a cada atributo encontram-se no item correspondente.

\subsection{População estudada}

Os dados dos dois grupos, referentes ao número de pacientes estudados, ao sexo, à idade, ao peso, à altura, ao índice de massa corpórea (IMC), ao tempo de cirurgia ao tempo de intubação (IOT) e ao tempo de circulação extracorpórea (CEC) encontramse na tabela 1, e os dados individuais, nos quadros I e II do apêndice.

Tabela 1. Dados demográficos dos pacientes dos dois grupos, tempo de cirurgia, tempo de IOT e tempo de CEC (média \pm DP).

\begin{tabular}{|c|c|c|c|}
\hline & Grupo CEC & Grupo sem CEC & $\mathrm{p}$ \\
\hline $\mathbf{N}$ & 10 & 10 & \\
\hline Sexo & $\mathrm{M}=9 \quad \mathrm{~F}=1$ & $\mathrm{M}=7 \quad \mathrm{~F}=3$ & \\
\hline Idade (anos) & $62,20 \pm 8,32$ & $68,50 \pm 6,57$ & 0,0766 \\
\hline Peso (kg) & $75,23 \pm 10,55$ & $74,87 \pm 8,17$ & 0,9329 \\
\hline Altura (cm) & $163,00 \pm 0,04$ & $166,00 \pm 0,10$ & 0,5548 \\
\hline IMC & $28,14 \pm 4,63$ & $27,58 \pm 2,70$ & 0,7466 \\
\hline Tempo de Cirurgia (min) & $277,50 \pm 53,66$ & $287,00 \pm 77,04$ & 0,7527 \\
\hline Tempo de IOT no P.O. (min) & $424,82 \pm 111,97$ & $279,24 \pm 78,17$ & $\mathbf{0 , 0 0 3}$ \\
\hline Tempo de CEC (min) & $79,00 \pm 23,37$ & & \\
\hline
\end{tabular}

As médias e os desvios-padrão da temperatura mínima durante a CEC foram: $(30,51 \pm 1,68)$. As médias e os desvios-padrão do hematócrito mínimo durante a CEC foram: $(23,00 \pm 1,16)$. Os dados individuais encontram-se no quadro XX do apêndice. 


\subsection{Infusão de propofol}

\subsubsection{Dose infundida de propofol}

Os dados referentes às médias e os desvios-padrão dos valores de dose infundida de propofol dos dois grupos, nos diferentes momentos do estudo, e os dados individuais encontram-se no quadro III do apêndice.

Os perfis médios (média \pm erro padrão) da dose infundida de propofol nos grupos CEC e sem CEC encontram se representados na figura 1.

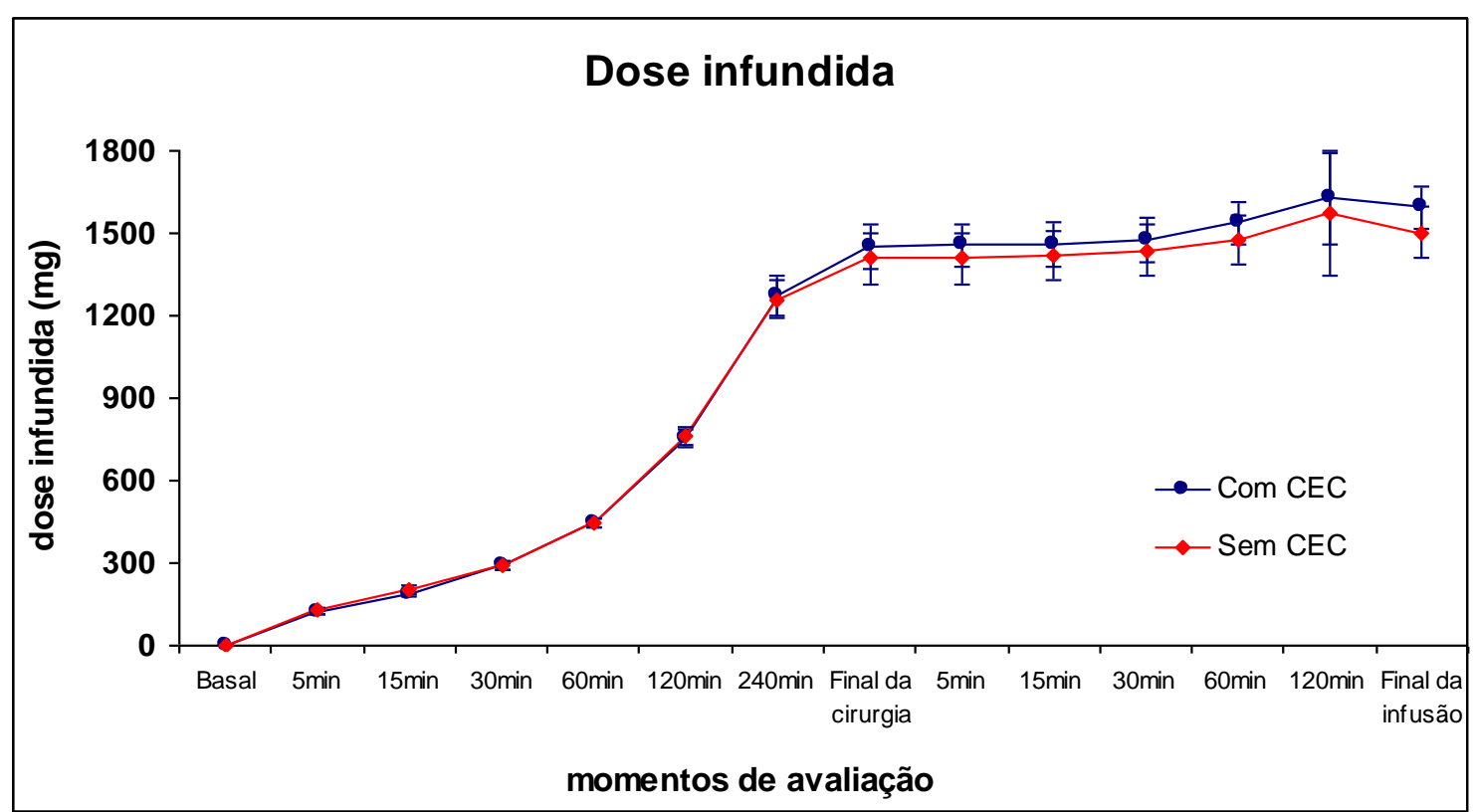

Figura 1. Perfil médio (média \pm erro padrão) da dose infundida de propofol, segundo grupo e momento de avaliação.

A análise estatística mostrou que os 2 grupos foram comparáveis em relação à dose infundida de propofol $(\mathrm{p}=0,65)$. 
Os perfis médios (média \pm erro padrão) da dose infundida de propofol no grupo CEC, durante a CEC, encontram-se representados na figura 2 e os dados individuais, no quadro IX do apêndice.

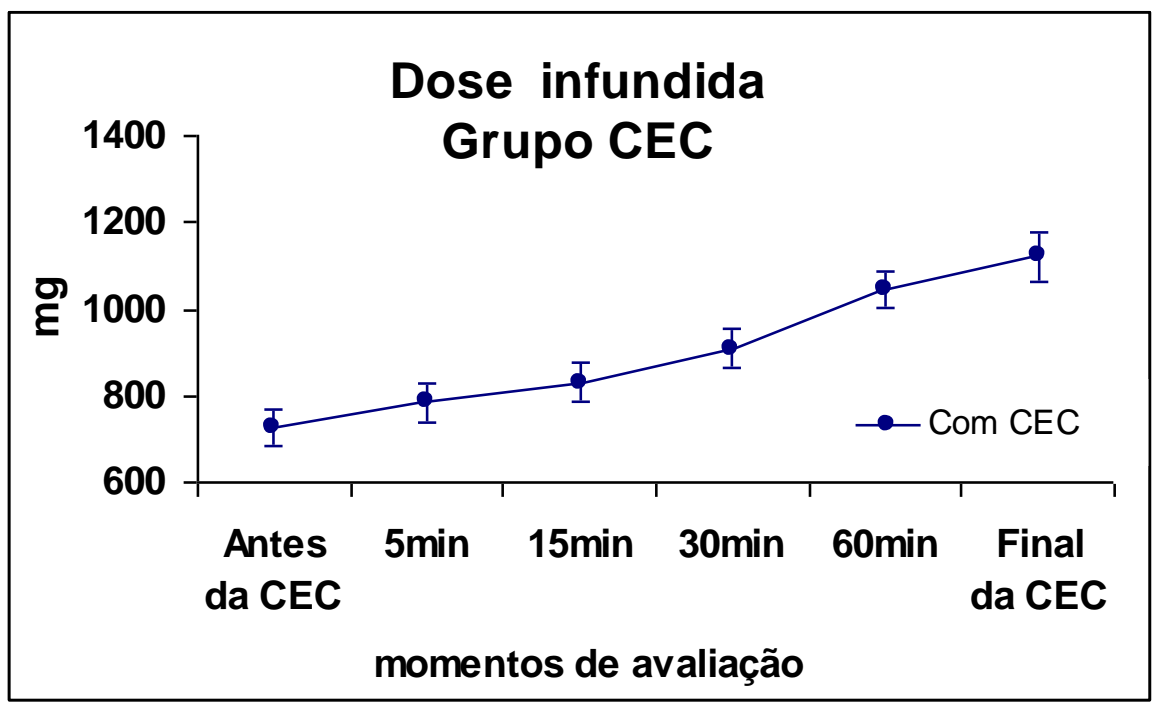

Figura 2. Perfil médio (média \pm erro padrão) da dose infundida de propofol durante CEC, no grupo CEC.

A análise de medidas repetidas da dose infundida durante a CEC no grupo CEC está descrita na tabela 2.

Tabela 2. Análise de medidas repetidas da dose infundida durante a CEC no grupo CEC.

\begin{tabular}{lc} 
Comparação & $\mathrm{p}$ \\
\hline Efeito de Avaliação & $<0,0001$ \\
Antes da CEC x 15m após & $<0,0001$ \\
$15 \mathrm{~m}$ após x 60m após & $<0,0001$ \\
Antes da CEC x final da CEC & $<0,0001$ \\
\hline
\end{tabular}




\subsubsection{Velocidade de infusão do propofol}

Os dados referentes às médias e desvios-padrão dos valores de velocidade de infusão do propofol dos dois grupos, nos diferentes momentos do estudo, e os dados individuais encontram-se no quadro IV do apêndice.

Os perfis médios (média \pm erro padrão) da velocidade de infusão do propofol nos grupos CEC e sem CEC encontram se representados na figura 3.

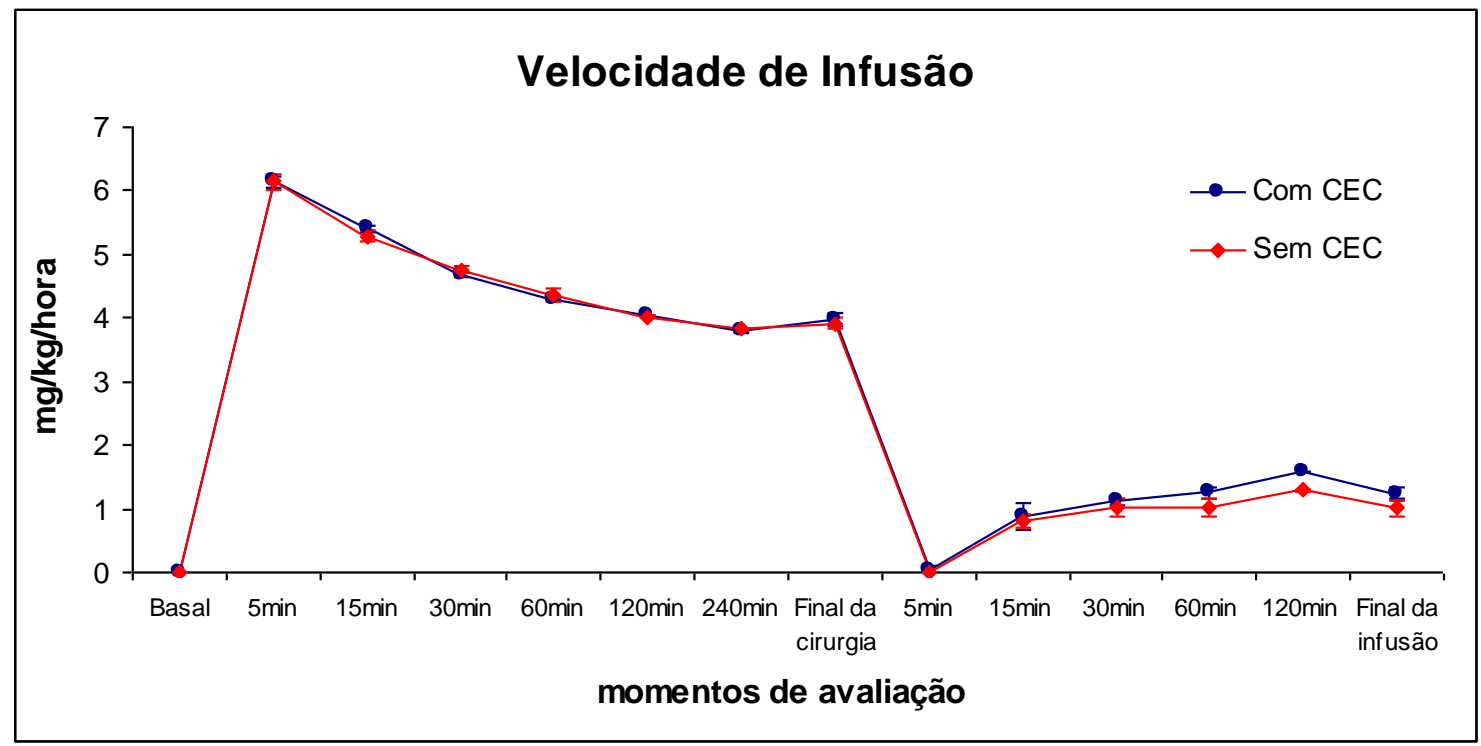

Figura 3. Perfil médio (média \pm erro padrão) da velocidade de infusão do propofol, segundo grupo e momento de avaliação.

A análise estatística mostrou que os 2 grupos foram comparáveis em relação à velocidade de infusão do propofol $(\mathrm{p}=0,83)$. 
Os perfis médios (média \pm erro padrão) da velocidade de infusão do propofol no grupo CEC, durante a CEC, encontram-se representados na figura 4 e os dados individuais, no quadro $\mathrm{X}$ do apêndice.

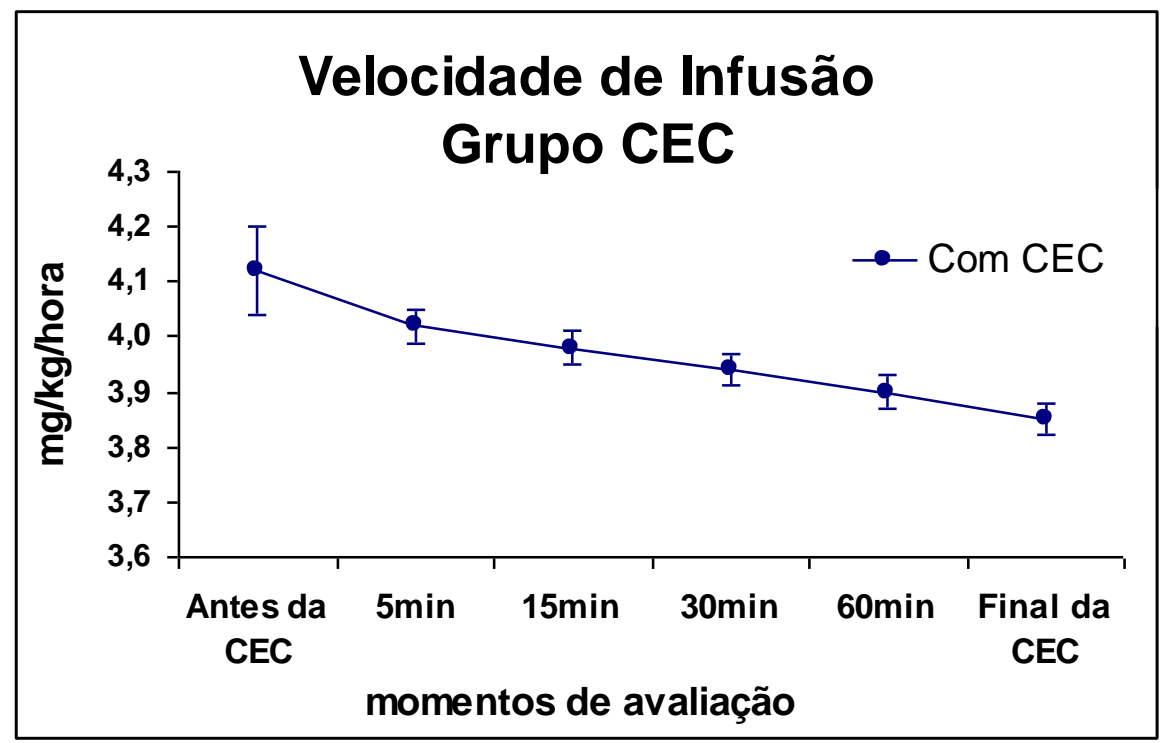

Figura 4. Perfil médio (média \pm erro padrão) da velocidade de infusão do propofol durante a CEC.

A análise de medidas repetidas da velocidade de infusão do propofol durante a CEC, no grupo CEC, está descrita na tabela 3.

Tabela 3. Análise de medidas repetidas da velocidade de infusão do propofol durante a CEC no grupo CEC.

\begin{tabular}{lc} 
Comparação & $\mathrm{p}$ \\
\hline Efeito de Avaliação & 0,0032 \\
Antes da CEC x 15m após & 0,0078 \\
$15 \mathrm{~m}$ após x 60m após & 0,2254 \\
Antes da CEC x final da CEC & $<0,0001$ \\
\hline
\end{tabular}




\subsubsection{Tempo previsto de regressão}

Os dados referentes às médias e desvios-padrão dos valores de tempo previsto de regressão dos dois grupos, nos diferentes momentos do estudo, e os dados individuais encontram-se no quadro $\mathrm{V}$ do apêndice.

Os perfis médios (média \pm erro padrão) do tempo previsto de regressão nos grupos CEC e sem CEC encontram-se representados na figura 5.

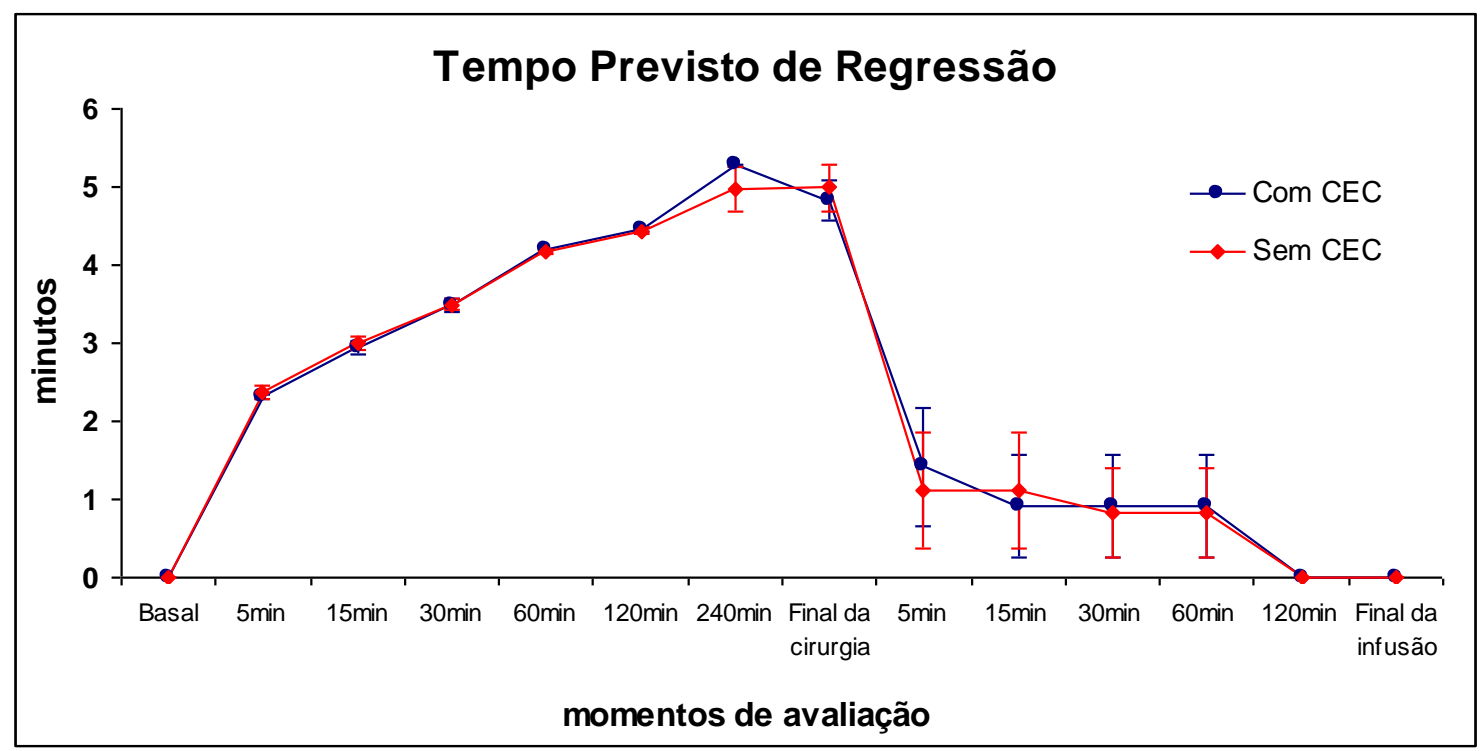

Figura 5. Perfil médio (média \pm erro padrão) do tempo previsto de regressão, segundo grupo e momento de avaliação.

A análise estatística mostrou que os 2 grupos foram comparáveis em relação ao tempo de regressão $(p=0,204)$. 
Os perfis médios (média \pm erro padrão) do tempo previsto de regressão no grupo CEC, durante a CEC, encontram-se representados na figura 6, e os dados individuais no quadro XI do apêndice.

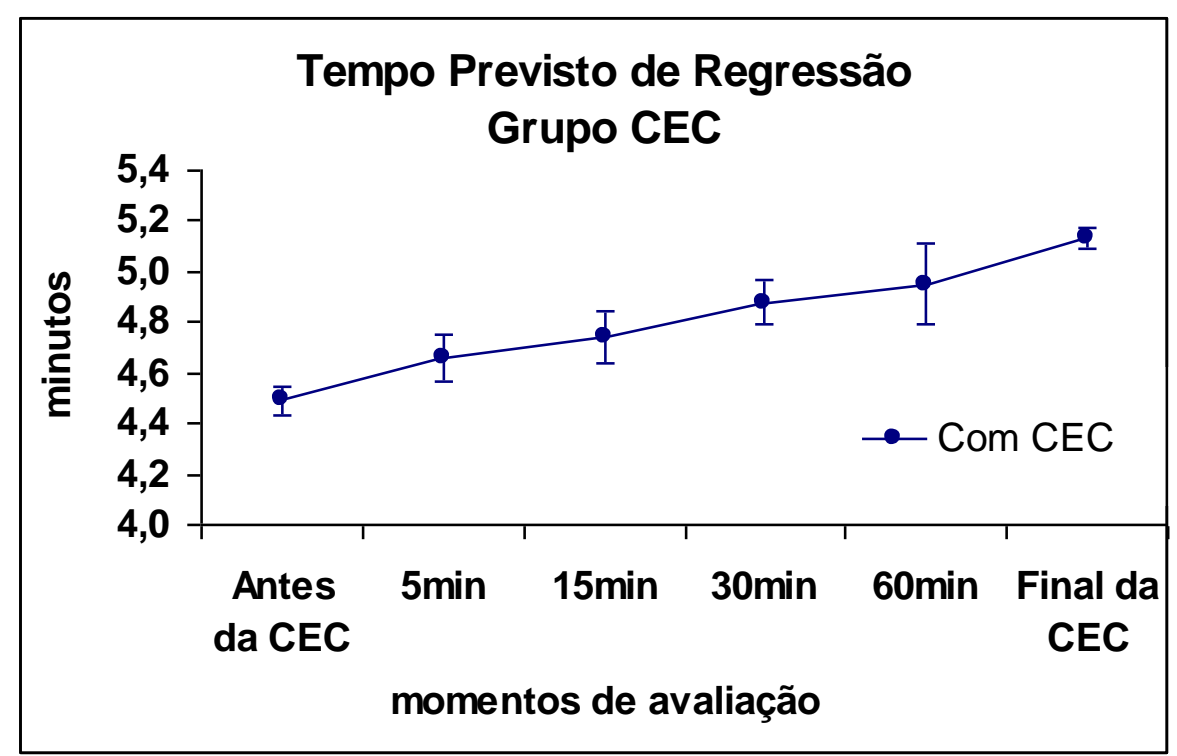

Figura 6. Perfil médio (média \pm erro padrão) do tempo previsto de regressão durante a CEC.

A análise de medidas repetidas do tempo previsto de regressão durante a CEC, no grupo CEC, está descrita na tabela 4.

Tabela 4. Análise de medidas repetidas do tempo previsto de regressão durante a CEC, no grupo CEC.

\begin{tabular}{lc} 
Comparação & $\mathrm{p}$ \\
\hline Efeito de Avaliação & $<0,0001$ \\
Antes da CEC x 15m após & 0,0087 \\
$15 \mathrm{~m}$ após x 60m após & 0,0493 \\
Antes da CEC x final da CEC & $<0,0001$ \\
\hline
\end{tabular}




\subsection{Concentrações plasmáticas de propofol}

Os dados referentes às médias e desvios-padrão dos valores da concentração plasmática medida de propofol dos dois grupos, nos diferentes momentos do estudo, e os dados individuais encontram-se nos quadros XIV e XV do apêndice.

Os perfis médios (média \pm erro padrão) da concentração prevista e plasmática de propofol dos grupos CEC e sem CEC encontram-se representados na figura 7.

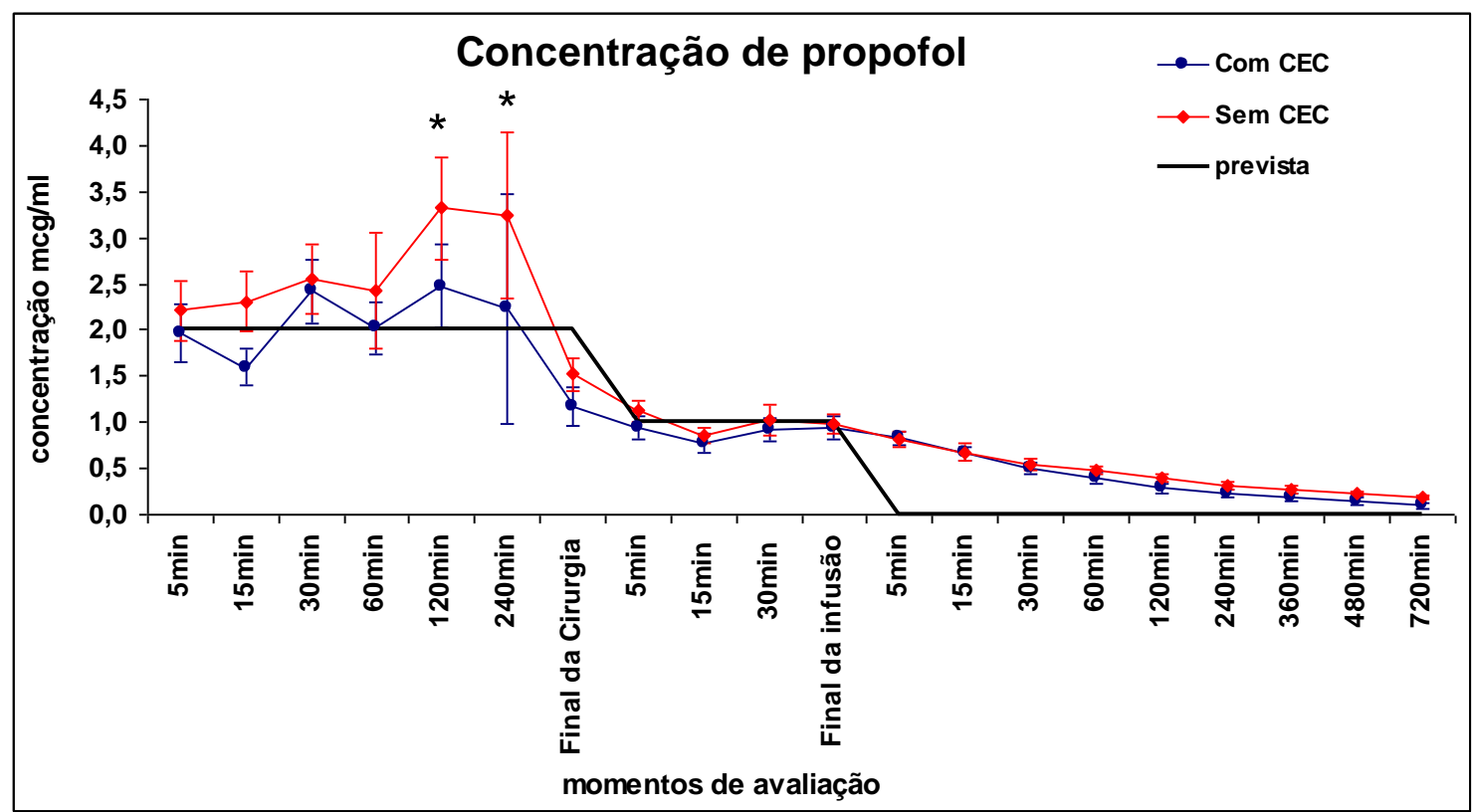

Figura 7. Perfil médio (média \pm erro padrão) da concentração plasmática de propofol e prevista, segundo grupo e momento de avaliação. A linha contínua refere-se à concentração prevista pelo equipamento de infusão alvo-controlada.

$$
*=\mathrm{p}<0,05
$$


A análise de medidas repetidas para concentração plasmática obtida de propofol está descrita na tabela 5.

Tabela 5. Análise de medidas repetidas paral concentração plasmática obtida de propofol.

\begin{tabular}{lc} 
Comparação & $\mathrm{p}$ \\
\hline Grupo x Avaliação & 0,9318 \\
Efeito de Grupo & $\mathbf{0 , 0 2 2 6}$ \\
Efeito de Avaliação & $\mathbf{< 0 , 0 0 0 1}$ \\
15m x 60m & 0,2904 \\
60m x 120m & $\mathbf{0 , 0 2 3 1}$ \\
120m x fim da Cirurgia & $<\mathbf{0 , 0 0 0 1}$ \\
Fim da Cirurgia x 30m após a Cirurgia & 0,1474 \\
Fim da Cirurgia x fim da Infusão & 0,1313 \\
Fim da Infusão x 30m após a Infusão & 0,0906 \\
120m após a Infusão x 240m após a Infusão & 0,7339 \\
360m após a Infusão x 720m após a Infusão & 0,7272 \\
\hline
\end{tabular}


A análise de medidas repetidas para concentração plasmática obtida de propofol, com comparação entre o grupo CEC e sem CEC, está descrita na tabela 6.

Tabela 6. Análise de medidas repetidas para concentração plasmática obtida de propofol, com comparação entre os grupos CEC e sem CEC.

\begin{tabular}{|c|c|}
\hline Comparação & $\mathrm{p}$ \\
\hline CEC $x$ sem $C E C-5 m$ & 0,5150 \\
\hline CEC $x$ sem $C E C-15 m$ & 0,0549 \\
\hline CEC $x$ sem $\mathrm{CEC}-30 \mathrm{~m}$ & 0,7247 \\
\hline CEC $x$ sem $C E C-60 m$ & 0,2637 \\
\hline CEC x sem CEC $-120 m$ & $\mathbf{0 , 0 0 5 0}$ \\
\hline CEC $x$ sem CEC $-240 m$ & $\mathbf{0 , 0 2 1 2}$ \\
\hline CEC x sem CEC - Final da Cirurgia & 0,3444 \\
\hline CEC x sem CEC - 5m após Cirurgia & 0,6298 \\
\hline CEC x sem CEC $-15 m$ após Cirurgia & 0,8019 \\
\hline CEC x sem CEC - 30m após Cirurgia & 0,7934 \\
\hline CEC x sem CEC - Fim da Infusão & 0,9061 \\
\hline CEC x sem CEC $-5 \mathrm{~m}$ após a Infusão & 0,9827 \\
\hline CEC x sem CEC - $15 \mathrm{~m}$ após a Infusão & 0,9397 \\
\hline CEC x sem CEC - 30m após a Infusão & 0,9174 \\
\hline CEC x sem CEC - 60m após a Infusão & 0,8336 \\
\hline CEC x sem CEC - 120m após a Infusão & 0,7600 \\
\hline CEC x sem CEC - 240m após a Infusão & 0,8334 \\
\hline CEC x sem CEC - 360m após a Infusão & 0,8376 \\
\hline CEC x sem CEC - 480m após a Infusão & 0,8334 \\
\hline CEC x sem CEC - 720m após a Infusão & 0,8252 \\
\hline
\end{tabular}


Os perfis médios (média \pm erro padrão) da concentração plasmática obtida de propofol no grupo CEC, durante a CEC, encontram-se representados na figura 8, e os dados individuais, no quadro XVI do apêndice.

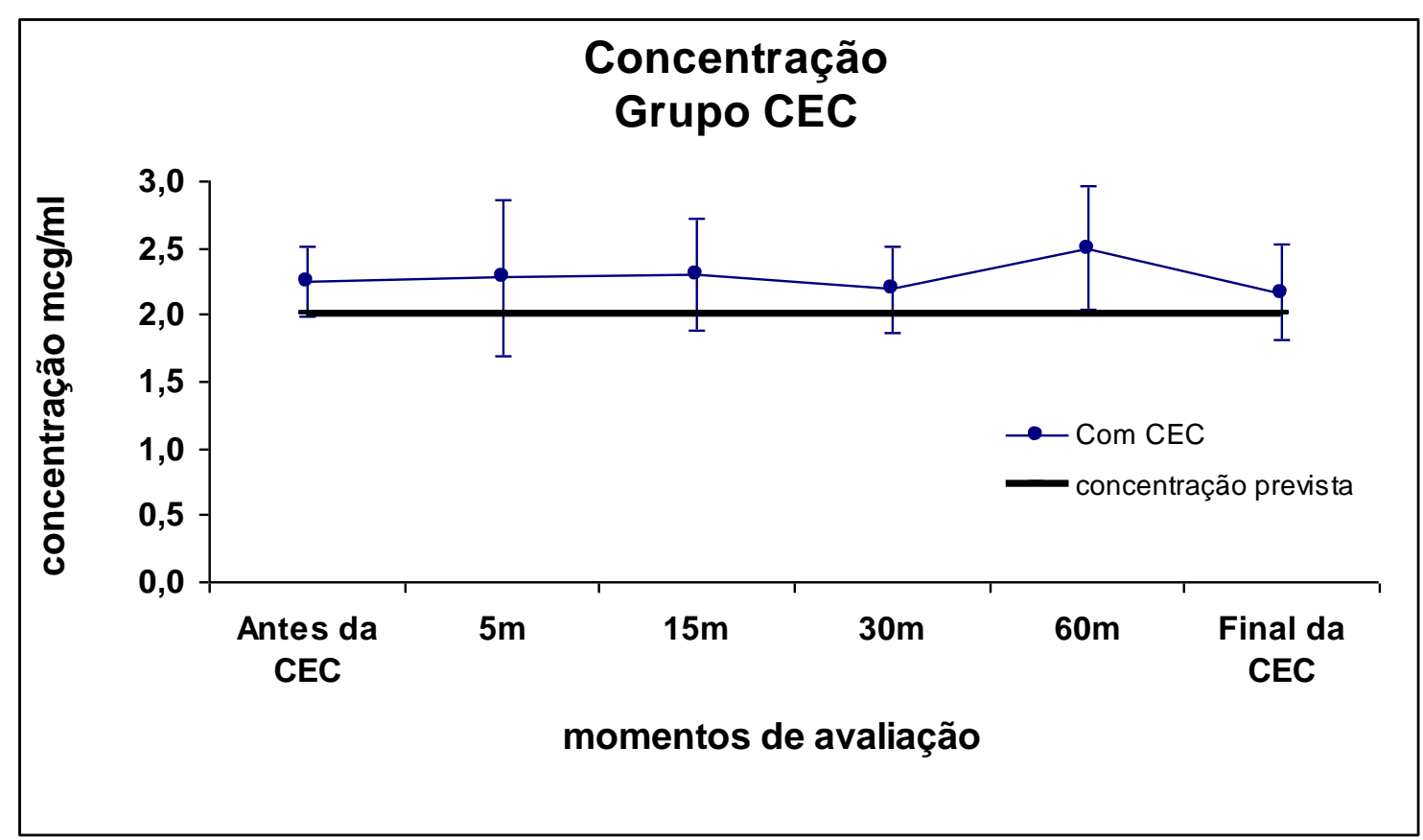

Figura 8. Perfil médio (média \pm erro padrão) da concentração plasmática obtida de propofol durante a CEC.

A análise estatística mostrou que a concentração plasmática obtida de propofol não apresentou alterações significativas durante o período de CEC $(\mathrm{p}=0,9997)$. A linha contínua refere-se à concentração prevista pelo equipamento de infusão alvo-controlada. 


\subsubsection{Cálculo da percentagem do erro de previsão}

Os perfis médios (média \pm erro padrão) da percentagem do erro de previsão nos grupos CEC e sem CEC estão representados na figura 9, e os dados individuais, no quadro XIX do apêndice.

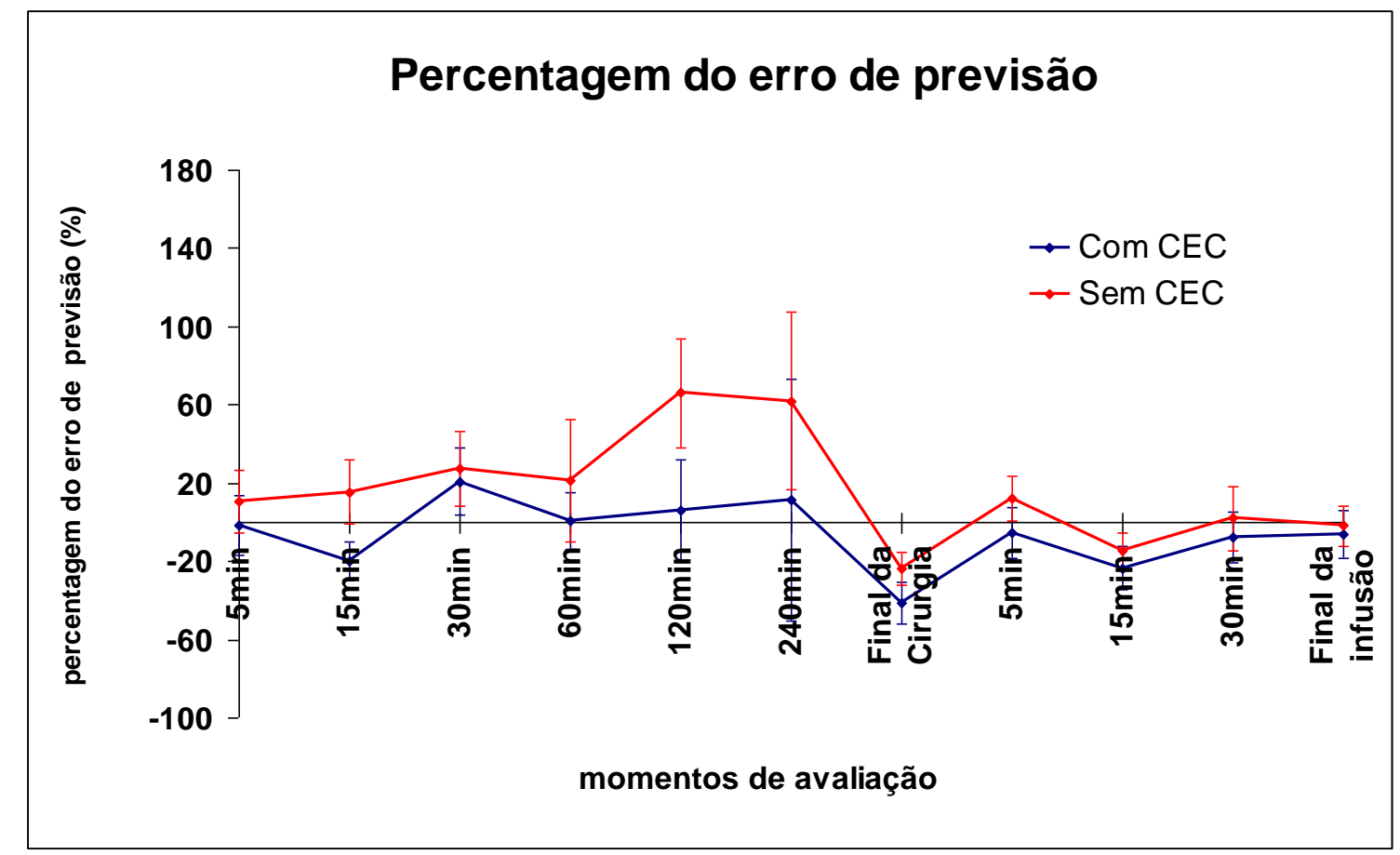

Figura 9. Perfis médios (média \pm erro padrão) da percentagem do erro de previsão do Grupo CEC e do Grupo sem CEC. 


\subsection{Farmacocinética do propofol}

Os dados referentes às médias e desvios-padrão das variáveis farmacocinéticas dos dois grupos, nos diferentes momentos do estudo, encontram-se na tabela 7, e os dados individuais, nos quadros XVII e XVIII do apêndice.

Tabela 7. Variáveis farmacocinéticas (média \pm desvio-padrão).

\begin{tabular}{|l|c|c|c|}
\hline Variáveis farmacocinéticas & Grupo CEC & Grupo sem CEC & p \\
\hline$\alpha$ hora $\left.^{-1}\right)$ & $4,172 \pm 1,530$ & $4,768 \pm 2,961$ & 0,5785 \\
\hline $\mathrm{T}_{1 / 2} \alpha$ (hora) & $0,19 \pm 0,07$ & $0,21 \pm 0,15$ & 0,7136 \\
\hline$\beta$ hora $\left.^{-1}\right)$ & $0,408 \pm 0,109$ & $0,207 \pm 0,064$ & $\mathbf{p}<\mathbf{0 , 0 0 0 1}$ \\
\hline $\mathrm{T}_{1 / 2} \beta$ (hora) & $1,82 \pm 0,5$ & $3,67 \pm 1,15$ & $\mathbf{0 , 0 0 0 5}$ \\
\hline$\gamma$ hora $\left.^{-1}\right)$ & $0,115 \pm 0,026$ & $0,068 \pm 0,013$ & $\mathbf{p}<\mathbf{0 , 0 0 0 1}$ \\
\hline $\mathrm{T}_{1 / 2} \gamma($ hora) & $6,27 \pm 1,29$ & $10,5 \pm 2,18$ & $\mathbf{p}<\mathbf{0 , 0 0 0 1}$ \\
\hline AUC 0-t (ng/ml x hora) & $13,37 \pm 5,4$ & $18,38 \pm 6,39$ & 0,0743 \\
\hline AUC 0-inf (ng/ml x hora) & $14,28 \pm 5,69$ & $21,11 \pm 7,29$ & $\mathbf{0 , 0 3 1 5}$ \\
\hline CLT (ml/min/kg) & $28,36 \pm 11,40$ & $18,29 \pm 7,67$ & $\mathbf{0 , 0 3}$ \\
\hline Vd_ B (l/kg) & $4,39 \pm 1,90$ & $5,61 \pm 2,69$ & 0,2571 \\
\hline Vd_ $\gamma(1 / \mathrm{kg})$ & $15,99 \pm 9,40$ & $16,74 \pm 8,69$ & 0,8550 \\
\hline
\end{tabular}

$\alpha=$ constante de velocidade de distribuição

$\mathrm{T}_{1 / 2} \alpha=$ meia-vida de distribuição

$\beta=$ constante de velocidade de eliminação rápida

$\mathrm{T}_{1 / 2} \beta=$ meia-vida de eliminação rápida

$\gamma=$ constante de velocidade de eliminação lenta

$\mathrm{T}_{1 / 2} \gamma=$ meia-vida de eliminação lenta

AUC 0-t $=$ área sobre a curva no intervalo de tempo de coleta

AUC O-inf = área sobre a curva de zero a infinito

$\mathrm{CLT}=$ clearance total

$\mathrm{Vd} \beta=$ volume de distribuição do compartimento beta

Vd $\gamma=$ volume de distribuição do compartimento gama 


\subsection{Farmacodinâmica do propofol}

\subsubsection{Avaliação do grau de hipnose}

Nenhum paciente relatou lembrança do período intra-operatório, quando avaliado no primeiro dia de pós-operatório.

\subsubsection{1 Índice bispectral (BIS)}

Os dados referentes às médias e desvios-padrão dos valores do índice bispectral (BIS) dos dois grupos, nos diferentes momentos do estudo, e os dados individuais encontram-se no quadro VI do apêndice.

Os perfis médios (média \pm erro padrão) do índice bispectral (BIS) nos grupos CEC e sem CEC encontram-se representados na figura 10.

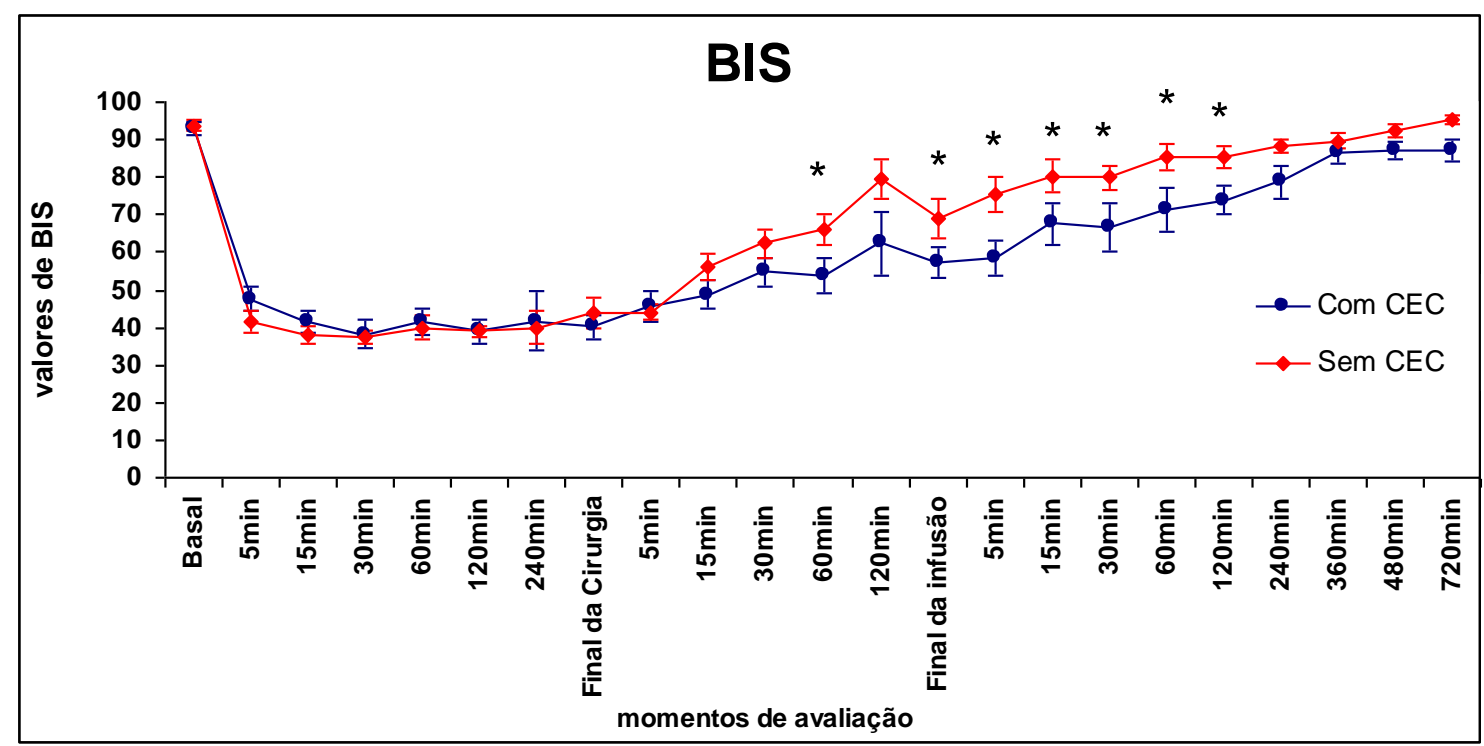

Figura 10. Perfil médio (média \pm erro padrão) do BIS, segundo grupo e momento de avaliação

$$
*=p<0,05
$$


A análise de medidas repetidas para o índice bispectral (BIS) está descrita na tabela 8 .

Tabela 8. Análise de medidas repetidas para o índice bispectral (BIS).

\begin{tabular}{lc} 
Comparação & $p$ \\
\hline CEC - Efeito de avaliação & $<0,0001$ \\
CEC - 15m x 60m & 0,9780 \\
CEC - 60m x 120m & 0,8080 \\
CEC - 120m x fim da Cirurgia & 0,8796 \\
CEC - Fim da Cirurgia x 30m após a Cirurgia & 0,0005 \\
CEC - Fm da Cirurgia x fim da Infusão & 0,0007 \\
CEC - Fim da Infusão x 30m após a Infusão & 0,0263 \\
CEC - 120m após a Infusão x 240m após a Infusão & 0,0683 \\
CEC - 360m após a Infusão x 720m após a Infusão & 0,8469 \\
\hline Sem CEC - Efeito de avaliação & $<0,0001$ \\
Sem CEC - 15m x 60m & 0,5643 \\
Sem CEC - 60m x 120m & 0,7129 \\
Sem CEC - 120m x fim da Cirurgia & 0,1853 \\
Sem CEC - Fim da Cirurgia x 30m após a Cirurgia & $<0,0001$ \\
Sem CEC - Fim da Cirurgia x fim da Infusão & $<0,0001$ \\
Sem CEC - Fim da Infusão x 30m após a Infusão & 0,0047 \\
Sem CEC - 120m após a Infusão x 240m após a Infusão & 0,2544 \\
Sem CEC - 360m após a Infusão x 720m após a Infusão & 0,1009 \\
\hline
\end{tabular}

Quanto ao índice bispectral (BIS), os perfis médios não parecem ser paralelos, portanto as comparações dos grupos foram feitas separadamente para cada momento de avaliação, e, além disso, o estudo do efeito do tempo foi feito separadamente para cada grupo. 
A análise de medidas repetidas para o índice bispectral (BIS), com comparação entre o grupo CEC e sem CEC, está descrita na tabela 9.

Tabela 9. Análise de medidas repetidas para a variável BIS.

\begin{tabular}{lc}
\hline Comparação & $p$ \\
\hline CEC x sem CEC - Basal & 0,8734 \\
CEC x sem CEC - 5m & 0,2175 \\
CEC x sem CEC - 15m & 0,4986 \\
CEC x sem CEC - 30m & 0,8422 \\
CEC x sem CEC - 60m & 0,7652 \\
CEC x sem CEC - 120m & 0,7304 \\
CEC x sem CEC - 240m & 0,7697 \\
CEC x sem CEC - Final da Cirurgia & 0,4986 \\
CEC x sem CEC - 5m após Cirurgia & 0,7501 \\
CEC x sem CEC - 15m após Cirurgia & 0,1258 \\
CEC x sem CEC - 30m após Cirurgia & 0,1412 \\
CEC x sem CEC - 60m após Cirurgia & $\mathbf{0 , 0 1 3 9}$ \\
CEC x sem CEC - 120m após Cirurgia & 0,3426 \\
CEC x sem CEC - Fim da Infusão & $\mathbf{0 , 0 2 1 4}$ \\
CEC x sem CEC - 5m após a Infusão & $\mathbf{0 , 0 0 0 7}$ \\
CEC x sem CEC - 15m após a Infusão & $\mathbf{0 , 0 1 1 2}$ \\
CEC x sem CEC - 30m após a Infusão & $\mathbf{0 , 0 0 8 4}$ \\
CEC x sem CEC - 60m após a Infusão & $\mathbf{0 , 0 0 5 2}$ \\
CEC x sem CEC - 120m após a Infusão & $\mathbf{0 , 0 2 2 5}$ \\
CEC x sem CEC - 240m após a Infusão & 0,0566 \\
CEC x sem CEC - 360m após a Infusão & 0,5504 \\
CEC x sem CEC - 480m após a Infusão & 0,3008 \\
CEC x sem CEC - 720m após a Infusão & 0,1118 \\
\hline
\end{tabular}


Os perfis médios (média \pm erro padrão) do BIS no grupo CEC, durante a CEC, encontram-se representados na figura 11, e os dados individuais, no quadro XII do apêndice.

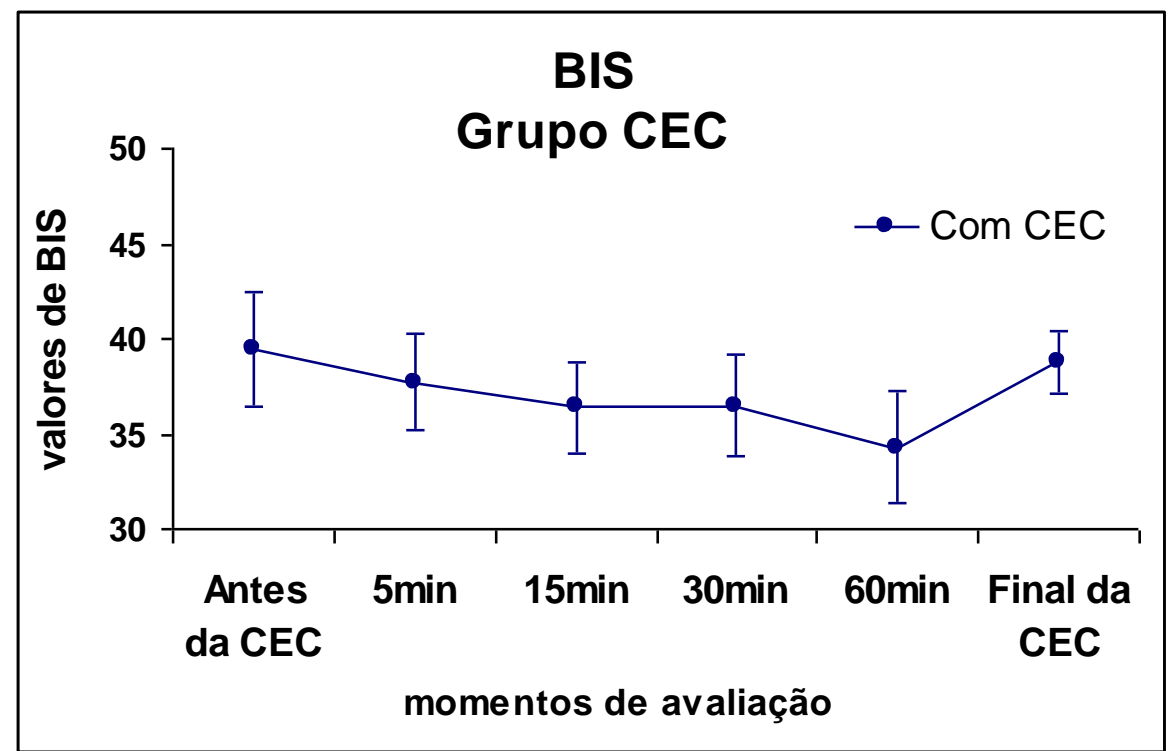

Figura 11. Perfil médio (média \pm erro padrão) da BIS durante a CEC.

A análise estatística mostrou que o índice bispectral não apresentou alterações significativas durante o período de CEC $(\mathrm{p}=0,5051)$. 


\subsubsection{Avaliação hemodinâmica}

\subsubsection{Pressão arterial média (PAM)}

Os perfis médios (média \pm erro padrão) da PAM nos grupos CEC e sem CEC encontramse representados na figura 12 , e os dados individuais, no quadro VII do apêndice.

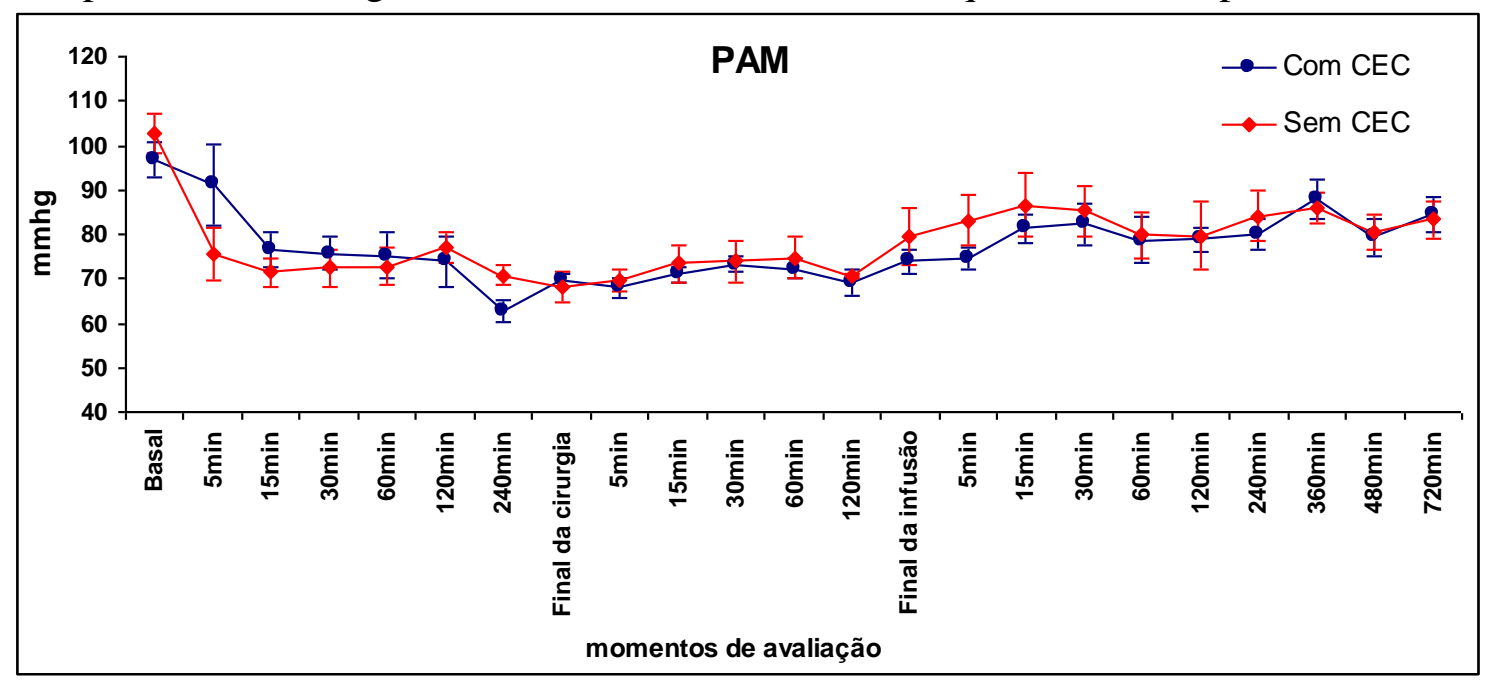

Figura 12. Perfil médio (média \pm erro padrão) da pressão arterial média (PAM), segundo grupo e momento de avaliação.

A análise de medidas repetidas para pressão arterial média está descrita na tabela 10 .

Tabela 10. Análise de medidas repetidas para pressão arterial média.

\begin{tabular}{lc} 
Comparação & $\mathrm{p}$ \\
\hline Grupo x Avaliação & 0,6081 \\
Efeito de Grupo & 0,8431 \\
Efeito de Avaliação & $<0,0001$ \\
$15 \mathrm{~m}$ x 60m & 0,9898 \\
60m x 120m & 0,7146 \\
120m x fim da Cirurgia & 0,1201 \\
Fim da Cirurgia x 30m após a Cirurgia & 0,2592 \\
Fim da Cirurgia x fim da Infusão & 0,0732 \\
Fim da Infusão x 30m após a Infusão & 0,0909 \\
120m após a Infusão x 240m após a Infusão & 0,3912 \\
360m após a Infusão x 720m após a Infusão & 0,4491 \\
\hline
\end{tabular}


Os perfis médios (média \pm erro padrão) da pressão arterial média (PAM) durante a CEC, no grupo CEC, encontram-se representados na figura 13 , e os dados individuais, no quadro XIII do apêndice.

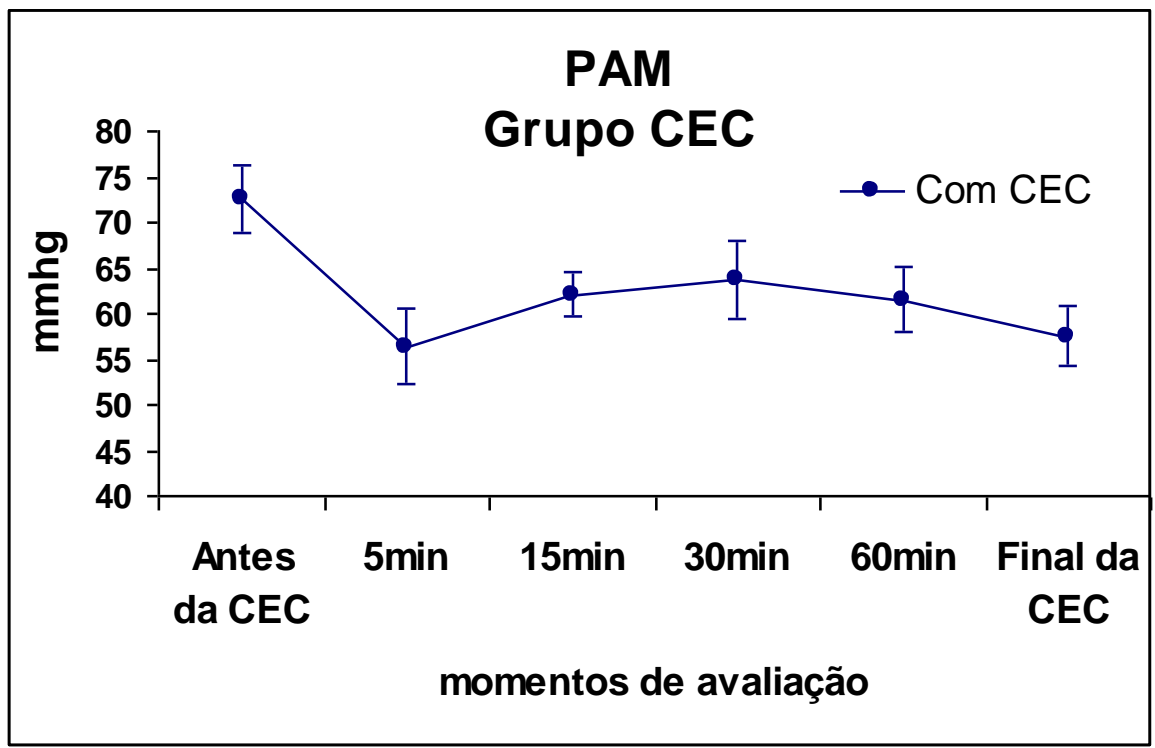

Figura 13. Perfil médio (média \pm erro padrão) da PAM durante a CEC.

A análise de medidas repetidas da pressão arterial média (PAM) durante a CEC, no grupo CEC, está descrita na tabela 11.

Tabela 11. Análise de medidas repetidas da PAM durante a CEC, no grupo CEC.

\begin{tabular}{lc} 
Comparação & $\mathrm{p}$ \\
\hline Efeito de Avaliação & 0,0292 \\
Antes da CEC x 15m após & 0,0450 \\
15m após x 60m após & 0,9288 \\
Antes da CEC x final da CEC & 0,0050 \\
\hline
\end{tabular}




\subsubsection{Freqüência cardíaca (FC)}

Os perfis médios (média \pm erro padrão) da freqüência cardíaca (FC) nos grupos CEC e sem CEC encontram se representados na figura 14, e os dados individuais, no quadro VIII do apêndice.

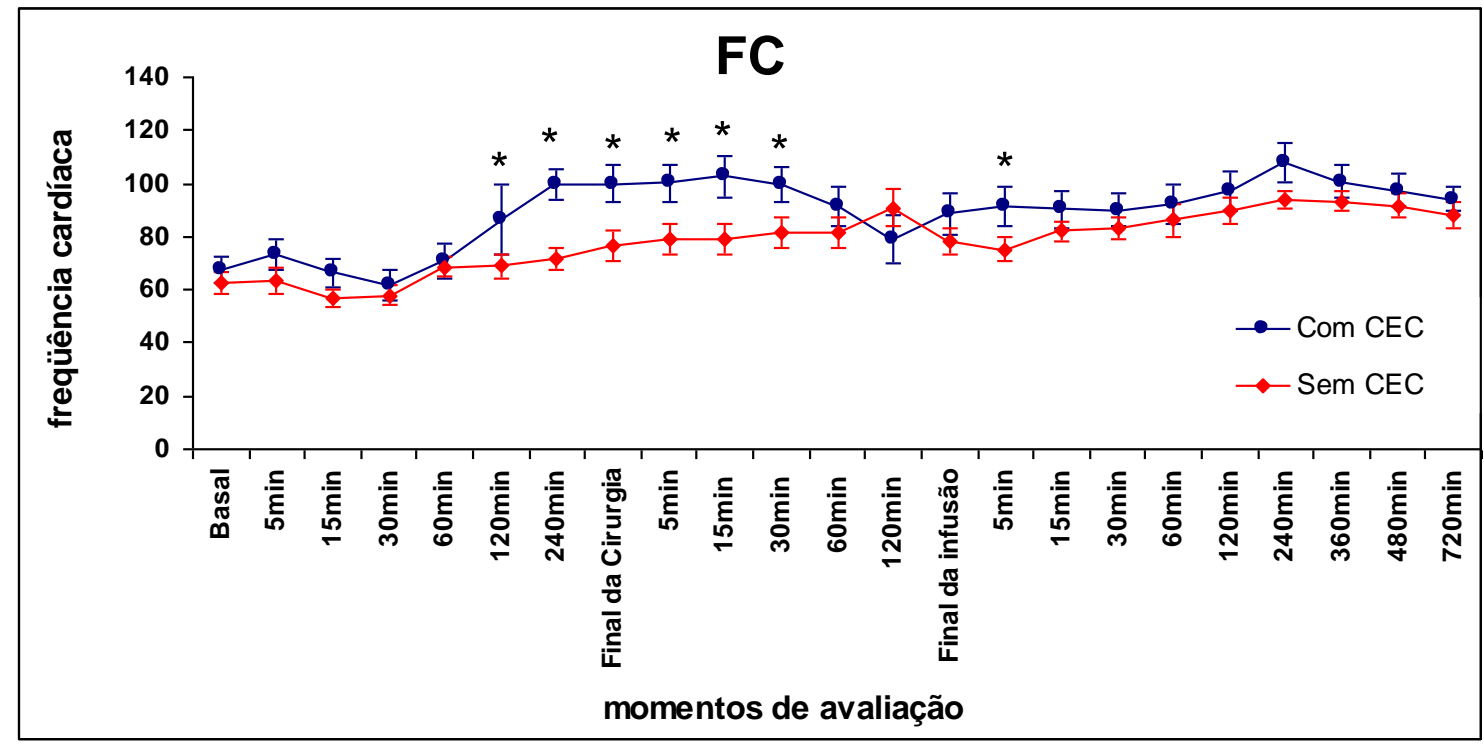

Figura 14. Perfil médio (média \pm erro padrão) da frequiência cardíaca (FC), segundo grupo e momento de avaliação.

$*=\mathrm{p}<0,05$ 
A análise de medidas repetidas para a frequiência cardíaca está descrita na tabela 12 .

Tabela 12. Análise de medidas repetidas para freqüência cardíaca.

\begin{tabular}{lc}
\hline Comparação & $\mathrm{p}$ \\
\hline CEC- Efeito de Avaliação & $<0,0001$ \\
CEC - 15m x 60m & 0,4273 \\
CEC - 60m x 120m & $<0,0001$ \\
CEC - 120m x fim da Cirurgia & 0,2412 \\
CEC - Fim da Cirurgia x 30m após a Cirurgia & 0,9879 \\
CEC - Fim da Cirurgia x fim da Infusão & 0,1659 \\
CEC - Fim da Infusão x 30m após a Infusão & 0,8440 \\
CEC - 120m após a Infusão x 240m após a Infusão & 0,0115 \\
CEC - 360m após a Infusão x 720m após a Infusão & 0,2518 \\
\hline & \\
Sem CEC - Efeito de Avaliação & 0,0005 \\
Sem CEC - 15m x 60m & 0,0037 \\
Sem CEC - 60m x 120m & 0,8955 \\
Sem CEC - 120m x fim da Cirurgia & 0,0661 \\
Sem CEC - Fim da Cirurgia x 30m após a Cirurgia & 0,3100 \\
Sem CEC - Fm da Cirurgia x fim da Infusão & 0,8080 \\
Sem CEC - Fim da Infusão x 30m após a Infusão & 0,2623 \\
Sem CEC - 120m após a Infusão x 240m após a Infusão & 0,1684 \\
Sem CEC - 360m após a Infusão x 720m após a Infusão & 0,2199 \\
\hline
\end{tabular}


A análise de medidas repetidas para freqüência cardíaca, com comparação entre o grupo CEC e sem CEC, está descrita na tabela 13.

Tabela 13. Análise de medidas repetidas para freqüência cardíaca.

\begin{tabular}{lc}
\hline Comparação & $p$ \\
\hline CEC x sem CEC - Basal & 0,5104 \\
CEC x sem CEC - 5m & 0,2374 \\
CEC x sem CEC - 15m & 0,2472 \\
CEC x sem CEC - 30m & 0,6345 \\
CEC x sem CEC - 60m & 0,7979 \\
CEC x sem CEC - 120m & $\mathbf{0 , 0 0 4 8}$ \\
CEC x sem CEC - 240m & $\mathbf{0 , 0 1 1 0}$ \\
CEC x sem CEC - Final da Cirurgia & $\mathbf{0 , 0 0 4 7}$ \\
CEC x sem CEC - 5m após Cirurgia & $\mathbf{0 , 0 1 0 4}$ \\
CEC x sem CEC - 15m após Cirurgia & $\mathbf{0 , 0 0 4 1}$ \\
CEC x sem CEC - 30m após Cirurgia & $\mathbf{0 , 0 2 5 4}$ \\
CEC x sem CEC - 60m após Cirurgia & 0,2374 \\
CEC x sem CEC - 120m após Cirurgia & 0,7558 \\
CEC x sem CEC - Fim da Infusão & 0,1967 \\
CEC x sem CEC - 5m após a Infusão & $\mathbf{0 , 0 4 8 8}$ \\
CEC x sem CEC - 15m após a Infusão & 0,3119 \\
CEC x sem CEC - 30m após a Infusão & 0,4212 \\
CEC x sem CEC - 60m após a Infusão & 0,4872 \\
CEC x sem CEC - 120m após a Infusão & 0,3481 \\
CEC x sem CEC - 240m após a Infusão & 0,0840 \\
CEC x sem CEC - 360m após a Infusão & 0,3672 \\
CEC x sem CEC - 480m após a Infusão & 0,4872 \\
CEC x sem CEC - 720m após a Infusão & 0,4721 \\
\hline
\end{tabular}




\section{DISCUSSÃO}




\section{DISCUSSÃO}

Os resultados obtidos mostram diferente perfil farmacocinético do propofol no grupo $\mathrm{CEC}$, em comparação com o grupo sem CEC, e também diferenças quanto à concentração de propofol obtida em relação à prevista pela infusão alvo-controlada. Houve também diferença entre os dois grupos, em relação ao grau de hipnose.

\subsection{Em relação à casuística e aos métodos}

A escolha dos grupos do estudo baseou-se nas citações que apresentam alterações na farmacocinética e na farmacodinâmica dos fármacos nos pacientes submetidos à cirurgia de revascularização miocárdica com circulação extracorpórea (CEC) (METS, 2000). Entretanto, as alterações produzidas pela CEC na cinética do propofol têm sido pouco estudadas, e os resultados obtidos ainda são bastante contraditórios (MASSEY et al., 1990; LEE et al., 1995; BAILEY et al., 1996; HAMMAREN et al., 1996). Tendo em vista a necessidade de manutenção dos níveis plasmáticos de propofol para manutenção do paciente com adequada hipnose durante toda a cirurgia cardíaca, torna-se importante a caracterização dos parâmetros farmacocinéticos e o ajuste de dose racional para o paciente submetido à cirurgia cardíaca com CEC.

Os dois grupos foram comparáveis em relação ao peso, à altura e ao índice de massa corpórea (IMC) (COPPINI et al., 1995). Em relação ao tempo de intubação, observou-se que o grupo CEC apresentou valores maiores para esta variável, fato 
justificado principalmente pelas alterações respiratórias promovidas pela CEC.

A faixa etária dos pacientes variou de 49 a 74 anos no grupo CEC (mediana=65,50) e de 52 a 75 anos no grupo sem CEC (mediana=69), sem diferença estatística entre os grupos. A exclusão dos pacientes com mais de 75 anos justifica-se pelas mudanças orgânicas fisiológicas da função desta faixa etária.

Os pacientes idosos apresentam alterações na farmacocinética do propofol (KIRKPATRICK et al., 1988) que neste estudo tornam-se importantes, pois grande parte dos pacientes foi de faixa etária avançada. Estas modificações ocasionam aumento na meia-vida de eliminação $\left(\mathrm{t}_{1 / 2} ß\right)$, que no idoso possui valor médio de 69,3 min, diminuição do clearance plasmático com valor de $23,2 \mathrm{ml} / \mathrm{kg} / \mathrm{min}$ e maior volume de distribuição de 12,8 1/kg (KIRKPATRICK et al., 1988). Isto acarreta aumento no tempo de eliminação do propofol. Em relação à farmacodinâmica, pacientes idosos possuem maior sensibilidade aos agentes anestésicos, justificando a necessidade de menores doses nesta faixa etária.

Nenhum dos pacientes incluídos apresentava antecedente de hepatite, sorologia positiva para hepatite ou insuficiência cardíaca congestiva que sugerisse alteração hepática secundária ou fazia uso de anticoagulante tipo cumarínico. Em relação à função cardíaca, foram incluídos no estudo apenas pacientes portadores de fração de ejeção do ventrículo esquerdo superior a 50\%, visto que o propofol promove diminuição na pressão arterial pela vasodilatação e depressão da contratilidade miocárdica (GROUNDS et al., 1985; VARRO et al., 2001; LEHMANN et al., 2001).

Neste estudo adotou-se concentração alvo de propofol de $2 \mu \mathrm{g} / \mathrm{ml}$ e nenhum paciente referiu lembrança de eventos intra-operatórios. Entretanto, Servin e 
colaboradores (2003), e Tackley e colaboradores (1989) utilizaram concentração alvo de propofol de 3 a $4 \mu \mathrm{g} / \mathrm{ml}$ para cirurgias não cardíacas (TACKLEY et al., 1989; SERVIN et al., 2003). Admite-se que a necessidade de menores doses de propofol nos pacientes cardiopatas deva-se à depressão da contratilidade miocárdica que o propofol determina nestes pacientes (GROUNDS et al., 1985; VARRO et al., 2001; LEHMANN et al., 2001). Adicionalmente, a hipotermia (ROSEN et al., 1997) e a própria CEC (KRISHNADASAN et al., 2002) podem potencializar a hipnose promovida pelo propofol.

\subsection{Infusão de propofol}

A tecnologia do equipamento diprifusor (Astra Zeneca, London, UK) utiliza modelo farmacocinético de três compartimentos que controla o ritmo de infusão do fármaco, proporcionando ao anestesiologista o controle direto da concentração-alvo de propofol que deseja utilizar nos pacientes submetidos à anestesia geral ou sedação (GRAY et al., 1998). Com a disponibilidade destes sistemas de infusão alvo-controlada, os anestesiologistas têm a oportunidade de ganhar experiência no cálculo de concentrações de propofol adequadas para a realização dos diversos procedimentos anestésicos e ajustar a infusão conforme a necessidade do procedimento, evitando dosagem excessiva ou insuficiente (GLEN, 1998).

Barvais e colaboradores (1996) descreveram a infusão alvo-controlada de propofol durante cirurgia de revascularização miocárdica que foi iniciada com $1 \mu \mathrm{g} / \mathrm{ml}$ e aumentada de $0,5 \mu \mathrm{g} / \mathrm{ml}$ a cada 2 minutos até $5 \mu \mathrm{g} / \mathrm{ml}$, associado ao alfentanil na concentração de $1 \mu \mathrm{g} / \mathrm{kg} / \mathrm{min}$, conforme a necessidade do estímulo cirúrgico. Foi 
observada diferença entre a concentração prevista pelo diprifusor e a concentração plasmática medida, calculando-se a percentagem do erro de previsão. Ocorreu diminuição da pressão arterial durante a infusão alvo-controlada que foi tratada com redução da concentração-alvo (BARVAIS et al., 1996)

Os dados avaliados em relação ao equipamento de infusão alvo-controlada utilizado no estudo atual foram a dose infundida de propofol, a velocidade de infusão e o tempo previsto para regressão. A dose infundida de propofol é calculada, considerandose o peso, o sexo e a idade dos pacientes. Uma vez que os dois grupos estudados foram comparáveis em relação ao peso, ao sexo e à idade, a dose total infundida de propofol foi semelhante nos dois grupos. O tempo de cirurgia também influi na dose total administrada de propofol, visto que, quanto maior o tempo de cirurgia, maior será o tempo de infusão e a dose administrada do propofol. Os grupos não apresentaram diferença significativa quanto ao tempo de cirurgia, o que ocasionou dose infundida semelhante de propofol.

A velocidade de infusão do propofol foi calculada pelo software do diprifusor para manter a concentração-alvo pré-determinada, que neste estudo foi de 2,0 $\mu \mathrm{g} / \mathrm{ml}$ do início da indução da anestesia até o final da cirurgia, e reduzida para $1,0 \mu \mathrm{g} / \mathrm{ml}$ até o final da infusão. Os dois grupos apresentaram comportamento semelhante, com aumento rápido na velocidade de infusão do propofol logo após a indução da anestesia, atingindo um valor máximo após 5 minutos. Este rápido aumento na velocidade de infusão é relacionado com a necessidade de uma alta velocidade inicial para que seja atingida a concentração-alvo de $2,0 \mu \mathrm{g} / \mathrm{ml}$ no tempo determinado para injeção inicial, 
que foi de 30 segundos. Possivelmente, a coleta de amostras sangüíneas em intervalos menores poderia detectar maiores velocidades iniciais de infusão. Posteriormente, observamos redução na velocidade de infusão durante a cirurgia, atingindo um valor de zero logo após o final da mesma, na mudança da concentração-alvo de $2 \mu \mathrm{g} / \mathrm{ml}$ para 1,0 $\mu \mathrm{g} / \mathrm{ml}$, nos dois grupos de pacientes. Esta mudança na concentração-alvo faz com que a velocidade de infusão de propofol fosse interrompida temporariamente para permitir que a concentração-alvo prevista de propofol atingisse o novo valor.

O tempo de regressão se relaciona ao tempo previsto para o despertar dos pacientes e é calculado a partir da concentração-alvo pré-determinada. Houve um aumento no tempo de regressão previsto logo após o início da cirurgia, atingindo um valor máximo em cerca de 240 minutos. Posteriormente observamos uma diminuição acentuada no tempo de regressão previsto, que se estendeu do final da cirurgia até 5 minutos após, ocasionada pela alteração na concentração-alvo de 2,0 $\mu \mathrm{g} / \mathrm{ml}$ para 1,0 $\mu \mathrm{g} / \mathrm{ml}$. Após o final da cirurgia ocorre uma redução contínua até o final da infusão. Não houve diferença significativa entre os grupos em relação ao tempo previsto de regressão. Entretanto, o modelo farmacocinético adotado pelo software do diprifusor considera apenas o sexo, o peso e a idade, e não leva em conta as alterações que ocorrem durante a revascularização miocárdica com ou sem CEC como: hemodiluição, hipotermia e a própria CEC, que podem alterar a concentração plasmática de propofol e a concentração alvo-esperada. 


\subsection{Concentrações plasmáticas de propofol}

As concentrações plasmáticas de propofol, obtidas pela dosagem utilizandose cromatografia líquida de alta eficiência (HPLC), diferiram daquelas previstas pelo diprifusor, durante a maior parte do estudo, nos dois grupos.

A diferença encontrada entre a concentração plasmática medida e a prevista pode ser explicada pela hipotermia (ROSEN et al., 1997), pela hemodiluição (BUYLAERT, et al., 1989) e pela provável diminuição da ligação protéica do propofol ocasionada pela CEC (WOOD et al., 1979; WOOD et al., 1980; HIRAOKA et al., 2004), que aumentam fração livre do mesmo. Como o propofol possui alta ligação protéica, este aumento na fração livre do propofol promove alterações na farmacocinética, com aumento na metabolização e eliminação do propofol, ocasionando diminuição no t t1/2 $_{2}$ e aumento do clearance plasmático nos pacientes do grupo CEC.

O efeito imediato da hemodiluição aguda durante a CEC é a diminuição na concentração sangüínea total de qualquer fármaco presente no sangue. A concentração plasmática final do fármaco depende de sua ligação protéica plasmática, de seu volume de distribuição original, bem como do extenso equilíbrio entre a concentração tecidual e a concentração plasmática no início da CEC (ROSEN et al., 1997).

Uma importante consideração que deve ser feita é a distinção entre a concentração plasmática total do fármaco (ligada a proteínas + fração livre) e sua fração livre. A fração livre do fármaco é somente a que tem efeitos ou pode se difundir para os tecidos. Se o fármaco tem alta ligação protéica plasmática, a hemodiluição resultará em grande aumento da fração livre, devido à diminuição nos níveis de albumina e alfa-1ácido glicoproteína com aumento na fração livre do fármaco e maior concentração 
sangüínea final (BUYLAERT et al., 1989).

Ressaltamos que no grupo sem CEC também ocorrem hemodiluição e hipotermia leve, que podem alterar as concentrações plasmáticas do propofol.

Comparativamente, a farmacocinética do propofol nos pacientes hígidos pode ser diferente daquela observada nos cardiopatas submetidos à cirurgia cardíaca com ou sem CEC, devido ao efeito da hipotermia, da hemodiluição, da CEC e da alteração do fluxo sangüíneo hepático, podendo interferir na meia-vida de eliminação $\left(\mathrm{t}_{1 / 2} ß\right)$, no clearance plasmático e no volume de distribuição do fármaco.

Neste estudo, o grupo sem CEC apresentou concentrações plasmáticas maiores com diferença significativa nos momentos 120 e 240 minutos após o início da cirurgia, que coincide com o período durante a CEC e após o final da mesma. Considerando-se que o propofol tem alta ligação protéica (98 a 99\%), esta maior concentração plasmática do propofol pode ser justificada pela redução da ligação protéica plasmática do propofol no grupo CEC, ocasionando maior fração livre de propofol, com maior metabolização, menor meia-vida de eliminação $\left(\mathrm{t}_{1 / 2} ß\right)(1,82$ hora no grupo CEC e 3,62 no grupo sem CEC) e maior clearance no grupo CEC (28,36 no grupo CEC e 18,89 no grupo sem CEC).

O cálculo da percentagem do erro de previsão mostrou que nos dois grupos houve diferença entre a concentração prevista e a obtida, causada pelos fatores explicados anteriormente. Barvais e colaboradores (1996) mostraram, em pacientes submetidos à revascularização miocárdica com CEC, que as concentrações plasmáticas obtidas de propofol foram maiores que a prevista pela infusão alvo-controlada (BARVAIS et al., 1996). 


\subsection{Avaliação farmacocinética do propofol}

A meia-vida de eliminação é parâmetro farmacocinético freqüentemente utilizado na clínica, sendo o tempo necessário para a quantidade de fármaco no organismo ser reduzida a $50 \%$ (WILKINSON, 2001). Facilmente determinado no modelo tricompartimental, a t $t_{1 / 2} ß$ é parâmetro de eliminação inversamente proporcional à depuração. À medida que o clearance plasmático diminui, devido a um processo patológico, por exemplo, seria esperado que a meia-vida aumentasse. Contudo, essa relação recíproca só será válida se a patologia não alterar o volume de distribuição. Da mesma maneira, as alterações na ligação protéica do fármaco podem alterar a depuração, assim como o volume de distribuição, levando a alterações imprevisíveis da meia-vida.

Em relação aos valores normais de referência da meia-vida de eliminação do propofol ( $\mathrm{t}_{1 / 2} ß=1,8$ horas) (LANGLEY et al., 1989; WILKINSON, 2001; WHITE, 2001), o grupo CEC apresentou valores semelhantes $\left(\mathrm{t}_{1 / 2} \beta=1,82\right.$ horas), enquanto o grupo sem CEC mostrou valores superiores ( $\mathrm{t}_{1 / 2} ß=3,62$ horas).

A meia-vida de eliminação foi menor no grupo CEC, provavelmente pela diminuição da ligação protéica do propofol (WOOD et al., 1979; WOOD et al., 1980; HIRAOKA et al., 2004) causada pela hipotermia (ROSEN et al., 1997), pela hemodiluição (BUYLAERT, et al., 1989) e pela CEC. Isto provavelmente gerou maior fração livre do fármaco com diminuição na meia-vida de eliminação neste grupo, redução da concentração plasmática e aumento do clearance plasmático. Como o propofol possui ligação protéica em torno de 98\% (LANGLEY et al., 1988; WHITE, 2001), este fato ocasiona maior fração livre do fármaco, intensificando as alterações farmacocinéticas. 
Como a infusão de propofol foi longa durante o estudo nos dois grupos, torna-se importante o conceito de meia-vida contexto-sensível. Hughes e colaboradores introduziram o termo "meia-vida contexto-sensível” para descrever a recuperação após infusões anestésicas de duração variada (HUGHES et al., 1992). A meia-vida-contextosensível é o tempo necessário para que a concentração do fármaco no compartimento central seja reduzida em 50\% após o término da infusão. O contexto relaciona-se com a duração da infusão do fármaco antes de ser interrompido. O propofol tem uma meia-vida contexto-sensível menor que 25 minutos após infusões que duram até 3 horas e, após infusões prolongadas, a meia-vida ainda é de apenas 50 minutos após o término da infusão (HUGHES et al., 1992). Em pacientes submetidos à cirurgia cardíaca, o longo período de infusão do propofol aumenta a meia-vida contexto-sensível que pode interferir no cálculo da meia-vida de eliminação.

O clearance plasmático é a medida da eficácia do corpo na eliminação do fármaco e é conceito importante a ser considerado, quando se planeja esquema racional para a administração prolongada de fármacos (WILKINSON, 2001). A taxa de apresentação do fármaco para determinado órgão é o produto do fluxo sangüíneo pela sua concentração arterial, e a taxa de saída do fármaco do órgão é o produto do fluxo sangüíneo pela concentração venosa. A diferença entre estas taxas, em estado de equilíbrio, é a eliminação do fármaco. A depuração do agente por determinado órgão é a relação entre a taxa de eliminação e a concentração de fármaco que penetrou no órgão. Em outras palavras, pode-se dizer que o clearance é diretamente proporcional ao fluxo sangüíneo e à extração do fármaco.

O cálculo do clearance plasmático é feito pela relação entre a taxa de 
eliminação e a concentração do fármaco. Desse modo, quando a depuração é constante, a taxa de eliminação do fármaco é diretamente proporcional à concentração do mesmo. $\mathrm{O}$ clearance não indica quanto está sendo removido, mas determinam o volume hipotético de plasma depurado do fármaco na unidade de tempo.

O volume de distribuição $(\mathrm{Vd})$ é a medida do espaço aparente para conter um fármaco (LANGLEY et al., 1989; WILKINSON, 2001) e relaciona a quantidade deste com a concentração plasmátca. O Vd não se refere a um volume fisiológico identificável, mas meramente ao volume líquido que seria necessário para conter o fármaco na mesma concentração que no plasma. Portanto, este volume reflete a extensão em que o fármaco está presente no sistema extravascular e pode variar amplamente, dependendo dos graus relativos de ligação às proteínas plasmáticas e teciduais, do coeficiente de partição do fármaco, assim como da idade, sexo, compleição física e presença de doenças associadas, (BATLOUNI, 1999). Para os fármacos de grande ligação protéica, o Vd irá se aproximar do volume plasmático. Outros fármacos, apesar de grande ligação às proteínas plasmáticas, possuem grandes volumes de distribuição, pois estas ligações são frágeis e permitem o seqüestro tecidual.

Não houve diferença significativa entre os grupos, todavia observou-se maior volume de distribuição em comparação a pacientes hígidos (LANGLEY et al., 1989; WILKINSON, 2001; WHITE, 2001).

Uma importante observação a ser feita é que o estudo farmacocinético foi realizado após a interrupção da administração de propofol pela infusão alvo-controlada, ou seja, após o fármaco ter sofrido os efeitos da cirurgia, como perda volêmica, hemodiluição, hipotermia e efeitos da circulação extracorpórea que ocasiona resultados 
diferentes dos indivíduos normais não submetidos a procedimentos cirúrgicos.

\subsection{Avaliação farmacodinâmica}

\subsubsection{Grau de hipnose}

O índice bispectral (BIS) está relacionado com o componente hipnótico da anestesia e indica o potencial de despertar e a sobredose de fármacos anestésicos, sem prever movimentos dos pacientes ou resposta hemodinâmica à estimulação dolorosa. Também não antecipa o exato momento de retorno da consciência (FISHER et al., 2000).

Os resultados mostraram que os valores de BIS diminuíram logo após a indução da anestesia, fato explicado pela ação dos anestésicos gerais sobre o sistema nervoso central. Os valores mantiveram-se baixos durante toda a cirurgia até 5 minutos após o final da mesma nos dois grupos, sem diferença significativa entre eles. Nenhum paciente relatou lembrança do período intra-operatório, quando avaliado no primeiro dia de pós-operatório.

Foram identificadas diferenças significativas entre os grupos CEC e sem CEC nos momentos: 60 minutos após o final da cirurgia, no final da infusão e 5, 15, 30, 60 e 120 minutos após o final da infusão, em que o grupo CEC apresentou valores de BIS menores que o grupo sem CEC. O maior grau de hipnose do grupo CEC pode ser justificado pela hipotermia nos pacientes do grupo CEC (ROSEN et al., 1997) e pela depressão do sistema nervoso central ocasionado pela CEC (KRISHNADASAN et al., 2002). A hipotermia ocasiona também uma diminuição do fluxo sangüíneo hepático com 
conseqüente redução na metabolização do propofol (MORI et al., 1988). Todos estes fatores podem aumentar o tempo de despertar dos pacientes deste grupo, justificando o maior tempo de intubação traqueal no pós-operatório.

Do momento 240 minutos após o término da infusão do propofol até o final do estudo, não ocorreu diferença significativa entre os grupos em relação ao BIS. Embora o grupo sem CEC tenha apresentado maiores valores de concentração plasmática de propofol, não se obsevou maior grau de hipnose mostrando interação farmacocinética e farmacodinâmica diferente nos dois grupos.

A associação de sufentanil e propofol, como utilizado neste estudo, promove uma potencialização do efeito hipnótico do propofol, intensificação no grau de hipnose observada pelo índice bispectral (BIS), conforme demonstrado por outros autores (LYSAKOWSKI et al., 2001; FORESTIER et al., 2003).

\subsubsection{Avaliação hemodinâmica}

Em estudos realizados em pacientes submetidos à cirurgia cardíaca com infusão alvo-controlada de propofol, observou-se, diminuição da pressão arterial média, do débito cardíaco, da contratilidade miocárdica, da frequiência cardíaca e da resistência vascular periférica (VARRO et al., 2001; LEHMANN et al., 2001), limitando sua utilização em pacientes cardiopatas. Por estas considerações clínicas foram excluídos do estudo os pacientes com fração de ejeção de ventrículo esquerdo inferior a $50 \%$.

Em relação à pressão arterial média, o comportamento durante o estudo foi semelhante nos dois grupos, com diminuição de valores até o momento final da cirurgia e posterior aumento durante o período pós-operatório. Os valores para a PAM foram 
maiores no grupo sem CEC, contudo sem diferença significativa entre os grupos.

A diminuição da pressão arterial média após a indução da anestesia pode estar relacionada tanto à função cardíaca e fármacos utilizados no pré-operatório, como a agentes empregados na anestesia (GROUNDS et al., 1985; VARRO et al., 2001; LEHMANN et al., 2001). A maior redução da pressão arterial ocorreu 120 minutos após o início da cirurgia e estendeu-se até 120 minutos após o final da mesma. Os efeitos da hipotermia e da CEC sobre a função contrátil do miocárdio podem contribuir para diminuição da pressão arterial

Após o término da cirurgia, a pressão arterial aumentou nos dois grupos estudados, contudo os valores não retornaram aos encontrados no início da cirurgia. Este aumento da pressão arterial pode estar associado não apenas à recuperação anestésica como à estabilização hemodinâmica dos pacientes e eventual presença de dor ou reação ao tubo traqueal, dentre outros estímulos (GROUNDS et al., 1985).

Os dois grupos apresentaram aumento da frequêencia cardíaca durante a cirurgia e no pós-operatório. A freqüência cardíaca do grupo CEC foi maior do que no grupo sem CEC, ocorrendo diferença significativa 120 e 240 minutos após o início da cirurgia, no final da cirurgia e 5, 15 e 30 minutos após o final da mesma. Estes valores superiores encontrados no grupo CEC podem ser justificados pela maior liberação de catecolaminas, pela vasodilatação e pela maior diminuição de pressão arterial causadas pela CEC. Outro fator que pode esclarecer este evento é a maior utilização de fármacos inotrópicos neste grupo de pacientes e maior diluição das concentrações de betabloqueadores pré-operatórias. No grupo CEC houve também aumento da freqüência cardíaca logo após a circulação extracorpórea, com diminuição após 60 minutos do final 
da cirurgia, não retornando aos valores basais.

\subsection{Considerações finais}

Este estudo mostrou que existe diferença na concentração prevista pela infusão alvo-controlada e a concentração obtida pela dosagem plasmática de propofol, indicando que existem muitos fatores que podem influenciar no cálculo da concentração de propofol administrada pelo diprifusor e não previstas no software específico.

Por outro lado, as alterações farmacocinéticas têm repercussões na farmacodinâmica do propofol, justificando muitas diferenças entre os dois grupos.

O estudo teve limitações principalmente relacionadas ao cálculo das variáveis farmacocinéticas que foram realizadas após o final da infusão de propofol, ou seja, após o fármaco ter sofrido os efeitos da cirurgia, como perda volêmica, hemodiluição, hipotermia e efeitos da circulação extracorpórea. $\mathrm{O}$ cálculo farmacocinético, após dose única na indução anestésica, poderia ter revelado parâmetros farmacocinéticos similares entre os grupos e comparáveis àqueles observados em pacientes geriátricos.

Considerando-se os resultados aqui encontrados, torna-se interessante estudos posteriores avaliando o efeito da cirurgia cardíaca com ou sem utilização de circulação extracorpórea sobre a ligação protéica do propofol e sua concentração plasmática livre. 


\section{CONCLUSÕES}




\section{CONCLUSÕES}

Considerando-se os objetivos deste estudo, pode-se concluir que:

1- A concentração plasmática obtida é maior que a prevista pela infusão alvo-controlada.

2- Pacientes submetidos à revascularização miocárdica sem utilização de circulação extracorpórea apresentam concentrações plasmáticas superiores e grau de hipnose inferior aos pacientes submetidos à revascularização miocárdica com circulação extracorpórea.

3- O clearance plasmático é maior e a meia-vida de eliminação, menor em pacientes submetidos à circulação extracorpórea. 
REFERÊNCIAS BIBLIOGRÁFICAS 


\section{REFERÊNCIAS BIBLIOGRÁFICAS}

Adam HK, Briggs LP, Bahar M, Douglas EJ, Dundee JW. Pharmacokinetic evaluation of ICI 35868 in man. Single induction doses with different rates of injection. Br J Anaesth. $1983 ; 55: 97-103$.

Antognini JF. Hypothermia eliminates isoflurane requirements at 20 degrees celsius. Anesthesiology. 1993;78:1152-56.

Bailey JM. A technique for approximately maintaining constant plasma levels of intravenous drugs. Anesthesiology. 1993;78:116-23.

Bailey JM, Mora, CT, Shafer, SL. Pharmacokinetics of propofol in adult patients undergiong coronary revascularization. Anesthesiology. 1996;84:1288-97.

Barvais L, Rausin I, Glen JB, Hunter SC. Administration of propofol by target-controlled infusion in patients undergoing coronary artery surgery. J Cardiothorac Vasc. Anesth. 1996;10:877-83.

Batlouni M. Princípios básicos da farmacologia clínica: I. Farmacocinética. In: Batlouni M, Ramirez JAF, editors. Farmacologia e terapêutica cardiovascular. São Paulo: Atheneu, 1999. p.1-16. 
Bentley JB, Conahan TJ, Cork RC. Fentanil sequestration in lungs during cardiopulmonary bypass. Clin Pharmacol Ther. 1983;34:703-6.

Blouin RT, Conard PF, Gross JB. Time course of ventilatory depression following induction doses of propofol and thiopental. Anesthesiology. 1991;75:940-944.

Boyle WA, White PF, Rending SV. Negative inotropic effects of Propofol versus etomidate and thiopental on rabbit papillary muscle. Anesth Analg. 1989; 68(35 Suppl):35.

Bruhn J, Bouillon TW, Ropcke H, Hoeft A. A manual slide rule for target-controlled infusion of propofol: development and evaluation. Anesth Analg. 2002;96:142-7.

Buylaret WA, Herregods LL, Mortier EP, Bogaert MG. Cardiopulmonary bypass and the pharmacokinetics of drugs. Clin Pharmacokinet Aucklandv. 1989;17:10-26.

Carmona MJC, Pereira VA, Bertolini MA, Malbouisson LMS, Le Bihan KB, Lopes MR, Auler Júnior JOC, Santos SRCJ. Atenolol and propranolol pharmacokinetics changes in patients undergoing coronary artery bypass surgery. Eur J Anesth. 2003;20:A530.

Chan K, So AP. The measurement of propofol in human blood samples by liquid chromatography. Methods Find Exp Clin Pharmacol. 1990;12:135-9.

Claeys MA, Gepts E, Camu F. Haemodynamic changes during anaesthesia induced and maintained with propofol. Br. J. Anaesth. 1988;60:3-9. 
Cockshott ID, Douglas EJ, Plummer GF, Simons PJ. The pharmacokinetics of propofol in laboratory animals. Xenobiotica. 1992;22:369-75.

Coetzeee JF, Glen JB, Wium CA, Boshoff L. Pharmacokinetics model selection for target controlled infusions of propofol: assessment of three parameter sets. Anesthesiology. $1995 ; 82: 1328-45$.

Coppini LZ, Waitzberg DL. Obesidade. In: Waitzberg, DL, editor Nutrição enteral $e$ parenteral na prática clínica, São Paulo, Atheneu. 1995. p. 402-6.

Ding Y, Fredman B, White PF. Recovery following outpatient anesthesia: use of enflurane versus propofol. J Clin Anesth. 1993;5:447-50.

Dowrie RH, Ebling WF, Mandema JW, Stanski DR. High-performance liquid chromatographic assay of propofol in human and rat plasma and fourteen rat tissues using eletrochemical detection. J Chromatogr B Biomed Suppl. 1996;678:279-88.

Durkan W, Lonergan M, Schwartz S. Effect of membrane oxygenators on sufentanil blood levels during cardiopulmonary bypass. Anesth Analg. 1988;67:s54.

El-Yazigi A, Hussein RF. Microdetermination of propofol in plasma by a rapid and sensitive liquid chromatographic method. J Pharm Bimed Anal. 1996;15:99-104. 
Emara S, Salch G, Fathy M, Bakr MA. Crhomatographic assay and pharmacokinetic studies of propofol in human serum. Biomed Chromatogr. 1999;13:299-303.

Fisher DM. Development and clinical application of electroencephalographic Bispectrum monitoring. Anesthesiology. 2000;93:1336-44.

Forestier F, Hirschi M, Rouget P, Rigal JC, Videcoq M, Girardet P, Durand M, Maitrasse B. Propofol and sufentanil titration with the bispectrum index to provide anesthesia for coronary artery surgery. Anesthesiology. 2003;99:334-46.

Gepts E, Camu F, Cockshott ID, Douglas EJ. Disposition of propofol administered as constant rate intravenous infusions in humans. Anesth Analg. 1987;66:1256-63.

Gibbs FA, Gibbs EL, Lennox WG. Effect of electroencephalogram of certain drugs which influence nervous activity. Arch Intern Med. 1987;60:154-66.

Glass PSA, Shafer SL, Reves J.. Intravenous drug delivery systems. In: Miller RD. Anesthesia $5^{\circ}$ ed Philadelphia: Churchill Livingstone. 2000. p.377-411.

Glass PSA, Markhan K, Ginsberg B, Hawkins ED. Propofol concentrations required for surgery. Anesthesiology. 1989;71:A273.

Glen JB. The development of "Diprifusor": a TCI system for propofol. Anaesthesia.1998;53:13-21. 
Goldman L, Shah MV, Hebden MW. Memory of cardiac anesthesia. Anaesthesia. 1987;42:596-603.

Gouke CR, Keaveny JP, Kay B, Healy TE, Ryan M. The effect of cardiopulmonary bypass on the pharmacokinetics of drugs. Clin. Pharmacokinet. 1982;7:234-51.

Gray JM, Kenny, GN. Development of the technology for "Diprifusor" TCI systems. Anaesthesia. 1998;53:22-7.

Grounds RM, Twigley AJ, Carli F, Whitwam JG, Morgan M. The haemodynamic effects of intravenous induction. Comparison of the effects of thiopentone and Propofol. Anaesthesia. 1985;40:735-40.

Hall R. The pharmacokinetic behavior of opioids administered during cardiac surgery. Can. J, Anaesth. 1991;38:747-56.

Hall RI, Murphy JT, Landymore R. Myocardial metabolic changes during propofol anesthesia for cardiac surgery in patients with reduced ventricular function. Anesth Analg. 1993;77:680-89.

Hammaren E, Yli-Hankala A, Rosenberg PH, Hynynem M. Cardiopulmonary bypass-induced changes in plasma concentrations of propofol and in auditory evoked potentials. $\mathrm{Br} J$ Anaesth. 1996;77:360-64. 
Hara M, Kai Y, Ikemoto Y. Propofol actives $\mathrm{GABA}_{\mathrm{a}}$ receptor-chloride inophore complex in dissociated hipocampal pyramidal neurons of the rat. Anesthesiology. 1993;79:781-88.

Heller BL. Routine neurologic monitoring for awareness should be performed in all patients undergoing cardiac surgery. J Thorac Cardiovasc Surg. 2002;1:1-7.

Higgins TL, Estafanous FG, Loop FD, Beck GJ, Blum JM, Paranandi L. Stratification of morbidity and mortality outcome by preoperative risk factors in coronary artery bypass patients. A clinical severety score. JAMA. 1992;267:2344-48.

Hiraoka H, Yamamoto K, Morita T, Goto F, Horiuchi R. Changes in drug plasma concentrations of an extesively bound and highly extracted drug, Propofol, in reponse to altered plasma binding. Clin Pharmacol Ther. 2004;75:324-30.

Holley FO, Ponganis KJ, Stanski DR. Effect of cardiopulmonary bypass on pharmacokinetics of drugs. Clin Pharmacokinet. 1982;7:234-51.

Hughes MA, Glass PSA, Jacobs JR. Context-sensive half time in multicompartment pharmacokinetics models for intravenous anesthetic drugs. Anesthesiology. 1992;76:33441.

Hynynem M. Binding of fentanyl and alfentanil the extracorporeal circuit. Acta Anaesthesiol Scand. 1987;31:706-10. 
Kamath B, Thomson D, Jonston B. Administration of drugs during cardiopulmonary bypass. Anaesthesia. 1980;35:908-13.

Kenny GNC, Sutcliffe N. European perspective. In: White PF. Textbook of intravenous anesthesia. Baltimore: Williams \& Wilkins. 1997. p.527-37.

Kirkpatrick T, Cockshott ID, Douglas EJ, Nimmo WS. Pharmacokinetics of Propofol (diprivan) in elderly patients. Br J Anaesth. 1988;60:146-50.

Knibbe CAJ, Koster VS, Deneer VHM, Stuurman RM, Kuks PFM, Lange R. Determination of propofol in low-volume samples by high-performance liquid chromatography with fluorescence detection. J Chromatogr B. 1998;706:305-10.

Koren G, Crean P, Klein J, Goresky G, Villamater J, Macleod S. Sequestration of fentanil by the cardiopulmonary bypass. Eur J Clin Pharmacol. 1984;27:51-6.

Krishnadasan B, Hampton CR, Griscavage-Ennis J, Dabal RJ, Verrier ED. Molecular mechanisms of neurologic injury following cardiopulmonary bypass. Semin Cardiothorac Vasc Anesth. 2002;6:43-53.

Kruger-Thiemer E. Continuos intravenous infusion and multicompartment accumulation. Eur J Pharmacol. 1968;4:317-24. 
Langley MS, Heel RC. A review of its pharmacodynamic and pharmacokinetic properties and use as an intravenous anaesthetic. Drugs. 1988;35:334-72.

Larsen J. The effects of cooling on liver function in cats. Acta Physiol Scand. 1971;81:197207.

Laycock GJA, Alston RP. Propofol and hypothermic cardiopulmonary bypass: vasodilatation and enhanced protection? Anaesthesia. 1992;33:382-7.

Lee HS, Khoo YM, Chua BC, Tan SS, Chew SL. Pharmacokinetics of propofol infusion in Asian patients undergoing coronary artery bypass grafting. Ther Drug Monit. $1995 ; 17: 336-41$.

Lehmann A, Boldt J, Rompert R, Thaler E, Kumle B, Weisse U. Target-controlled infusion of propofol in high-risk patients with severely reduced left ventricular function. $J$ Cardiothorac Vasc Anesth. 2001;15;445-50.

Leslie K, Daniel DI, Bjorksten AR, Moayeri A. Mild hypothermia alters propofol pharmacokinetics and increases the duration of action of atracurium. Anesth Analg. 1995;80:1007-14.

Lysakowski C, Dumont L, Pellegrini M, Clergue F, Tassony E. Effects of fentanyl, alfentanil, remifentanil and sufentanil on loss of consciousness and bispectrum index during Propofol induction of anaesthesia. Br J Anaesth. 2001;86:523-7. 
Mackenzie N, Grant IS. Comparison of the new emulsion formulation of propofol with methohexitone and thiopentone for induction of anaesthesia in day cases. Br J Anaesth. 1985;57:725-31.

Macquaire V, Cantraine F, Schmartz D, Coussaert E, Barvais L. Target-controlled infusion of propofol induction with or without plasma concentration constrait in high-risk adult patients undergoing cardiac surgery. Acta Anaesthesiol Scand. 2002;46:1010-6.

Massey NJ, Sherry KM, Oldroyd S, Peaccock JE. Pharmacokinetics of infusion of propofol during cardiac surgery. Br J Anaesth. 1990;65:475-79.

Mathie RT. Hepatic blood flow during cardiopulmonary bypass. Crit Care Med. 1993;21(2 Suppl):72.

Matot I, Neely CF, Katz RY, Neufeld GR. Pulmonary uptake of propofol in cats. Anesthesiology. 1993;78:1157-65.

Matsukawa T, Kurz A, Sessler D. Propofol linearly reduces the vasoconstriction and shivering thresholds. Anesthesiology. 1995;82:1169-80.

Mcallister RG Junior, TAN TG. Effect of hypothermia on drug metabolism. In vitro studies with propranolol and verapamil. Pharmacology. 1980;20:95-100.

Merin RG. Propofol causes cardiovascular depression. Anesthesiology. 1990;72:393-4. 
Mets B. The pharmacokinetics of anesthetic drugs and adjuvants during cardiopulmonary bypass. Acta Anaesthesiol Scand. 2000;44:261-73.

Mori A, Watanabe K, Onoe M, Watarida S, Nakamura Y, Tatsho M. Regional blood flow in the liver, pancreas and kidney during pulsatile and nonpulsatile perfusion under profound hypothermia. Jpn Circ J. 1988;52:219-27.

Morioka N, Ozaki M, Matsukawa T, Sessler DI, Atarashi K, Suzuki, H. Ketamine causes a paradoxical increase in the bispectral index. Anesthesiology. 1997;87:A502.

Morrel D, Harrisson G. Lidocaine kinetics during cardiopulmonary bypass. Br J Anaesth. 1983;55:1173-77.

Nathan N, Debord J, Narcise F. Pharmacokinetics of propofol and its conjugates after continuos infusion in normal and in renal failure patients: a preliminart study. Acta Anaesthesiol Belg. 1993;44:77-85.

Newson C, Joshi GP, Victory R, White, PF. Comparison of propofol administration techniques for sedation during monitored anesthesia care. Anesth Analg. 1995;81:486-91.

O' Connor M, Pohlman A, Tung A, Hall J. Pitfalls of monitoring sedation in the ICU with the bispectral index. Anesthesiology. 1998;89:A461. 
Okutani R, Philbin DM, Rsow CE. Effect of hypothermic hemodilutional cardiopulmonary bypass on plasma sufentanil and cathecolamine concentrations in humans. Clin Pharmacol Anesth Analg. 1988;67:667-70.

Pagel PS, Warltier DC. Negative inotropic effects of Propofol as evaluated by the regional preload recruitable stroke work relationship in chronically instrumented dogs. Anesthesiology. 1993;78:100-8.

Pensado A, Mollins N. Effects of propofol on mean arterial pressure and systemic vascular resistance during cardiopulmonary bypass. Acta Anaesthesiol Scand. 1993;37:498-501.

Phillips AA, Maclean RF, Harrington EM. Recall of intraoperative events after general anesthesia and cardiopulmonary bypass. Can J Anaesth. 1993;40:922-6.

Plachetka JR, Salomon NW, Copeland JG. Plasma propranolol before, during and after cardiopulmonary bypass. Clin Pharmacol Ther. 1981;30:748-51.

Puig M, Warner W, Tang C. Effects of tempperature on the interaction of morphine with opioid receptors. Br J Anaesth. 1987;59:1459-64.

Rampil IJ. A primer for EEG signal processing in anesthesia. Anesthesiology. 1998;89:9801002. 
Reves JG, Glass PSA, Lubarsky D. Nonbarbiturate intravenous anesthetics. In: Miller RD Anesthesia. $5^{\circ}$ ed. Philadelphia: Churchill Livingstone, 2000. p.228-72.

Rosen DA, Rosen KR. Elimination of drugs and toxins during cardiopulmonary bypass. $J$ Cardiothorac Vasc Anesth. 1997;11:337-40.

Rosen DA, Rosen KR, Davidson B. In vitro variability in fentanyl absorption by different membrane oxygenator. J Cardiothorac Anesth. 1990;4:332-5.

Rosenblatt M, Van Ness JW. Estimation of the bispectrum. Ann Math Stat. 1972;36:1120-36.

Rosner B. Fundamentals of biostatistics. 2ed. PWS Publishers; Massachusetts:1986. p.575579.

Roth R, Wiersma D. Role of the lung in total body clearance of circulating drugs. Clin Pharmacokinetic. 1979;4:355-367.

Sanders LD, Isaac PA, Yeomans WA. Propofol-induced anesthesia: double-blind comparison of recovery after anaesthesia induced by propofol or thiopentone. Anaesthesia. $1989 ; 44: 200-4$

Schuttler J, Kloos, Schwilden H, Stoeckel H. Total intravenous anesthesia with propofol and alfentanil by computer-assisted infusion. Anaesthesia. 1988;43(4 Suppl):2-7. 
Schuttler J, Schwilden H, Stoeckel H. Pharmacokinetic and pharmacodynamic modelling of Propofol in volunteers and surgical patients. Posgraduate Medical Journal. 1985;61(Suppl 3):53-54.

Schwilden H, Schuttler J, Stoeckel H. Quantitation of the EEG and pharmacodynamic modeling of hypnotic drugs: Etomidato as an example. Eur J Anaesth. 1985;2:121-31.

Sear JW, Glen JB. Propofol administered by a manual infusion regimen. Br J Anaesth. $1995 ; 74: 362-7$

Sebel PS, Lowdon JD. Propofol: a new intravenous anesthesia. Can J Anaesth. 1997;44:2430.

Sebel PS. Awareness during general anesthesia. Anesthesiology. 2003;31:171-5.

Servin F, Bougeouis B, Gomeni R, Mentré F, Farinotti R, Desmonts JM. Pharmacokinetics of propofol administered by target-contolled infusion to alcoholic patients. Anesthesiology. 2003;99:576-585.

Servin F, Farinotti R, Desmonts JM. Propofol infusion maintenance of anesthesia in morbidly obese patients receiving nitrous oxide. Anesthesiology. 1993;78:657-65. 
Servin F, Desmonts JM, Haberer JP, Cockshott ID, Plummer GF, Farinotti R. Pharmacokinetics and protein binding of propofol in patients with cirrhosis. Anesthesiology. 1988;69:887-91.

Shafer SL. Advances in propofol pharmacokinetics and pharmacodynamics. J Clin Anesth. 1993;5 (6 Suppl):14-21.

Shafer SL, Stansky DR. Improving the clinical utility of the anesthetic drug pharmacokinetics. Anesthesiology. 1992;76:327-30.

Short TG, Aun CST, Tan P, Wong J, Tan YH, Oh TE. A prospective evaluation of pharmacokinetic model controlled infusion of propofol in paediatric patients. $\mathrm{Br} J$ Anaesth. 1994;72:302-6.

Sigl JC, Chamoun NG. An introduction to bispectral analysis for the electroencephalogram. $J$ Clin Monit. 1994;10:392-404.

Skacel M, Knott C, Reynolds F, Aps S. Extracorporeal circuit sequestration of fentanil and alfentanil. Br J Anaesth. 1986;58:947-9.

Skipsey IG, Colvin JR, Mackenzie N, Kenny GN. Sedation with propofol during surgery under local blockade: assessment of a target-controlled infusion system. Anaesthesia. $1993 ; 48: 210-13$ 
Spackman TN, Abel MD. BIS monitoring: there is more to it than awareness. Anesthesiology. $2002 ; 1: 255-6$.

Stanley TH. Arterial pressure and deltoid muscle gas tensions during cardiopulmonary bypass in man. Can Anaesth Soc J. 1978;25:286-90.

Stenson RE, Constantino RT, Harrison DC. Interrelationships of hepatic blood flow, cardiac output, and blood levels of lidocaine in man. Circulation. 1971;63:205-11.

Stetson PL, Domino EF, Sneyd JR. Determination of plasma propofol levels using gas chromatography-mass spectrometry with selected-ion monitoring. $J$ Chromatogr. 1993;620:260-7.

Sung YF, Reiss N, Tillette T. The differential cost of anesthesia and recovery with Propofolnitrous oxide anesthesia versus thiopental sodium-nitrous oxide anesthesia. J Clin Anesth. $1991 ; 3 ; 391-4$

Tackley RM, Lewis GTR, Prys-Roberts C, Boaden RW. Computer controlled infusion of propofol. Br J Anaesth. 1989;62:46-53.

Vandesteene A, Trempont V, Engelman E, Delof T, Focroul M, Schoutens A. Effect of Propofol on cerebral blood flow and metabolism in man. Anaesthesia. 1988;43(Suppl);42-3. 
Varro M, Wrana G, Gombocz K, Alotti N. Hemodynamic effects of Propofol induction administered with target controlled infusion pump in patients scheduled for open heart surgery. Orv Hetil. 2001;142:331-4.

Veroli P, O’ Kelly B, Bertrand F. Extrahepatic metabolism of propofol in man during the anehepatic phase of orthotopic liver transplantation. Br J Anaesth. 1992;68:183-6.

Vianna PTG, Ganem ME, Castiglia YMM Método simplificado para manutenção da concentração plasmática de propofol em nível aproximadamente constante em pacientes pediátricos. Rev Bras Anestésiol. 1995;45 (Suppl. 19):72.

Vianna PTG, Gusman P, Castiglia YMM, Ganem ME, Amorin RB. Método simplificado para manutenção da concentração plasmática de sufentanil em nível aproximadamente constante. Rev Bras Anestesiol. 1996;46;249-58.

Vuyk J. Clinical interpretation of pharmacokinetic and pharmacodynamic propofol-opioid intereactions. Acta Anaesthesiol Belg. 2001;52:445-451.

Vuyk J, Lim T, Engbers FHM, Burm AGL. Performance of computer-controlled infusion of propofol in an evaluation of five pharmacokinetic parameter sets. Anesth Analg 1995;81:1275-82.

Vuyk J, Lim T, Engbers FHM. The pharmacodynamic interaction of propofol dnd alfentanil during lower abdominal surgery in women. Anesthesiology. 1995;83:8-22. 
Vuyk J. The clinical pharmacology of Propofol. An overview. In: Vuyk J. The pharmacodynamic interaction of propofol and alfentanil in surgical patients. A Basis for Computer Controlled Intravenous Anaesthesia. Ridderkerk, Pasmans Offsetdrukkerij B. V. Den Haag, 1993;3;11-34.

Vuyk J, Lim T, Engbers FHM, Burm AGL, Vletter AA, Bovill JG. Pharmacodynamics of alfentanil as a supplement to propofol or nitrous oxide for lower abdominal surgery in female patients. Anesthesiology. 1993;78:1036-45.

White PF. Tratado de anestesia venosa. Porto Alegre: Artmed. 2001. p.121-60.

White PF. Intravenous anesthesia and analgesia: what is the role of target-controlled infusion (TCI). J Clin Anesth. 1996;8(3Suppl):26-8.

Wilkinson GR. Pharmacokinetics: The dynamics of drug absorption, distribution and elimination. In: Hardman JG, Limbird LE. The pharmacological basis of therapeutics. Chicago: McGraw-Hill; 2001. p.3-29.

Winer BJ. Statistical principles in experimental design. $2^{\circ}$ ed. New York: McGraw-Hill, 1971. p.123-40.

Wood M, Shand DG, Wood AJJ. Propranolol binding in plasma during cardiopulmonary bypass. Anesthesiology. 1979;51;512. 
Wood AJJ, Robertson D, Robertson RM, Wilkinson GR, Wood M. Elevated plasma free drug concentrations of propranolol and diazepam during cardiac catheterization. Circulation. $1980 ; 62: 1119$.

Wood M. Plasma drug binding: implications for anesthesiologists. Anesth Analg 1986;65 (7):786-804.

Yeganch MH, Ramzan I. Determination of propofol in rat whole blood and plasma by highperformance liquid chromatography. J Chromatogr B Biomed Sci Appl. 1997;691:478-82.

Zacny JP, Lichtor JL, Coalson DW. Subjective and physicomotor effects of subanesthetic doses of propofol in healthy volunteers. Anesthesiology. 1992;76:696-702.

Zhang H, Wang P, Bartlett MG, Stewart JT. HPLC determination of cisatracurium besylate and propofol mixtures with LC-MS identification of degradation products. $J$ Biomed. 1998;7:1241-9. 
APÊNDICE 
Quadro I. Dados individuais: Dados demográficos individuais dos grupos CEC e sem CEC

\begin{tabular}{|c|c|c|c|c|c|}
\hline Grupo CEC & & & & & \\
\hline PACIENTE & & Idade & Peso & Altura & IMC \\
\hline 1 & Masculino & 67 & 66 & 1,66 & 23,91 \\
\hline 2 & Masculino & 64 & 0,25 & 1,64 & 34,38 \\
\hline 3 & Masculino & 56 & $8^{\prime} 4$ & 1,6 & 32,81 \\
\hline 4 & Masculino & 52 & 65 & 1,69 & 22,75 \\
\hline 5 & Masculino & 74 & 65 & 1,67 & 23,29 \\
\hline 6 & Feminino & 69 & 76 & 1,65 & 26,47 \\
\hline 7 & Masculino & 67 & 72,6 & 1,57 & 29,51 \\
\hline 8 & Masculino & 68 & 74,2 & 1,66 & 27,7 \\
\hline 9 & Masculino & 56 & 65 & 1,6 & 25,39 \\
\hline 10 & Masculino & 49 & 90 & 1,6 & 35,15 \\
\hline Média & & 62,2 & 65,80 & 1,63 & 28,13 \\
\hline DP & & 8,32 & 10,5 & $\mathbf{0 , 0 3}$ & 4,62 \\
\hline \multicolumn{6}{|l|}{$\begin{array}{c}\text { Grupo sem } \\
\text { CEC } \\
\end{array}$} \\
\hline PACIENTE & & Idade & Peso & Altura & IMC \\
\hline 1 & Feminino & 74 & 63 & 1,5 & 28 \\
\hline 2 & Feminino & 67 & 78 & 1,69 & 27,36 \\
\hline 3 & Feminino & 52 & 71 & 1,46 & 33,33 \\
\hline 4 & Masculino & 66 & 95 & 1,8 & 29,32 \\
\hline 5 & Masculino & 72 & 73,7 & 1,64 & 27,5 \\
\hline 6 & Masculino & 70 & 64,8 & 1,66 & 23,56 \\
\hline 7 & Masculino & 73 & 81 & 1,69 & 28,42 \\
\hline 8 & Masculino & 68 & 82 & 1,71 & 28,08 \\
\hline 9 & Masculino & 75 & 71 & 1,68 & 25,15 \\
\hline 10 & Masculino & 68 & 74,2 & 1,72 & 25,08 \\
\hline Média & & 68,5 & $\mathbf{7 5 , 3 7}$ & 1,65 & 27,58 \\
\hline DP & & 6,57 & 9,27 & 0,1 & 2,69 \\
\hline
\end{tabular}


Quadro II. Tempo de cirurgia, tempo de CEC grupo CEC e tempo de intubaçao traqueal (IOT)

\begin{tabular}{|c|c|c|c|c|}
\hline Tempo de cirurgia & & & Tempo de CEC & \\
\hline Paciente & Grupo CEC & Grupo sem CEC & Paciente & Grupo CEC \\
\hline $\mathbf{1}$ & 270 & 270 & 1 & 95 \\
\hline $\mathbf{2}$ & 230 & 330 & 2 & 64 \\
\hline $\mathbf{3}$ & 310 & 260 & 3 & 52 \\
\hline $\mathbf{4}$ & 235 & 205 & 4 & 30 \\
\hline $\mathbf{5}$ & 325 & 220 & 5 & 96 \\
\hline $\mathbf{6}$ & 225 & 210 & 6 & 74 \\
\hline $\mathbf{7}$ & 390 & 455 & 7 & 94 \\
\hline $\mathbf{8}$ & 300 & 255 & 8 & 95 \\
\hline $\mathbf{9}$ & 260 & 330 & 9 & 95 \\
\hline $\mathbf{1 0}$ & 230 & 335 & 10 & 95 \\
\hline Média & $\mathbf{2 7 7 , 5}$ & $\mathbf{2 8 7}$ & Média & $\mathbf{7 9}$ \\
\hline $\mathbf{D P}$ & $\mathbf{5 3 , 6 5}$ & $\mathbf{7 7 , 0 3}$ & DP & $\mathbf{2 3 , 3 7}$ \\
\hline
\end{tabular}

\begin{tabular}{|c|c|c|l|l|}
\hline Tempo de IOT (min) & & & & \\
\hline Paciente & Grupo CEC & Grupo sem CEC & & \\
\hline $\mathbf{1}$ & 291,6 & 232,2 & & \\
\hline $\mathbf{2}$ & 286,8 & 288 & & \\
\hline $\mathbf{3}$ & 291,8 & 198 & & \\
\hline $\mathbf{4}$ & 534 & 289,2 & & \\
\hline $\mathbf{5}$ & 549 & 339 & & \\
\hline $\mathbf{6}$ & 519 & 378 & & \\
\hline $\mathbf{7}$ & 330 & 411 & & \\
\hline $\mathbf{8}$ & 450 & 273 & & \\
\hline $\mathbf{9}$ & 468 & 186 & & \\
\hline $\mathbf{1 0}$ & 528 & 198 & & \\
\hline Média & $\mathbf{4 2 4 , 8 2}$ & $\mathbf{2 7 9 , 2 4}$ & & \\
\hline DP & $\mathbf{1 1 1 , 9 7}$ & $\mathbf{7 8 , 1 7}$ & & \\
\hline
\end{tabular}


Quadro III. Dose infundida de propofol

\begin{tabular}{|c|c|c|c|c|c|c|c|c|c|c|c|c|c|c|}
\hline \multicolumn{15}{|c|}{ Grupo CEC } \\
\hline Paciente & Basal & $5 \mathrm{~m}$ & $15 \mathrm{~m}$ & $30 \mathrm{~m}$ & $60 \mathrm{~m}$ & $120 \mathrm{~m}$ & $240 \mathrm{~m}$ & F. Cir. & $5 \mathrm{~m}$ & $15 \mathrm{~m}$ & $30 \mathrm{~m}$ & $60 \mathrm{~m}$ & $120 \mathrm{~m}$ & F. Inf \\
\hline 1 & 0 & 112 & 186 & 268 & 408 & 673 & 1189 & 1272 & 1288 & 1289 & 1306 & 1346 & & 1385 \\
\hline 2 & 0 & 132 & 220 & 348 & 543 & 938 & & 1543 & 1543 & 1554 & 1574 & 1694 & 1800 & 1840 \\
\hline 3 & 0 & 113 & 196 & 328 & 501 & 838 & 1484 & 1813 & 1813 & 1818 & 1834 & 1891 & & 1893 \\
\hline 4 & 0 & 86,7 & 145 & 234 & 380 & 643 & & 1103 & 1131 & 1137 & 1147 & 1192 & & 1300 \\
\hline 5 & 0 & 132 & 194 & 265 & 412 & 659 & 1172 & 1493 & 1496 & 1499 & 1510 & 1530 & & 1540 \\
\hline 6 & 0 & 131 & 200 & 270 & 450 & 763 & & 1253 & 1256 & 1261 & 1274 & 1349 & 1456 & 1480 \\
\hline 7 & 0 & 99 & 169 & 273 & 413 & 731 & 1248 & 1876 & 1877 & 1878 & 1882 & 1920 & & 1940 \\
\hline 8 & 0 & 143 & 206 & 305 & 467 & 784 & & 1588 & 1588 & 1588 & 1611 & 1668 & & 1780 \\
\hline 9 & 0 & 92 & 150 & 287 & 377 & & & 1246 & 1246 & 1249 & 1263 & 1357 & & 1359 \\
\hline 10 & 0 & 149 & 208 & 307 & 507 & & & 1328 & 1329 & 1336 & 1355 & 1437 & & 1438 \\
\hline Média & 0 & 119 & 187 & 289 & 446 & 754 & 1273 & 1452 & 1457 & 1461 & 1476 & 1538 & 1570 & 1596 \\
\hline DP & 0 & 21,64 & 25 & 33,7 & 57,2 & 100 & 144 & 256 & 251 & 250 & 249 & 247 & 243,2 & 242,6 \\
\hline Max & $\mathbf{0}$ & 149 & 220 & 348 & 543 & 938 & 1484 & 1876 & 1877 & 1878 & 1882 & 1920 & 1800 & 1940 \\
\hline Min & 0 & 86,7 & 145 & 234 & 377 & 643 & 1172 & 1103 & 1131 & 1137 & 1147 & 1192 & 1456 & 1300 \\
\hline \multicolumn{15}{|l|}{$\begin{array}{c}\text { Grupo sem } \\
\text { CEC } \\
\end{array}$} \\
\hline Paciente & Basal & $5 \mathrm{~m}$ & $15 \mathrm{~m}$ & $30 \mathrm{~m}$ & $60 \mathrm{~m}$ & $120 \mathrm{~m}$ & $240 \mathrm{~m}$ & F. Cir. & $5 \mathrm{~m}$ & $15 \mathrm{~m}$ & $30 \mathrm{~m}$ & $60 \mathrm{~m}$ & $120 \mathrm{~m}$ & F. Inf \\
\hline 1 & 0 & 114 & 182 & 260 & 400 & 658 & 1154 & 1267 & 1267 & 1269 & 1296 & 1320 & 1328 & 1328 \\
\hline 2 & 0 & 83,2 & 153 & 275 & 410 & 724 & 1342 & 1733 & 1733 & 1739 & 1760 & 1770 & & 1774 \\
\hline 3 & 0 & 117 & 180 & 236 & 427 & 715 & 1266 & 1314 & 1317 & 1324 & 1340 & 1361 & & 1361 \\
\hline 4 & 0 & 128 & 201 & 335 & 552 & 940 & & 1417 & 1417 & 1428 & 1448 & 1533 & & 1533 \\
\hline 5 & 0 & 105 & 176 & 278 & 425 & 743 & & 1164 & 1164 & 1174 & 1192 & 1261 & 1372 & 1389 \\
\hline 6 & 0 & 122 & 168 & 268 & 397 & 651 & 857 & 860 & 860 & 870 & 885 & 926 & & 933 \\
\hline 7 & 0 & 192 & 229 & 343 & 530 & 815 & 1443 & 1800 & 1800 & 1830 & 1845 & 1902 & 2008 & 2010 \\
\hline 8 & 0 & 188,5 & 320 & 389 & 469 & 897 & 1466 & 1511 & 1517 & 1530 & 1540 & 1570 & & 1570 \\
\hline 9 & 0 & 116 & 179 & 235 & 426 & 714 & 1265 & 1313 & 1315 & 1320 & 1326 & 1357 & & 1357 \\
\hline 10 & 0 & 113 & 219 & 286 & 435 & 750 & 1273 & 1697 & 1697 & 1703 & 1728 & 1750 & & 1770 \\
\hline Média & 0 & 127,9 & 201 & 290 & 447 & 761 & 1258 & 1468 & 1469 & 1477 & 1494 & 1529 & 1560 & 1545 \\
\hline DP & 0 & 34,98 & 47,9 & 49,9 & 53,7 & 95,6 & 191 & 416 & 416 & 416 & 415 & 404 & 31,11 & 396,5 \\
\hline Max & 0 & 192 & 320 & 389 & 552 & 940 & 1466 & 2406 & 2406 & 2415 & 2426 & 2437 & 2008 & 2437 \\
\hline Min & 0 & \begin{tabular}{|l|}
83,2 \\
\end{tabular} & 153 & 235 & 397 & 651 & 857 & 860 & 860 & 870 & 885 & 926 & 1328 & 933 \\
\hline
\end{tabular}


Quadro IV. Velocidade de infusão

\begin{tabular}{|c|c|c|c|c|c|c|c|c|c|c|c|c|c|c|}
\hline \multicolumn{15}{|c|}{ Grupo CEC } \\
\hline Paciente & Basal & $5 \mathrm{~m}$ & $15 \mathrm{~m}$ & $30 \mathrm{~m}$ & $60 \mathrm{~m}$ & $120 \mathrm{~m}$ & $240 \mathrm{~m}$ & F. Cir. & $5 \mathrm{~m}$ & $15 \mathrm{~m}$ & $30 \mathrm{~m}$ & $60 \mathrm{~m}$ & $120 \mathrm{~m}$ & F. Inf. \\
\hline 1 & 0 & 6,1 & 5,15 & 4,69 & 4,24 & 4,09 & 3,8 & 3,78 & 0 & 2,63 & 1,13 & 1,45 & & 1,45 \\
\hline 2 & 0 & 6,3 & 5,54 & 4,78 & 4,34 & 4,02 & & 4,02 & 0,5 & 0,95 & 1,25 & 1,56 & 1,59 & 1,59 \\
\hline 3 & 0 & 6,4 & 5,47 & 4,76 & 4,28 & 4,04 & 3,8 & 4 & 0 & 0,7 & 1,09 & 1,09 & & 1 \\
\hline 4 & 0 & 6,5 & 5,53 & 4,36 & 4,3 & 4 & & 3,8 & 0 & 0,8 & 1,15 & 1,49 & & 1,49 \\
\hline 5 & 0 & 5,8 & 5,07 & 4,61 & 4,3 & 4 & 3,8 & 3,69 & 0 & 0,69 & 1,01 & 1,01 & & 1,01 \\
\hline 6 & 0 & 6,1 & 5,39 & 4,86 & 4,34 & 4,07 & & 3,81 & 0 & 0,75 & 1,13 & 1,55 & 1,6 & 1,6 \\
\hline 7 & 0 & 5,9 & 5,55 & 4,72 & 4,3 & 4,02 & 3,8 & 3,61 & 0 & 0,55 & 0,75 & 0,72 & & 0,72 \\
\hline 8 & 0 & 5,9 & 5,26 & 4,73 & 4,21 & 4,07 & & 4,73 & 0 & 0 & 1,25 & 1,2 & & 1,2 \\
\hline 0 & 0 & 6,5 & 5,67 & 4,62 & 4,32 & & & 4,28 & 0 & 0,67 & 1,1 & 1,2 & & 1,12 \\
\hline 10 & 0 & 6 & 5,36 & 4,75 & 4,26 & & & 4,03 & 0 & 0,98 & 1,23 & 1,2 & & 1,2 \\
\hline Média & 0 & 6,1 & 5,4 & 4,69 & 4,29 & 4,04 & 3,8 & 3,97 & 0,05 & $\mathbf{0 , 8 7}$ & 1,10 & 1,25 & 1,595 & 1,09 \\
\hline DP & 0 & 0,2 & 0,19 & 0,14 & 0,04 & 0,03 & 0 & $\mathbf{0 , 3 3}$ & 0,16 & 0,67 & 0,14 & 0,27 & 0,01 & 0,48 \\
\hline Max & 0 & 6,5 & 5,67 & 4,86 & 4,34 & 4,09 & 3,8 & 4,73 & 0,5 & 2,63 & 1,25 & 1,56 & 1,6 & 1,6 \\
\hline Min & 0 & 5,8 & 5,07 & 4,36 & 4,21 & 4 & 3,8 & 3,61 & 0 & 0 & 0,75 & 0,72 & 1,59 & 0 \\
\hline \multicolumn{15}{|l|}{$\begin{array}{c}\text { Grupo sem } \\
\text { CEC }\end{array}$} \\
\hline Paciente & Basal & $5 \mathrm{~m}$ & $15 \mathrm{~m}$ & $30 \mathrm{~m}$ & $60 \mathrm{~m}$ & $120 \mathrm{~m}$ & $240 \mathrm{~m}$ & F. Cir. & $5 \mathrm{~m}$ & $15 \mathrm{~m}$ & $30 \mathrm{~m}$ & $60 \mathrm{~m}$ & $120 \mathrm{~m}$ & F. Inf. \\
\hline 1 & 0 & 6,2 & 5,39 & 4,76 & 4,2 & 3,96 & 3,8 & 3,8 & 0 & 0,63 & 1,28 & 1,28 & 1,28 & 1,28 \\
\hline 2 & 0 & 6,7 & 5,76 & 4,87 & 5,25 & 4,1 & 3,8 & 4,2 & 0 & 0,74 & 0,74 & 0,74 & & 0,74 \\
\hline 3 & 0 & 6,2 & 5,35 & 5,02 & 4,22 & 4,08 & 3,8 & 3,8 & 0 & 1 & 1 & 1 & & 1 \\
\hline 4 & 0 & 6,4 & 5,08 & 4,84 & 4,31 & 4 & & 4 & 0 & 0,93 & 1,26 & 1,26 & & 1,26 \\
\hline 5 & 0 & 6,4 & 5,47 & 4,79 & 4,24 & 3,97 & & 3,69 & 0 & 0,98 & 1,3 & 1,3 & 1,3 & 1,3 \\
\hline 6 & 0 & 6 & 5,38 & 4,61 & 4,3 & 4 & 4 & 4 & 0 & 0,98 & 1,29 & 1,29 & & 1,2 \\
\hline 7 & 0 & 5,6 & 5,18 & 4,56 & 4,32 & 4,07 & 3,8 & 3,58 & 0 & 0 & 0 & 0 & & 0 \\
\hline 8 & 0 & 5,6 & 4,69 & 4,44 & 4,32 & 3,95 & 3,8 & 4,56 & 0 & 1 & 1 & 1 & & 1 \\
\hline O & 0 & 6,2 & 5,34 & 5 & 4,2 & 4,02 & 3,7 & 3,7 & 0 & 1 & 1 & 1 & & 1 \\
\hline 10 & 0 & 6,2 & 5,13 & 4,72 & 4,32 & 4,05 & 3,8 & 3,78 & 0 & 0,75 & 1,29 & 1,29 & & 1,29 \\
\hline Média & 0 & 6,1 & 5,28 & 4,76 & 4,37 & 4,02 & 3,8 & 3,91 & O & 0,8 & 1,01 & 1,02 & 1,29 & 1,01 \\
\hline DP & 0 & 0,4 & 0,28 & 0,19 & 0,31 & 0,05 & 0,1 & 0,29 & O & 0,31 & $\mathbf{0 , 4 0}$ & 0,4 & 0,01 & 0,4 \\
\hline Max & 0 & 6,7 & 5,76 & 5,02 & 5,25 & 4,1 & 4 & 4,56 & O & 1 & 1,3 & 1,3 & 1,3 & 1,3 \\
\hline Min & 0 & 5,6 & 4,69 & 4,44 & 4,2 & 3,95 & 3,7 & 3,58 & 0 & 0 & 0 & 0 & 1,28 & 0 \\
\hline
\end{tabular}


Quadro V. Tempo Previsto de Regressão

\begin{tabular}{|c|c|c|c|c|c|c|c|c|c|c|c|c|c|c|}
\hline Grupo CEC & & & & & & & & & & & & & & \\
\hline Paciente & Basal & $5 \mathrm{~m}$ & $15 \mathrm{~m}$ & $30 \mathrm{~m}$ & $60 \mathrm{~m}$ & $120 \mathrm{~m}$ & $240 \mathrm{~m}$ & F. Cir. & $5 \mathrm{~m}$ & $15 \mathrm{~m}$ & $30 \mathrm{~m}$ & $60 \mathrm{~m}$ & $120 \mathrm{~m}$ & F. Inf. \\
\hline 1 & 0 & 2,4 & 3,1 & 3,5 & 4,2 & 4,5 & 5,3 & 5,3 & 0 & 0 & 0 & 0 & & 0 \\
\hline 2 & 0 & 2,3 & 3 & 3,4 & 4,2 & 4,5 & & 3,2 & 3,2 & 3,2 & 3,2 & 3,2 & 3,2 & 4,05 \\
\hline 3 & 0 & 2,2 & 3 & 3,4 & 4,2 & 4,5 & 5,3 & 5,2 & 6 & 6 & 6 & 6 & & 6 \\
\hline 4 & 0 & 2,2 & 2,5 & 3,3 & 4,2 & 4,5 & & 5,2 & 0 & 0 & 0 & 0 & & 0 \\
\hline 5 & 0 & 2,4 & 3,2 & 3,5 & 4,2 & 4,5 & 5,3 & 5,25 & 0 & 0 & 0 & 0 & & 0 \\
\hline 6 & 0 & 2,3 & 3 & 3,3 & 4,2 & 4,5 & & 5,2 & 5 & 0 & 0 & 0 & 0 & 0 \\
\hline 7 & 0 & 2,4 & 3 & 3,4 & 4,2 & 4,3 & 5,2 & 6 & 0 & 0 & 0 & 0 & & 0 \\
\hline 8 & 0 & 2,4 & 3,1 & 3,4 & 4,2 & 4,3 & & 4,35 & 0 & 0 & 0 & 0 & & 0 \\
\hline 9 & 0 & 2,2 & 2,5 & 4,2 & 4,23 & & & 4,15 & 0 & 0 & 0 & 0 & & 0 \\
\hline 10 & 0 & 2,4 & 3 & 3,4 & 4,2 & & & 4,4 & 0 & 0 & 0 & 0 & & 0 \\
\hline Média & 0 & 2,32 & 2,94 & 3,48 & 4,2 & $\mathbf{4 , 4 5}$ & 5,3 & 4,825 & 1,4 & 0,92 & 0,92 & 0,92 & 1,6 & 1,01 \\
\hline DP & 0 & $\mathbf{0 , 0 9}$ & 0,24 & 0,26 & $\mathbf{0 , 0 1}$ & 0,09 & 0,1 & 0,79 & 2,4 & 2,05 & 2,05 & 2,05 & 2,26 & 2,17 \\
\hline Max & 0 & 2,4 & 3,2 & 4,2 & 4,23 & 4,5 & 5,3 & 6 & 6 & 6 & 6 & 6 & 3,2 & 6 \\
\hline Min & 0 & 2,2 & 2,5 & 3,3 & 4,2 & 4,3 & 5,2 & 3,2 & 0 & 0 & 0 & 0 & 0 & 0 \\
\hline \multicolumn{15}{|c|}{ Grupo sem CEC } \\
\hline Paciente & Basal & $5 \mathrm{~m}$ & $15 \mathrm{~m}$ & $30 \mathrm{~m}$ & $60 \mathrm{~m}$ & $120 \mathrm{~m}$ & $240 \mathrm{~m}$ & F. Cir. & $5 \mathrm{~m}$ & $15 \mathrm{~m}$ & $30 \mathrm{~m}$ & $60 \mathrm{~m}$ & $120 \mathrm{~m}$ & F. Inf. \\
\hline 1 & 0 & 2,3 & 3,1 & 3,4 & 4,2 & 4,5 & 5,3 & 6 & 6 & 6 & 3 & 0 & 0 & 0 \\
\hline 2 & 0 & 2,2 & 2,5 & 3,3 & 4,1 & 4,5 & 5,3 & 4,4 & 0 & 0 & 0 & 0 & & 0 \\
\hline 3 & 0 & 2,3 & 3 & 3,3 & 4,2 & 4,51 & 5,3 & 5,3 & 0 & 0 & 0 & 0 & & 0 \\
\hline 4 & 0 & 2,2 & 2,5 & 3,3 & 4,2 & 4,5 & & 5 & 0 & 0 & 0 & 0 & & 0 \\
\hline 5 & 0 & 2,2 & 3 & 3,4 & 4,2 & 4,5 & & 4,3 & 0 & 0 & 0 & 0 & 0 & 0 \\
\hline 6 & 0 & 2,4 & 3 & 3,5 & 4,2 & 4,5 & 3 & 3 & 0 & 0 & 0 & 0 & & 0 \\
\hline 7 & 0 & 3 & 3,1 & 3,5 & 4,2 & 4,5 & 5,3 & 6,2 & 0 & 0 & 0 & 0 & & 0 \\
\hline 8 & 0 & 2,5 & 3,4 & 4 & 4,2 & 4,5 & 5,3 & 5,3 & 0 & 0 & 0 & 0 & & 0 \\
\hline 9 & 0 & 2,4 & 3,3 & 3,9 & 4 & 4,3 & 5,1 & 5,2 & 0 & 0 & 0 & 0 & & 0 \\
\hline 10 & 0 & 2,3 & 3,1 & 3,4 & 4,2 & 4,1 & 5,2 & 5,2 & 5,2 & 5,2 & 5,2 & 5,2 & & 0 \\
\hline Média & 0 & 2,38 & 3 & 3,5 & 4,17 & $\mathbf{4 , 4 4}$ & 5 & 4,99 & 1,1 & 1,12 & $\mathbf{0 , 3}$ & 0 & 0 & 0 \\
\hline DP & 0 & $\mathbf{0 , 2 3}$ & 0,29 & 0,24 & $\mathbf{0 , 0 7}$ & $\mathbf{0 , 1 3}$ & 0,8 & $\mathbf{0 , 9 1}$ & 2,4 & 2,37 & $\mathbf{0 , 9 5}$ & 0 & 0 & 0 \\
\hline Max & 0 & 3 & 3,4 & 4 & 4,2 & $\mathbf{4 , 5 1}$ & 5,3 & 6,2 & 6 & 6 & 3 & 0 & 0 & 0 \\
\hline Min & 0 & 2,2 & 2,5 & 3,3 & 4 & 4,1 & 3 & 3 & 0 & 0 & 0 & 0 & 0 & 0 \\
\hline
\end{tabular}




\section{Quadro VI. Índice bispectral (BIS)}

\begin{tabular}{|c|c|c|c|c|c|c|c|c|c|c|c|c|c|c|c|c|c|c|c|c|c|c|c|}
\hline $\begin{array}{c}\text { Grupo } \\
\text { CEC } \\
\text { Paciente }\end{array}$ & Basal & $\begin{array}{c}5 \\
\min \end{array}$ & $\begin{array}{c}15 \\
\min \end{array}$ & $\begin{array}{c}30 \\
\min \end{array}$ & $\begin{array}{c}60 \\
\min \end{array}$ & $\begin{array}{l}120 \\
\min \end{array}$ & $\begin{array}{l}240 \\
\min \end{array}$ & $\begin{array}{l}\text { Final } \\
\text { cirur. }\end{array}$ & $\begin{array}{c}5 \\
\min \end{array}$ & $\begin{array}{c}15 \\
\min \end{array}$ & $\begin{array}{r}30 \\
\min \end{array}$ & $\begin{array}{c}60 \\
\min \end{array}$ & $\begin{array}{l}120 \\
\min \end{array}$ & $\begin{array}{c}\text { Final } \\
\text { inf. }\end{array}$ & $\begin{array}{c}5 \\
\text { min }\end{array}$ & $\begin{array}{c}15 \\
\min \end{array}$ & $\begin{array}{c}30 \\
\min \end{array}$ & $\begin{array}{c}60 \\
\min \end{array}$ & $\begin{array}{l}120 \\
\min \end{array}$ & $\begin{array}{c}240 \\
\min \end{array}$ & $\begin{array}{l}360 \\
\min \end{array}$ & $\begin{array}{c}480 \\
\min \end{array}$ & $\begin{array}{r}720 \\
\min \end{array}$ \\
\hline 1 & 82 & 34 & 24 & 20 & 36 & 25 & 24 & 23 & 23 & 32 & 42 & 39 & & 32 & 33 & 35 & 37 & 42 & 52 & 78 & 78 & 80 & 85 \\
\hline 2 & 90 & 55 & 46 & 34 & 49 & 39 & & 31 & 47 & 60 & 46 & 51 & 54 & 54 & 55 & 80 & 80 & 69 & 76 & 78 & 80 & 77 & 85 \\
\hline 3 & 97 & 53 & 54 & 40 & 40 & 53 & 57 & 53 & 66 & 46 & 62 & 64 & & 65 & 60 & 77 & 63 & 84 & 90 & 96 & 97 & 98 & 98 \\
\hline 4 & 92 & 50 & 48 & 40 & 41 & 45 & & 41 & 39 & 40 & 41 & 40 & & 58 & 58 & 61 & 60 & 58 & 61 & 60 & 90 & 88 & 89 \\
\hline 5 & 84 & 52 & 44 & 46 & 44 & 45 & 53 & 45 & 50 & 51 & 59 & 54 & & 54 & 54 & 66 & 66 & 80 & 80 & 80 & 80 & 80 & 98 \\
\hline 6 & 98 & 38 & 35 & 36 & 35 & 40 & & 57 & 47 & 47 & 72 & 71 & 71 & 61 & 74 & 80 & 84 & 83 & 83 & 73 & 84 & 84 & 87 \\
\hline 7 & 97 & 35 & 35 & 25 & 35 & 35 & 33 & 32 & 38 & 37 & 42 & 43 & & 42 & 41 & 41 & 30 & 46 & 61 & 62 & 71 & 79 & 72 \\
\hline 8 & 94 & 38 & 34 & 35 & 31 & 30 & & 36 & 36 & 40 & 53 & 38 & & 68 & 62 & 66 & 68 & 68 & 70 & 99 & 97 & 97 & 73 \\
\hline 0 & 98 & 60 & 40 & 45 & 36 & & & 36 & 49 & 66 & 58 & 58 & & 58 & 66 & 84 & 87 & 88 & 80 & 68 & 94 & 94 & 90 \\
\hline 10 & 98 & 61 & 54 & 62 & 68 & & & 48 & 62 & 67 & 74 & 80 & & 81 & 81 & 86 & 91 & 97 & 85 & 94 & 94 & 94 & 95 \\
\hline Média & 93 & 48 & 41 & 38 & 42 & 39 & 42 & 40 & 46 & 49 & 55 & 54 & 62,5 & 57 & 58 & 68 & 67 & 72 & 74 & 79 & 87 & 87 & 87 \\
\hline DP & 6 & 10 & 10 & 12 & 11 & 9 & 16 & 11 & 13 & 12 & 12 & 14 & 12 & 14 & 14 & 18 & 20 & 18 & 12 & 14 & 9 & 8 & 9,1 \\
\hline Max & 98 & 61 & 54 & 62 & 68 & 53 & 57 & 57 & 66 & 67 & 74 & 80 & 71 & 81 & 81 & 86 & 91 & 97 & 90 & 99 & 97 & 98 & 98 \\
\hline Min & 82 & 34 & 24 & 20 & 31 & 25 & 24 & 23 & 23 & 32 & 41 & 38 & 54 & 32 & 33 & 35 & 30 & 42 & 52 & 60 & 71 & 77 & 72 \\
\hline $\begin{array}{c}\text { Grupo sem } \\
\text { CEC } \\
\text { Paciente }\end{array}$ & Basal & $\begin{array}{c}5 \\
\min \end{array}$ & $\begin{array}{c}15 \\
\min \end{array}$ & $\begin{array}{c}30 \\
\min \end{array}$ & $\begin{array}{c}60 \\
\min \end{array}$ & $\begin{array}{l}120 \\
\min \end{array}$ & $\begin{array}{l}240 \\
\min \end{array}$ & $\begin{array}{c}\text { Final } \\
\text { cir. }\end{array}$ & $\begin{array}{c}5 \\
\min \end{array}$ & $\begin{array}{c}15 \\
\min \end{array}$ & $\begin{array}{c}30 \\
\min \end{array}$ & $\begin{array}{c}60 \\
\min \end{array}$ & $\begin{array}{l}120 \\
\min \end{array}$ & $\begin{array}{c}\text { Final } \\
\text { inf. }\end{array}$ & $\begin{array}{c}5 \\
\min \end{array}$ & $\begin{array}{c}15 \\
\min \end{array}$ & $\begin{array}{c}30 \\
\min \end{array}$ & $\begin{array}{c}60 \\
\min \end{array}$ & $\begin{array}{l}120 \\
\min \end{array}$ & $\begin{array}{c}240 \\
\min \end{array}$ & $\begin{array}{l}360 \\
\min \end{array}$ & $\begin{array}{c}480 \\
\min \end{array}$ & $\begin{array}{r}720 \\
\min \end{array}$ \\
\hline 1 & 98 & 58 & 49 & 4 & 45 & 45 & 41 & 41 & 48 & 60 & 74 & 74 & 74 & 90 & 93 & 92 & 90 & 89 & 84 & 90 & 84 & 84 & 94 \\
\hline 2 & 86 & 35 & 35 & 29 & 39 & 45 & 36 & 46 & 48 & 49 & 64 & 65 & & 64 & 71 & 75 & 74 & 74 & 81 & 82 & 82 & 84 & 86 \\
\hline 3 & 94 & 34 & 34 & 34 & 32 & 38 & 41 & 31 & 47 & 67 & 80 & 79 & & 80 & 81 & 82 & 81 & 82 & 76 & 84 & 83 & 95 & 94 \\
\hline 4 & 98 & 57 & 41 & 42 & 57 & 46 & & 46 & 37 & 57 & 63 & 75 & & 75 & 66 & 97 & 67 & 96 & 97 & 93 & 94 & 96 & 98 \\
\hline 5 & 95 & 39 & 37 & 41 & 31 & 38 & & 64 & 43 & 60 & 63 & 78 & 85 & 87 & 89 & 97 & 78 & 83 & 83 & 84 & 97 & 95 & 98 \\
\hline 6 & 96 & 36 & 48 & 40 & 50 & 39 & 68 & 68 & 59 & 78 & 70 & 77 & & 80 & 80 & 60 & 91 & 98 & 95 & 92 & 88 & 95 & 96 \\
\hline 7 & 93 & 33 & 27 & 31 & 48 & 35 & 31 & 35 & 38 & 36 & 37 & 38 & & 36 & 51 & 74 & 82 & 97 & 82 & 79 & 82 & 86 & 97 \\
\hline 8 & 84 & 40 & 35 & 37 & 32 & 33 & 39 & 33 & 40 & 55 & 54 & 54 & & 54 & 54 & 56 & 63 & 63 & 70 & 90 & 91 & 94 & 95 \\
\hline 9 & 96 & 40 & 36 & 36 & 36 & 36 & 32 & 36 & 41 & 50 & 60 & 60 & & 61 & 83 & 84 & 85 & 86 & 90 & 92 & 96 & 96 & 96 \\
\hline 10 & 98 & 42 & 38 & 36 & 30 & 35 & 32 & 36 & 40 & 51 & 58 & 62 & & 62 & 87 & 87 & 88 & 88 & 95 & 98 & 98 & 98 & 98 \\
\hline Média & 94 & 41 & 38 & 37 & 40 & 39 & 40 & 44 & 44 & 56 & 62 & 66 & 79,5 & 69 & 76 & 80 & 80 & 86 & 85 & 88 & 90 & 92 & 95 \\
\hline DP & 5 & 9 & 7 & 5,4 & 9,5 & 4,7 & 12 & 13 & 7 & 11 & 12 & 13 & 7,78 & 17 & 15 & 14 & 10 & 11 & 9 & 6 & 7 & 5 & 3,5 \\
\hline $\operatorname{Max}$ & 98 & 58 & 49 & 47 & 57 & 46 & 68 & 68 & 59 & 78 & 80 & 79 & 85 & 90 & 93 & 97 & 91 & 98 & 97 & 98 & 98 & 98 & 98 \\
\hline Min & 84 & 33 & 27 & 29 & 30 & 33 & 31 & 31 & 37 & 36 & 37 & 38 & 74 & 36 & 51 & 56 & 63 & 63 & 70 & 79 & 82 & 84 & 86 \\
\hline
\end{tabular}




\section{Quadro VII. Pressão arterial média (PAM)}

\begin{tabular}{|c|c|c|c|c|c|c|c|c|c|c|c|c|c|c|c|c|c|c|c|c|c|c|c|}
\hline $\begin{array}{c}\text { Grupo } \\
\text { CEC } \\
\text { Paciente }\end{array}$ & Basal & $\begin{array}{c}5 \\
\min \end{array}$ & $\begin{array}{c}15 \\
\min \end{array}$ & $\begin{array}{c}30 \\
\text { min }\end{array}$ & $\begin{array}{c}60 \\
\min \end{array}$ & $\begin{array}{l}120 \\
\min \end{array}$ & $\begin{array}{l}240 \\
\min \end{array}$ & $\begin{array}{l}\text { Fim } \\
\text { Cir. }\end{array}$ & $\begin{array}{c}5 \\
\min \end{array}$ & $\begin{array}{c}15 \\
\min \end{array}$ & $\begin{array}{c}30 \\
\text { min }\end{array}$ & $\begin{array}{c}60 \\
\min \end{array}$ & $\begin{array}{l}120 \\
\min \end{array}$ & $\begin{array}{l}\text { Fim } \\
\text { Inf. }\end{array}$ & $\begin{array}{c}5 \\
\min \end{array}$ & $\begin{array}{c}15 \\
\min \end{array}$ & $\begin{array}{c}30 \\
\min \end{array}$ & $\begin{array}{c}60 \\
\min \end{array}$ & $\begin{array}{l}120 \\
\min \end{array}$ & $\begin{array}{l}240 \\
\min \end{array}$ & $\begin{array}{l}360 \\
\min \end{array}$ & $\begin{array}{l}480 \\
\min \end{array}$ & $\begin{array}{l}720 \\
\min \end{array}$ \\
\hline 1 & 94 & 130 & 64 & 70 & 74 & 76 & 68 & 67 & 64 & 72 & 79 & 71 & & 78 & 80 & 82 & 89 & 95 & 73 & 96 & 102 & 95 & 96 \\
\hline 2 & 94 & 136 & 77 & 66 & 85 & 51 & & 72 & 74 & 71 & 71 & 82 & 66 & 67 & 69 & 80 & 69 & 75 & 77 & 73 & 72 & 84 & 86 \\
\hline 3 & 99 & 104 & 92 & 79 & 58 & 75 & 65 & 72 & 69 & 72 & 72 & 73 & & 73 & 77 & 80 & 81 & 82 & 87 & 78 & 80 & 79 & 87 \\
\hline 4 & 115 & 119 & 103 & 91 & 107 & 101 & & 70 & 61 & 68 & 74 & 77 & & 91 & 90 & 100 & 91 & 80 & 97 & 68 & 98 & 84 & 87 \\
\hline 5 & 85 & 55 & 59 & 67 & 60 & 66 & 60 & 74 & 73 & 80 & 72 & 72 & & 66 & 68 & 76 & 85 & 107 & 70 & 71 & 113 & 78 & 92 \\
\hline 6 & 115 & 64 & 72 & 64 & 65 & 65 & & 72 & 77 & 75 & 79 & 78 & 72 & 71 & 78 & 92 & 112 & 91 & 74 & 95 & 77 & 76 & 91 \\
\hline 7 & 74 & 81 & 80 & 79 & 82 & 67 & 58 & 65 & 59 & 61 & 60 & 61 & & 68 & 68 & 68 & 58 & 62 & 75 & 74 & 86 & 49 & 62 \\
\hline 8 & 101 & 72 & 71 & 60 & 92 & 90 & & 64 & 64 & 68 & 75 & 63 & & 79 & 66 & 69 & 81 & 71 & 77 & 66 & 92 & 95 & 73 \\
\hline 0 & 93 & 76 & 74 & 97 & 70 & & & 79 & 79 & 76 & 72 & 82 & & 82 & 81 & 89 & 73 & 52 & 72 & 88 & 85 & 69 & 69 \\
\hline 10 & 100 & 75 & 73 & 85 & 58 & & & 61 & 60 & 66 & 78 & 64 & & 64 & 70 & 78 & 84 & 72 & 86 & 91 & 74 & 85 & 101 \\
\hline Média & 97 & 91 & 77 & 76 & 75 & 74 & 63 & 70 & 68 & 71 & 73 & 72 & 69 & 74 & 75 & 81 & 82 & 79 & 79 & 80 & 88 & 79 & 84 \\
\hline DP & 12 & 29 & 13 & 12 & 16 & 16 & 4,6 & 5 & 7 & 5,4 & 6 & 8 & 4 & 9 & 8 & 10 & 14 & 16 & 8,5 & 11 & 13 & 13 & 12 \\
\hline Max & 115 & 136 & 103 & 97 & 107 & 101 & 68 & 79 & 79 & 80 & 79 & 82 & 72 & 91 & 90 & 100 & 112 & 107 & 97 & 96 & 113 & 95 & 101 \\
\hline Min & 74 & 55 & 59 & 60 & 58 & 51 & 58 & 61 & 59 & 61 & 60 & 61 & 66 & 64 & 66 & 68 & 58 & 52 & 70 & 66 & 72 & 49 & 62 \\
\hline $\begin{array}{c}\text { Grupo sem } \\
\text { CEC } \\
\text { Paciente }\end{array}$ & Basal & $\begin{array}{c}5 \\
\min \end{array}$ & $\begin{array}{c}15 \\
\min \end{array}$ & $\begin{array}{c}30 \\
\text { min }\end{array}$ & $\begin{array}{c}60 \\
\min \end{array}$ & $\begin{array}{l}120 \\
\min \end{array}$ & $\begin{array}{l}240 \\
\min \end{array}$ & $\begin{array}{l}\text { Fim } \\
\text { Cir. }\end{array}$ & $\begin{array}{c}5 \\
\min \end{array}$ & $\begin{array}{c}15 \\
\min \end{array}$ & $\begin{array}{c}30 \\
\text { min }\end{array}$ & $\begin{array}{c}60 \\
\min \end{array}$ & $\begin{array}{l}120 \\
\min \end{array}$ & $\begin{array}{l}\text { Fim } \\
\text { Inf. }\end{array}$ & $\begin{array}{c}5 \\
\min \end{array}$ & $\begin{array}{c}15 \\
\min \end{array}$ & $\begin{array}{c}30 \\
\min \end{array}$ & $\begin{array}{c}60 \\
\min \end{array}$ & $\begin{array}{c}120 \\
\min \end{array}$ & $\begin{array}{l}240 \\
\min \end{array}$ & $\begin{array}{l}360 \\
\min \end{array}$ & $\begin{array}{l}480 \\
\min \end{array}$ & $\begin{array}{l}720 \\
\min \end{array}$ \\
\hline 1 & 135 & 102 & 72 & 71 & 71 & 61 & 73 & 67 & 67 & 68 & 93 & 93 & 70 & 116 & 119 & 119 & 121 & 86 & 77 & 99 & 88 & 89 & 76 \\
\hline 2 & 111 & 67 & 66 & 74 & 85 & 70 & 76 & 63 & 62 & 69 & 62 & 64 & & 62 & 72 & 72 & 104 & 73 & 100 & 103 & 100 & 88 & 102 \\
\hline 3 & 104 & 58 & 55 & 49 & 68 & 88 & 73 & 77 & 75 & 88 & 88 & 87 & & 88 & 88 & 68 & 68 & 95 & 86 & 75 & 88 & 91 & 90 \\
\hline 4 & 92 & 71 & 84 & 73 & 91 & 86 & & 51 & 64 & 74 & 83 & 83 & & 84 & 71 & 99 & 88 & 116 & 136 & 115 & 85 & 89 & 94 \\
\hline 5 & 91 & 40 & 67 & 58 & 77 & 90 & & 92 & 75 & 92 & 78 & 77 & 71 & 100 & 104 & 120 & 81 & 77 & 80 & 78 & 100 & 90 & 93 \\
\hline 6 & 104 & 101 & 89 & 67 & 52 & 79 & 72 & 72 & 79 & 83 & 57 & 58 & & 80 & 83 & 76 & 60 & 59 & 47 & 64 & 89 & 76 & 64 \\
\hline 7 & 102 & 79 & 75 & 85 & 51 & 70 & 57 & 72 & 72 & 45 & 52 & 54 & & 47 & 70 & 69 & 89 & 73 & 64 & 66 & 68 & 54 & 60 \\
\hline 8 & 110 & 85 & 62 & 93 & 86 & 87 & 68 & 61 & 79 & 76 & 92 & 94 & & 90 & 92 & 108 & 93 & 83 & 71 & 97 & 84 & 84 & 86 \\
\hline 9 & 93 & 85 & 64 & 86 & 71 & 79 & 76 & 68 & 68 & 70 & 65 & 66 & & 69 & 67 & 68 & 72 & 69 & 68 & 69 & 68 & 68 & 80 \\
\hline 10 & 85 & 68 & 80 & 68 & 75 & 62 & 71 & 59 & 54 & 69 & 70 & 72 & & 61 & 65 & 67 & 78 & 68 & 68 & 75 & 87 & 76 & 88 \\
\hline Média & 103 & 76 & 71 & 72 & 73 & 77 & 71 & 68 & 70 & 73 & 74 & 75 & 94 & 80 & 83 & 87 & 85 & 80 & 80 & 84 & 86 & 81 & 83 \\
\hline DP & 14 & 19 & 11 & 13 & 13 & 11 & 6,1 & 11 & 8 & 13 & 15 & 14 & 1 & 20 & 18 & 22 & 18 & 16 & 24 & 18 & 11 & 12 & 13 \\
\hline Max & 135 & 102 & 89 & 93 & 91 & 90 & 76 & 92 & 79 & 92 & 93 & 94 & 94 & 116 & 119 & 120 & 121 & 116 & 136 & 115 & 100 & 91 & 60 \\
\hline Min & 85 & 40 & 55 & 49 & 51 & 61 & 57 & 51 & 54 & 45 & 52 & 54 & 93 & 47 & 65 & 67 & 60 & 59 & 47 & 64 & 68 & 54 & 60 \\
\hline
\end{tabular}




\section{Quadro VIII. Freqüência cardíaca (FC)}

\begin{tabular}{|c|c|c|c|c|c|c|c|c|c|c|c|c|c|c|c|c|c|c|c|c|c|c|c|}
\hline $\begin{array}{c}\text { Grupo } \\
\text { CEC } \\
\text { Paciente }\end{array}$ & Basal & $\begin{array}{c}5 \\
\min \end{array}$ & $\begin{array}{c}15 \\
\min \end{array}$ & $\begin{array}{c}30 \\
\min \end{array}$ & $\begin{array}{c}60 \\
\min \end{array}$ & $\begin{array}{l}120 \\
\min \end{array}$ & $\begin{array}{l}240 \\
\min \end{array}$ & $\begin{array}{c}\text { Fim. } \\
\text { Cir. }\end{array}$ & $\begin{array}{c}5 \\
\min \end{array}$ & $\begin{array}{c}15 \\
\text { inm }\end{array}$ & $\begin{array}{c}30 \\
\min \end{array}$ & $\begin{array}{c}60 \\
\text { inm }\end{array}$ & $\begin{array}{l}120 \\
\min \end{array}$ & $\begin{array}{l}\text { Fim. } \\
\text { Inf. }\end{array}$ & $\begin{array}{c}5 \\
\min \end{array}$ & $\begin{array}{c}15 \\
\text { inm }\end{array}$ & $\begin{array}{c}30 \\
\min \end{array}$ & $\begin{array}{c}60 \\
\min \end{array}$ & $\begin{array}{r}120 \\
\min \end{array}$ & $\begin{array}{r}240 \\
\min \end{array}$ & $\begin{array}{l}360 \\
\text { min }\end{array}$ & $\begin{array}{c}480 \\
\min \end{array}$ & $\begin{array}{r}720 \\
\text { min }\end{array}$ \\
\hline 1 & 48 & 77 & 72 & 49 & 80 & 130 & 83 & 63 & 74 & 72 & 80 & 50 & & 52 & 54 & 50 & 50 & 57 & 73 & 93 & 69 & 65 & 68 \\
\hline 2 & 57 & 70 & 50 & 47 & 46 & 48 & & 76 & 70 & 74 & 72 & 72 & 70 & 68 & 72 & 74 & 77 & 75 & 70 & 107 & 118 & 100 & 102 \\
\hline 3 & 66 & 66 & 57 & 57 & 69 & 68 & 106 & 106 & 106 & 119 & 110 & 104 & & 104 & 99 & 98 & 98 & 92 & 101 & 113 & 100 & 96 & 98 \\
\hline 4 & 76 & 69 & 63 & 60 & 61 & 112 & & 92 & 87 & 85 & 81 & 78 & & 62 & 84 & 90 & 90 & 90 & 97 & 95 & 81 & 75 & 81 \\
\hline 5 & 84 & 82 & 81 & 80 & 78 & 145 & 100 & 110 & 110 & 124 & 120 & 120 & & 109 & 108 & 100 & 99 & 99 & 108 & 110 & 114 & 113 & 111 \\
\hline 6 & 58 & 54 & 51 & 45 & 49 & 55 & & 119 & 117 & 118 & 116 & 91 & 88 & 90 & 87 & 85 & 79 & 77 & 91 & 84 & 85 & 86 & 74 \\
\hline 7 & 57 & 55 & 53 & 50 & 50 & 61 & 110 & 128 & 134 & 134 & 122 & 118 & & 124 & 128 & 130 & 100 & 136 & 134 & 150 & 129 & 130 & 97 \\
\hline 8 & 57 & 54 & 52 & 49 & 70 & 74 & & 74 & 74 & 70 & 69 & 67 & & 65 & 65 & 69 & 77 & 75 & 61 & 72 & 88 & 102 & 100 \\
\hline 0 & 79 & 110 & 104 & 97 & 105 & & & 119 & 120 & 120 & 116 & 107 & & 107 & 111 & 103 & 119 & 119 & 116 & 129 & 119 & 122 & 110 \\
\hline 10 & 96 & 95 & 80 & 85 & 100 & & & 112 & 110 & 112 & 112 & 105 & & 105 & 105 & 105 & 110 & 100 & 123 & 128 & 103 & 86 & 100 \\
\hline Média & 68 & 73 & 66 & 62 & 71 & 87 & 100 & 100 & 100 & 103 & 100 & 91 & 79 & 89 & 91 & 90 & 90 & 92 & 97 & 108 & 101 & 98 & 94 \\
\hline DP & 15 & 18 & 18 & 19 & 20 & 37 & 12 & 22 & 22 & 25 & 21 & 24 & 13 & 25 & 23 & 22 & 20 & 23 & 24 & 23 & 19 & 20 & 15 \\
\hline Max & 96 & 110 & 104 & 97 & 105 & 145 & 110 & 128 & 134 & 134 & 122 & 120 & 88 & 124 & 128 & 130 & 119 & 136 & 134 & 150 & 129 & 130 & 111 \\
\hline Min & 48 & 54 & 50 & 45 & 46 & 48 & 83 & 63 & 70 & 70 & 69 & 50 & 70 & 52 & 54 & 50 & $\mathbf{5 0}$ & 57 & 61 & 72 & 69 & 65 & 68 \\
\hline $\begin{array}{c}\text { Grupo sem } \\
\text { CEC } \\
\text { Paciente }\end{array}$ & Basal & $\begin{array}{c}5 \\
\min \end{array}$ & $\begin{array}{c}15 \\
\min \end{array}$ & $\begin{array}{c}30 \\
\min \end{array}$ & $\begin{array}{c}60 \\
\min \end{array}$ & $\begin{array}{l}120 \\
\min \end{array}$ & $\begin{array}{l}240 \\
\min \end{array}$ & $\begin{array}{c}\text { Fim. } \\
\text { Cir. }\end{array}$ & $\begin{array}{c}5 \\
\min \end{array}$ & $\begin{array}{c}15 \\
\text { inm }\end{array}$ & $\begin{array}{c}30 \\
\min \end{array}$ & $\begin{array}{c}60 \\
\text { inm }\end{array}$ & $\begin{array}{l}120 \\
\min \end{array}$ & $\begin{array}{c}\text { Fim. } \\
\text { Inf. }\end{array}$ & $\begin{array}{c}5 \\
\min \end{array}$ & $\begin{array}{c}15 \\
\text { inm }\end{array}$ & $\begin{array}{c}30 \\
\text { min }\end{array}$ & $\begin{array}{c}60 \\
\min \end{array}$ & $\begin{array}{r}120 \\
\min \end{array}$ & $\begin{array}{r}240 \\
\min \end{array}$ & $\begin{array}{l}360 \\
\min \end{array}$ & $\begin{array}{c}480 \\
\min \end{array}$ & $\begin{array}{r}720 \\
\text { min }\end{array}$ \\
\hline 1 & 77 & 76 & 61 & 58 & 71 & 77 & 76 & 65 & 70 & 70 & 100 & 98 & 98 & 97 & 71 & 72 & 100 & 109 & 83 & 85 & 86 & 72 & 68 \\
\hline 2 & 54 & 49 & 48 & 48 & 65 & 69 & 68 & 76 & 83 & 77 & 81 & 82 & & 81 & 77 & 77 & 67 & 62 & 110 & 108 & 104 & 102 & 100 \\
\hline 3 & 59 & 79 & 80 & 81 & 85 & 94 & 89 & 91 & 91 & 98 & 98 & 98 & & 98 & 98 & 90 & 91 & 92 & 91 & 87 & 103 & 103 & 105 \\
\hline 4 & 58 & 53 & 51 & 52 & 54 & 68 & 66 & 66 & 65 & 64 & 64 & 64 & & 65 & 65 & 66 & 64 & 71 & 74 & 93 & 68 & 68 & 68 \\
\hline 5 & 60 & 56 & 52 & 50 & 66 & 81 & 78 & 78 & 77 & 78 & 78 & 78 & 84 & 71 & 74 & 79 & 77 & 81 & 78 & 79 & 97 & 92 & 76 \\
\hline 6 & 85 & 85 & 61 & 58 & 76 & 77 & 80 & 80 & 80 & 84 & 80 & 84 & & 84 & 84 & 84 & 98 & 88 & 77 & 96 & 96 & 98 & 99 \\
\hline 7 & 52 & 50 & 51 & 51 & 80 & 51 & 58 & 57 & 69 & 71 & 74 & 73 & & 72 & 70 & 74 & 72 & 85 & 84 & 91 & 90 & 95 & 84 \\
\hline 8 & 41 & 43 & 42 & 46 & 43 & 45 & 48 & 49 & 47 & 48 & 44 & 45 & & 44 & 44 & 78 & 78 & 55 & 78 & 83 & 82 & 78 & 79 \\
\hline 0 & 70 & 73 & 57 & 69 & 74 & 64 & 71 & 101 & 107 & 108 & 102 & 101 & & 88 & 86 & 100 & 94 & 110 & 110 & 108 & 102 & 104 & 101 \\
\hline 10 & 68 & 71 & 65 & 67 & 73 & 65 & 83 & 103 & 102 & 93 & 93 & 92 & & 80 & 82 & 101 & 92 & 110 & 112 & 109 & 104 & 106 & 102 \\
\hline Média & 62 & 64 & 57 & 58 & 69 & 69 & 72 & 77 & 79 & 79 & 81 & 82 & 91 & 78 & 75 & 82 & 83 & 86 & 90 & 94 & 93 & 92 & 88 \\
\hline DP & 13 & 15 & 11 & 11 & 12 & 14 & 12 & 18 & 18 & 18 & 18 & 18 & 10 & 16 & 14 & 12 & 13 & 20 & 15 & 11 & 12 & 14 & 15 \\
\hline Max & 85 & 85 & 80 & 81 & 85 & 94 & 89 & 103 & 107 & 108 & 102 & 101 & 98 & 98 & 98 & 101 & 100 & 110 & 112 & 109 & 104 & 106 & 105 \\
\hline Min & 41 & 43 & 42 & 46 & 43 & 45 & 48 & 49 & 47 & 48 & 44 & 45 & 84 & 44 & 44 & 66 & 64 & 55 & 74 & 79 & 68 & 68 & 68 \\
\hline
\end{tabular}


Quadro IX. Dose infundida de propofol Grupo CEC (período durante a CEC)

\begin{tabular}{|c|c|c|c|c|c|c|}
\hline $\begin{array}{c}\text { Dose } \\
\text { infundida } \\
\text { total (mg) }\end{array}$ & Antes da \\
CEC & $\begin{array}{c}\mathbf{5} \text { min após } \\
\text { CEC }\end{array}$ & $\begin{array}{c}\mathbf{1 5} \text { min após } \\
\text { CEC }\end{array}$ & $\begin{array}{c}\mathbf{3 0} \text { min após } \\
\text { CEC }\end{array}$ & $\begin{array}{c}\mathbf{6 0} \text { min após } \\
\text { CEC }\end{array}$ & $\begin{array}{c}\text { Final } \\
\text { CEC }\end{array}$ \\
\hline $\mathbf{1}$ & 673 & 696 & 764 & 832 & 961 & 1076 \\
\hline $\mathbf{2}$ & 888 & 940 & 978 & 1077 & 1165 & 1245 \\
\hline $\mathbf{3}$ & 895 & 975 & 1037 & 1119 & & 1245 \\
\hline $\mathbf{4}$ & 682 & 771 & 811 & 879 & & 888 \\
\hline $\mathbf{5}$ & 713 & 843 & 867 & 935 & 1060 & 1211 \\
\hline $\mathbf{6}$ & 605 & 718 & 763 & 847 & 987 & 1052 \\
\hline $\mathbf{7}$ & 914 & 941 & 987 & 1067 & 1194 & 1341 \\
\hline $\mathbf{8}$ & 784 & 804 & 855 & 929 & 1078 & 1320 \\
\hline $\mathbf{9}$ & 560 & 575 & 608 & 692 & & 795 \\
\hline $\mathbf{1 0}$ & 568 & 590 & 635 & 719 & 882 & 1054 \\
\hline Média & $\mathbf{7 2 8 , 2}$ & $\mathbf{7 8 5 , 3}$ & $\mathbf{8 3 0 , 5}$ & $\mathbf{9 0 9 , 6}$ & $\mathbf{1 0 4 6 , 7 1}$ & $\mathbf{1 1 2 2 , 7}$ \\
\hline $\mathbf{E P}$ & $\mathbf{4 2 , 8 9}$ & $\mathbf{4 5 , 0 8}$ & $\mathbf{4 5 , 6 9}$ & $\mathbf{4 6 , 2 1}$ & $\mathbf{4 2 , 2 2}$ & $\mathbf{5 7 , 6 1}$ \\
\hline
\end{tabular}

Quadro X. Velocidade de infusão Grupo CEC (período durante a CEC)

\begin{tabular}{|c|c|c|c|c|c|c|}
\hline $\begin{array}{c}\begin{array}{c}\text { Velocidade } \\
\text { (mg/kg/hora) }\end{array} \\
\end{array}$ & & & & & & \\
\hline Paciente & $\begin{array}{l}\text { Antes da } \\
\text { CEC }\end{array}$ & $\begin{array}{c}5 \mathrm{~min} \\
\text { após CEC }\end{array}$ & $\begin{array}{l}15 \min \\
\text { após CEC }\end{array}$ & $\begin{array}{c}30 \mathrm{~min} \\
\text { após CEC }\end{array}$ & $\begin{array}{c}60 \mathrm{~min} \\
\text { após CEC }\end{array}$ & $\begin{array}{l}\text { Final } \\
\text { CEC }\end{array}$ \\
\hline 1 & 4,09 & 3,93 & 3,93 & 3,93 & 3,93 & 3,78 \\
\hline 2 & 4,01 & 4,02 & 4,02 & 4 & 3,91 & 3,91 \\
\hline 3 & 4,04 & 3,92 & 3,92 & 3,92 & & 3,8 \\
\hline 4 & 4 & 4 & 4 & 3,8 & & 3,84 \\
\hline 5 & 4,76 & 4 & 3,84 & 3,84 & 3,84 & 3,69 \\
\hline 6 & 4,07 & 4,07 & 4,07 & 3,94 & 3,94 & 3,94 \\
\hline 7 & 3,88 & 3,88 & 3,88 & 3,88 & 3,75 & 3,75 \\
\hline 8 & 4,07 & 4,07 & 3,94 & 3,94 & 3,94 & 3,86 \\
\hline 9 & 4,17 & 4,17 & 4,02 & 4,02 & & 4,02 \\
\hline 10 & 4,14 & 4,14 & 4,14 & 4,14 & 4,02 & 3,9 \\
\hline Média & 4,12 & 4,02 & 3,98 & 3,94 & 3,9 & 3,85 \\
\hline EP & 0,08 & $\mathbf{0 , 0 3}$ & $\mathbf{0 , 0 3}$ & $\mathbf{0 , 0 3}$ & $\mathbf{0 , 0 3}$ & $\mathbf{0 , 0 3}$ \\
\hline
\end{tabular}


Quadro XI. Tempo previsto de regressão Grupo CEC (período durante a CEC)

\begin{tabular}{|c|c|c|c|c|c|c|}
\hline $\begin{array}{c}\text { Tempo previsto de regressão } \\
\text { (min) }\end{array}$ & & & & & & \\
\hline Paciente & Antes da CEC & $\begin{array}{c}\mathbf{5} \text { min } \\
\text { após CEC }\end{array}$ & $\begin{array}{c}\mathbf{1 5} \text { min } \\
\text { após CEC }\end{array}$ & $\begin{array}{c}\mathbf{3 0} \text { min } \\
\text { após CEC }\end{array}$ & $\begin{array}{c}\mathbf{6 0} \text { min } \\
\text { após CEC }\end{array}$ & Final CEC \\
\hline $\mathbf{1}$ & 4,5 & 4,53 & 5 & 5 & 5,1 & 5 \\
\hline $\mathbf{2}$ & 4,5 & 4,5 & 4,5 & 5 & 5 & 5,1 \\
\hline $\mathbf{3}$ & 4,5 & 5 & 5 & 5,1 & & 5,1 \\
\hline $\mathbf{4}$ & 4,5 & 5 & 5 & 5,1 & & 5,1 \\
\hline $\mathbf{5}$ & 4,5 & 5 & 5,1 & 5,1 & 5,2 & 5,3 \\
\hline $\mathbf{6}$ & 4,4 & 4,4 & 4,5 & 4,5 & 5 & 5,1 \\
\hline $\mathbf{7}$ & 5 & 5 & 5,1 & 5,1 & 5,2 & 5,3 \\
\hline $\mathbf{8}$ & 4,3 & 4,5 & 4,5 & 5 & 5,1 & 5,3 \\
\hline $\mathbf{9}$ & 4,4 & 4,4 & 4,4 & 4,5 & & 5 \\
\hline $\mathbf{1 0}$ & 4,3 & 4,3 & 4,3 & 4,4 & 4,02 & 5 \\
\hline Média & $\mathbf{4 , 4 9}$ & $\mathbf{4 , 6 6}$ & $\mathbf{4 , 7 4}$ & $\mathbf{4 , 8 8}$ & $\mathbf{4 , 9 5}$ & $\mathbf{5 , 1 3}$ \\
\hline $\mathbf{E P}$ & $\mathbf{0 , 0 6}$ & $\mathbf{0 , 0 9}$ & $\mathbf{0 , 1}$ & $\mathbf{0 , 0 9}$ & $\mathbf{0 , 1 6}$ & $\mathbf{0 , 0 4}$ \\
\hline
\end{tabular}

Quadro XII. Índice bispectral (BIS) Grupo CEC (período durante a CEC)

\begin{tabular}{|c|c|c|c|c|c|c|}
\hline BIS & & & & & & \\
\hline Paciente & $\begin{array}{c}\text { Antes da } \\
\text { CEC }\end{array}$ & $\begin{array}{c}\mathbf{5} \text { min } \\
\text { após CEC }\end{array}$ & $\begin{array}{c}\mathbf{1 5} \text { min } \\
\text { após CEC }\end{array}$ & $\begin{array}{c}\mathbf{3 0} \text { min } \\
\text { após CEC }\end{array}$ & $\begin{array}{c}\mathbf{6 0} \text { min } \\
\text { após CEC }\end{array}$ & Final CEC \\
\hline $\mathbf{1}$ & 25 & 22 & 24 & 20 & 20 & 39 \\
\hline $\mathbf{2}$ & 44 & 38 & 40 & 37 & 40 & 31 \\
\hline $\mathbf{3}$ & 52 & 51 & 48 & 50 & & 45 \\
\hline $\mathbf{4}$ & 42 & 40 & 40 & 40 & & 40 \\
\hline $\mathbf{5}$ & 43 & 40 & 41 & 39 & 38 & 39 \\
\hline $\mathbf{6}$ & 40 & 40 & 40 & 39 & 41 & 40 \\
\hline $\mathbf{7}$ & 37 & 40 & 32 & 38 & 33 & 34 \\
\hline $\mathbf{8}$ & 30 & 34 & 28 & 25 & 28 & 34 \\
\hline $\mathbf{9}$ & 28 & 28 & 30 & 39 & & 38 \\
\hline $\mathbf{1 0}$ & 53 & 44 & 41 & 38 & 40 & 48 \\
\hline Média & $\mathbf{3 9 , 4}$ & $\mathbf{3 7 , 7}$ & $\mathbf{3 6 , 4}$ & $\mathbf{3 6 , 5}$ & $\mathbf{3 4 , 2 9}$ & $\mathbf{3 8 , 8}$ \\
\hline EP & $\mathbf{3 , 0 1}$ & $\mathbf{2 , 5 6}$ & $\mathbf{2 , 3 6}$ & $\mathbf{2 , 6 3}$ & $\mathbf{2 , 9 7}$ & $\mathbf{1 , 6 1}$ \\
\hline
\end{tabular}


Quadro XIII. Pressão arterial média (PAM) Grupo CEC (período durante a CEC)

\begin{tabular}{|c|c|c|c|c|c|c|}
\hline PAM & Antes da & $\begin{array}{c}\mathbf{5} \text { min } \\
\text { Cpós CEC }\end{array}$ & $\begin{array}{c}\mathbf{1 5} \text { min } \\
\text { após CEC }\end{array}$ & $\begin{array}{c}\mathbf{3 0} \text { min } \\
\text { após CEC }\end{array}$ & $\begin{array}{c}\mathbf{6 0} \text { min } \\
\text { após CEC }\end{array}$ & Final CEC \\
\hline $\mathbf{1}$ & 76 & 76 & 73 & 67 & 78 & 76 \\
\hline $\mathbf{2}$ & 86 & 51 & 66 & 84 & 68 & 48 \\
\hline $\mathbf{3}$ & 62 & 70 & 65 & 67 & & 45 \\
\hline $\mathbf{4}$ & 82 & 76 & 61 & 60 & & 67 \\
\hline $\mathbf{5}$ & 54 & 54 & 67 & 47 & 61 & 47 \\
\hline $\mathbf{6}$ & 70 & 47 & 61 & 52 & 56 & 52 \\
\hline $\mathbf{7}$ & 71 & 55 & 50 & 81 & 49 & 65 \\
\hline $\mathbf{8}$ & 90 & 55 & 71 & 45 & 60 & 57 \\
\hline $\mathbf{9}$ & 74 & 40 & 51 & 75 & & 52 \\
\hline $\mathbf{1 0}$ & 60 & 40 & 56 & 60 & 59 & 66 \\
\hline Média & $\mathbf{7 2 , 5}$ & $\mathbf{5 6 , 4}$ & $\mathbf{6 2 , 1}$ & $\mathbf{6 3 , 8}$ & $\mathbf{6 1 , 5 7}$ & $\mathbf{5 7 , 5}$ \\
\hline EP & $\mathbf{3 , 6 7}$ & $\mathbf{4 , 2 4}$ & $\mathbf{2 , 4 8}$ & $\mathbf{4 , 2 9}$ & $\mathbf{3 , 4 8}$ & $\mathbf{3 , 3}$ \\
\hline
\end{tabular}




\section{Quadro XIV. Concentração plasmática obtida de propofol Grupo CEC}

\begin{tabular}{|c|c|c|c|c|c|c|c|c|c|c|c|c|c|c|c|c|c|c|c|c|c|}
\hline Paciente & $\begin{array}{c}5 \\
\text { min }\end{array}$ & $\begin{array}{c}15 \\
\min \end{array}$ & $\begin{array}{c}30 \\
\text { min }\end{array}$ & $\begin{array}{c}60 \\
\min \end{array}$ & $\begin{array}{l}120 \\
\min \end{array}$ & $\begin{array}{l}240 \\
\min \end{array}$ & $\begin{array}{c}\text { final } \\
\text { cir. }\end{array}$ & $\begin{array}{c}5 \\
\min \end{array}$ & $\begin{array}{c}15 \\
\min \end{array}$ & $\begin{array}{c}30 \\
\min \end{array}$ & $\begin{array}{c}60 \\
\min \end{array}$ & $\begin{array}{c}\text { Final } \\
\text { inf. }\end{array}$ & $\begin{array}{c}5 \\
\min \end{array}$ & $\begin{array}{c}15 \\
\min \end{array}$ & $\begin{array}{c}30 \\
\min \end{array}$ & $\begin{array}{c}60 \\
\min \end{array}$ & $\begin{array}{c}120 \\
\min \end{array}$ & $\begin{array}{c}240 \\
\min \end{array}$ & $\begin{array}{c}360 \\
\min \end{array}$ & $\begin{array}{c}480 \\
\min \end{array}$ & $\begin{array}{l}720 \\
\text { min }\end{array}$ \\
\hline 1 & 1,49 & 1,05 & 3,01 & 1,12 & 2,91 & 1,56 & 1,71 & 1,39 & 0,78 & 1,21 & 1,07 & 1,36 & 1,05 & 0,78 & 0,75 & 0,58 & 0,45 & 0,34 & 0,29 & 0,17 & 0,1 \\
\hline 2 & 2,98 & 1,40 & 1,74 & 1,50 & & 0,87 & 0,32 & 0,79 & 0,43 & 0,58 & 0,84 & 0,61 & 0,89 & 0,67 & 0,36 & 0,18 & 0,18 & 0,07 & 0,05 & 0,04 & 0,03 \\
\hline 3 & 1,75 & 1,11 & 1,96 & 1,55 & 0,89 & 0,58 & 1,64 & 1,00 & 0,63 & 1,54 & 1,13 & 1,17 & 0,96 & 0,71 & 0,65 & 0,59 & 0,44 & 0,31 & 0,27 & 0,20 & 0,13 \\
\hline 4 & 0,96 & 2,15 & 2,76 & 2,88 & 4,11 & & 1,96 & 1,07 & 1,14 & 1,37 & 0,31 & 0,59 & 0,47 & 0,39 & 0,27 & 0,20 & 0,16 & 0,10 & 0,08 & 0,06 & 0,00 \\
\hline 5 & 3,26 & 2,96 & 4,59 & 2,33 & 3,08 & 5,89 & 1,72 & 1,33 & 1,27 & 1,10 & 0,95 & 0,94 & 0,82 & 0,72 & 0,64 & 0,50 & 0,33 & 0,28 & 0,16 & 0,13 & 0,09 \\
\hline 6 & 2,63 & 1,04 & 3,09 & 2,63 & & & 1,17 & 1,34 & 0,84 & 0,69 & 0,35 & 0,97 & 0,91 & 0,80 & 0,54 & 0,40 & 0,25 & 0,20 & 0,16 & 0,12 & 0,09 \\
\hline 7 & 3,19 & 2,04 & 1,99 & 2,34 & 1,91 & & 1,65 & 0,93 & 1,21 & 1,13 & & 1,74 & 1,25 & 1,18 & 0,75 & 0,73 & 0,55 & 0,53 & 0,47 & 0,40 & 0,25 \\
\hline 8 & 1,79 & 1,12 & 2,90 & 3,71 & 1,95 & & 1,08 & 1,08 & 0,42 & 0,82 & 0,45 & 0,80 & 0,98 & 0,52 & 0,40 & 0,28 & 0,16 & 0,13 & 0,10 & & \\
\hline 9 & 0,71 & 1,38 & 0,63 & 1,05 & & & 0,21 & 0,21 & 0,30 & 0,21 & 0,54 & 0,51 & 0,40 & 0,32 & 0,29 & 0,22 & 0,13 & 0,12 & 0,09 & 0,08 & 0,06 \\
\hline 10 & 0,95 & 1,81 & 1,51 & 1,07 & & & 0,30 & 0,30 & 0,62 & 0,57 & 0,68 & 0,69 & 0,59 & 0,49 & 0,41 & 0,37 & 0,28 & 0,23 & 0,21 & 0,16 & 0,11 \\
\hline Média & 1,97 & 1,60 & 2,42 & $\mathbf{2 , 0 2}$ & 2,48 & 2,23 & 1,18 & 0,94 & 0,77 & 0,92 & $\mathbf{0 , 7 0}$ & 0,94 & 0,83 & 0,66 & 0,51 & $\mathbf{0 , 4 0}$ & 0,29 & 0,23 & 0,19 & 0,15 & 0,10 \\
\hline DF & 0,98 & 0,63 & 1,09 & $\mathbf{0 , 9 0}$ & 1,12 & 2,48 & 0,67 & $\mathbf{0 , 4 1}$ & $\mathbf{0 , 3 5}$ & 0,42 & $\mathbf{0 , 3 1}$ & $\mathbf{0 , 3 9}$ & 0,27 & 0,25 & $\mathbf{0 , 1 8}$ & 0,19 & 0,15 & 0,14 & 0,13 & $\mathbf{0 , 1 1}$ & $\mathbf{0 , 0 8}$ \\
\hline
\end{tabular}




\section{Quadro XV. Concentração plasmática obtida de propofol Grupo sem CEC}

\begin{tabular}{|c|c|c|c|c|c|c|c|c|c|c|c|c|c|c|c|c|c|c|c|c|}
\hline Paciente & \begin{tabular}{|c}
5 \\
min \\
\end{tabular} & $\begin{array}{c}15 \\
\text { min }\end{array}$ & $\begin{array}{c}\mathbf{3 0} \\
\text { min }\end{array}$ & $\begin{array}{c}60 \\
\min \end{array}$ & $\begin{array}{l}120 \\
\text { min } \\
\end{array}$ & $\begin{array}{l}240 \\
\text { min } \\
\end{array}$ & $\begin{array}{c}\text { final } \\
\text { cir. }\end{array}$ & $\begin{array}{c}5 \\
\text { min }\end{array}$ & $\begin{array}{c}15 \\
\text { min }\end{array}$ & $\begin{array}{c}30 \\
\text { min }\end{array}$ & $\begin{array}{c}\text { final } \\
\text { inf. }\end{array}$ & $\begin{array}{c}5 \\
\text { min }\end{array}$ & $\begin{array}{c}15 \\
\text { min }\end{array}$ & $\begin{array}{c}30 \\
\text { min }\end{array}$ & $\begin{array}{c}\mathbf{6 0} \\
\text { min }\end{array}$ & $\begin{array}{l}120 \\
\text { min }\end{array}$ & $\begin{array}{l}240 \\
\text { min } \\
\end{array}$ & $\begin{array}{l}360 \\
\text { min } \\
\end{array}$ & $\begin{array}{l}480 \\
\text { min } \\
\end{array}$ & $\begin{array}{l}720 \\
\text { min }\end{array}$ \\
\hline 1 & 1,63 & 3,03 & 0,96 & 1,35 & 2,42 & 1,15 & 1,29 & 0,98 & 0,77 & 0,54 & 0,46 & 0,44 & 0,37 & 0,29 & 0,26 & 0,25 & 0,11 & & 0,11 & 0,08 \\
\hline 2 & 2,72 & 1,45 & 3,42 & 0,80 & 3,54 & 5,13 & 2,40 & 1,67 & 1,22 & 0,80 & 0,63 & 0,68 & 0,61 & 0,58 & 0,54 & 0,53 & 0,40 & 0,38 & 0,29 & 0,27 \\
\hline 3 & 1,11 & 3,66 & 3,57 & 6,54 & 3,15 & 1,78 & 1,23 & 0,55 & 0,33 & 0,91 & 0,91 & 0,78 & 0,42 & 0,34 & 0,33 & 0,30 & 0,21 & 0,18 & 0,14 & 0,10 \\
\hline 4 & 1,68 & 1,52 & 0,82 & 1,08 & 1,48 & & 0,97 & 1,26 & 0,80 & 0,91 & 0,76 & 0,53 & 0,45 & 0,37 & 0,32 & 0,28 & 0,22 & 0,16 & 0,14 & 0,11 \\
\hline 5 & 2,59 & 0,99 & 4,55 & 1,57 & 3,61 & 0,67 & 1,19 & 0,92 & 0,65 & 2,26 & 1,50 & 1,45 & 1,32 & 0,89 & 0,80 & 0,58 & 0,37 & 0,33 & 0,31 & 0,22 \\
\hline 6 & 4,60 & 2,59 & 3,17 & 5,47 & 7,62 & 1,67 & 1,67 & 0,74 & 1,16 & 0,79 & 1,27 & 1,03 & 0,83 & 0,61 & 0,59 & 0,46 & 0,31 & 0,20 & 0,18 & 0,14 \\
\hline 7 & 2,63 & 3,75 & 1,53 & 1,12 & 2,09 & 3,08 & 0,96 & 1,41 & 1,01 & & 1,01 & 0,93 & 0,88 & 0,79 & 0,66 & 0,50 & 0,46 & & 0,38 & 0,28 \\
\hline 8 & 1,22 & 1,71 & 2,75 & 2,23 & 4,56 & 0,92 & 1,28 & 1,06 & 0,58 & 0,97 & 0,97 & 0,79 & 0,64 & 0,49 & 0,41 & 0,31 & 0,22 & 0,19 & 0,16 & 0,13 \\
\hline 9 & 2,11 & 1,37 & 2,03 & 1,60 & 2,68 & 7,08 & 1,92 & 1,02 & 1,18 & 0,80 & 1,00 & 0,86 & 0,75 & 0,59 & 0,53 & 0,48 & 0,45 & 0,43 & 0,32 & 0,24 \\
\hline 10 & 1,79 & 3,03 & 2,68 & 2,51 & 2,06 & 7,66 & 2,32 & 1,60 & 0,87 & 1,18 & 1,32 & 0,74 & 0,58 & 0,51 & 0,38 & 0,36 & 0,35 & 0,29 & 0,23 & 0,20 \\
\hline Média & 2,21 & 2,31 & 2,55 & 2,43 & $\mathbf{3 , 3 2}$ & 3,24 & 1,52 & 1,12 & 0,86 & 1,02 & 0,98 & $\mathbf{0 , 8 2}$ & 0,68 & $\mathbf{0 , 5 5}$ & 0,48 & 0,40 & 0,31 & $\mathbf{0 , 2 7}$ & $\mathbf{0 , 2 3}$ & 0,18 \\
\hline DP & 1,0 & 1,0 & 1,2 & 2,0 & 1,8 & 2,7 & 0,5 & 0,4 & $\mathbf{0 , 3}$ & 0,5 & $\mathbf{0 , 3}$ & 0,3 & 0,3 & 0,2 & 0,2 & 0,1 & 0,1 & 0,1 & 0,1 & 0,1 \\
\hline
\end{tabular}


Quadro XVI. Concentração plasmática obtida de propofol Grupo CEC (período durante a CEC)

\begin{tabular}{|c|c|c|c|c|c|c|}
\hline Paciente & $\begin{array}{c}\text { Antes da } \\
\text { CEC }\end{array}$ & $\begin{array}{c}\mathbf{5} \text { min pós } \\
\text { CEC }\end{array}$ & $\begin{array}{c}\mathbf{1 5} \text { min } \\
\text { pós CEC }\end{array}$ & $\begin{array}{c}\text { 30 min } \\
\text { pós CEC }\end{array}$ & $\begin{array}{c}\text { 60 min } \\
\text { pós CEC }\end{array}$ & $\begin{array}{c}\text { Final } \\
\text { CEC }\end{array}$ \\
\hline $\mathbf{1}$ & 2,91 & 0,90 & 1,67 & 2,04 & 2,50 & 2,10 \\
\hline $\mathbf{2}$ & 2,03 & 2,05 & 3,90 & 2,46 & 2,81 & 2,68 \\
\hline $\mathbf{3}$ & 3,10 & 1,12 & 1,62 & 1,67 & & 0,90 \\
\hline $\mathbf{4}$ & 2,37 & 2,80 & 2,84 & 2,73 & & 1,43 \\
\hline $\mathbf{5}$ & 2,78 & 6,10 & 2,68 & 4,16 & 2,85 & 3,54 \\
\hline $\mathbf{6}$ & 1,95 & 4,74 & 4,74 & 2,93 & 4,01 & 4,24 \\
\hline $\mathbf{7}$ & 3,50 & 1,72 & 2,09 & 1,87 & 3,48 & 2,03 \\
\hline $\mathbf{8}$ & 1,95 & 2,23 & 2,27 & 2,53 & 1,35 & 2,67 \\
\hline $\mathbf{9}$ & 1,31 & 0,78 & 0,51 & 0,82 & & 1,25 \\
\hline $\mathbf{1 0}$ & 0,64 & 0,40 & 0,65 & 0,68 & 0,51 & 0,88 \\
\hline Média & $\mathbf{2 , 2 5}$ & $\mathbf{2 , 2 8}$ & $\mathbf{2 , 3 0}$ & $\mathbf{2 , 1 9}$ & $\mathbf{2 , 5 0}$ & $\mathbf{2 , 1 7}$ \\
\hline DP & $\mathbf{0 , 8 6}$ & $\mathbf{1 , 8 4}$ & $\mathbf{1 , 3 2}$ & $\mathbf{1 , 0 2}$ & $\mathbf{1 , 2 1}$ & $\mathbf{1 , 1 2}$ \\
\hline
\end{tabular}




\section{Quadro XVII. Dados Farmacocinéticos (Grupo CEC)}

\begin{tabular}{|c|c|c|c|c|c|c|c|c|c|c|c|c|c|}
\hline Paciente & Peso & dose & alfa & $\begin{array}{c}\text { t1/2 } \\
\text { alfa }\end{array}$ & Beta & $\begin{array}{c}\mathbf{t 1 / 2} \\
\text { beta }\end{array}$ & gama & $\begin{array}{c}\mathbf{t 1 / 2} \\
\text { gama }\end{array}$ & $\begin{array}{c}\text { AUC } \\
\mathbf{0 - t}\end{array}$ & $\begin{array}{c}\text { AUC } \\
\text { 0-inf }\end{array}$ & CLT & $\begin{array}{c}\text { Vd } \\
\text { beta }\end{array}$ & $\begin{array}{c}\text { Vd } \\
\text { gama }\end{array}$ \\
\hline $\mathbf{1}$ & 66,0 & 1385 & 2,20 & 0,31 & 0,53 & 1,30 & 0,15 & 4,58 & 13,26 & 14,40 & 24,30 & 2,70 & 9,70 \\
\hline $\mathbf{2}$ & 92,5 & 1840 & 2,98 & 0,23 & 0,38 & 1,80 & 0,12 & 5,78 & 11,01 & 11,28 & 29,40 & 4,60 & 14,70 \\
\hline $\mathbf{3}$ & 84,0 & 1893 & 3,56 & 0,19 & 0,30 & 2,31 & 0,11 & 6,32 & 11,42 & 12,63 & 29,70 & 5,90 & 16,20 \\
\hline $\mathbf{4}$ & 65,0 & 1300 & 3,20 & 0,22 & 0,34 & 2,00 & 0,15 & 4,36 & 12,88 & 12,88 & 25,90 & 4,50 & 9,80 \\
\hline $\mathbf{5}$ & 65,0 & 1540 & 2,56 & 0,27 & 0,40 & 1,70 & 0,13 & 5,03 & 22,60 & 23,26 & 17,00 & 2,50 & 7,40 \\
\hline $\mathbf{6}$ & 76,0 & 1480 & 5,49 & 0,13 & 0,47 & 1,46 & 0,10 & 6,81 & 16,02 & 16,92 & 19,20 & 2,40 & 11,30 \\
\hline $\mathbf{7}$ & 72,6 & 1940 & 3,77 & 0,18 & 0,28 & 2,45 & 0,09 & 7,44 & 20,24 & 22,97 & 19,40 & 4,10 & 12,50 \\
\hline $\mathbf{8}$ & 76,2 & 1780 & 5,83 & 0,12 & 0,53 & 1,31 & 0,09 & 7,09 & 14,49 & 14,96 & 26,00 & 2,90 & 15,90 \\
\hline $\mathbf{9}$ & 65,0 & 1359 & 6,37 & 0,11 & 0,55 & 1,25 & 0,08 & 8,13 & 5,54 & 6,19 & 56,30 & 6,10 & 39,70 \\
\hline $\mathbf{1 0}$ & 90,0 & 1438 & 5,71 & 0,12 & 0,26 & 2,61 & 0,09 & 7,18 & 6,23 & 7,32 & 36,40 & 8,20 & 22,70 \\
\hline Média & $\mathbf{7 5 , 2}$ & $\mathbf{1 5 9 6}$ & $\mathbf{4 , 1 7}$ & $\mathbf{0 , 1 9}$ & $\mathbf{0 , 4 0}$ & $\mathbf{1 , 8 2}$ & $\mathbf{0 , 1 1}$ & $\mathbf{6 , 2 7}$ & $\mathbf{1 3 , 3 7}$ & $\mathbf{1 4 , 2 8}$ & $\mathbf{2 8 , 3 6}$ & $\mathbf{4 , 3 9}$ & $\mathbf{1 5 , 9 9}$ \\
\hline DP & $\mathbf{1 0 , 5}$ & $\mathbf{2 4 3}$ & $\mathbf{1 , 5 3}$ & $\mathbf{0 , 0 7}$ & $\mathbf{0 , 1 0}$ & $\mathbf{0 , 5 0}$ & $\mathbf{0 , 0 2}$ & $\mathbf{1 , 2 9}$ & $\mathbf{5 , 4 0}$ & $\mathbf{5 , 6 9}$ & $\mathbf{1 1 , 4 0}$ & $\mathbf{1 , 9 0}$ & $\mathbf{9 , 4 0}$ \\
\hline
\end{tabular}

\section{Quadro XVIII. Dados Farmacocinéticos (Grupo sem CEC)}

\begin{tabular}{|c|c|c|c|c|c|c|c|c|c|c|c|c|c|}
\hline Paciente & Peso & dose & alfa & $\begin{array}{l}\mathrm{t} 1 / 2 \\
\text { alfa }\end{array}$ & beta & $\begin{array}{l}\text { t1/2 } \\
\text { beta }\end{array}$ & Gama & $\begin{array}{c}\mathrm{T} 1 / 2 \\
\text { gama }\end{array}$ & $\begin{array}{c}\text { AUC } \\
0-\mathbf{t}\end{array}$ & $\begin{array}{l}\text { AUC } \\
\text { 0-inf }\end{array}$ & CLT & $\begin{array}{c}\text { Vd } \\
\text { beta }\end{array}$ & $\begin{array}{c}\text { Vd } \\
\text { gama }\end{array}$ \\
\hline 1 & 63,0 & 1328 & 4,67 & 0,15 & 0,26 & 2,58 & 0,04 & 14,51 & 9,86 & 11,61 & 30,30 & 6,70 & 37,80 \\
\hline 2 & 78,0 & 1774 & 11,79 & 0,06 & 0,13 & 5,10 & 0,06 & 10,28 & 23,78 & 27,87 & 13,60 & 6,00 & 12,20 \\
\hline 3 & 71,0 & 1361 & 6,74 & 0,10 & 0,15 & 4,48 & 0,08 & 8,01 & 16,99 & 18,2 & 17,50 & 6,80 & 12,20 \\
\hline 4 & 90,0 & 1533 & 4,86 & 0,14 & 0,16 & 4,33 & 0,08 & 8,20 & 7,38 & 8,64 & 32,90 & 12,30 & 23,50 \\
\hline 5 & 73,7 & 1389 & 1,17 & 0,59 & 0,25 & 2,71 & 0,06 & 11,01 & 17,29 & 20,82 & 15,10 & 3,50 & 14,40 \\
\hline 6 & 64,8 & 933 & 3,91 & 0,18 & 0,20 & 3,35 & 0,05 & 12,29 & 20,63 & 23,17 & 10,40 & 3,00 & 11,10 \\
\hline 7 & 81,0 & 2437 & 2,09 & 0,33 & 0,26 & 2,59 & 0,05 & 12,83 & 21,04 & 26,24 & 19,10 & 4,30 & 21,20 \\
\hline 8 & 82,0 & 1570 & 3,75 & 0,18 & 0,30 & 2,27 & 0,08 & 8,37 & 14,83 & 16,41 & 19,40 & 3,80 & 14,10 \\
\hline 9 & 71,0 & 1357 & 3,01 & 0,23 & 0,12 & 5,51 & 0,07 & 9,18 & 25,54 & 28,65 & 11,10 & 5,30 & 8,80 \\
\hline 10 & 74,2 & 1770 & 5,66 & 0,12 & 0,18 & 3,73 & 0,06 & 10,33 & 26,48 & 29,44 & 13,50 & 4,40 & 12,10 \\
\hline Media & 74,9 & 1545 & 4,76 & 0,21 & 0,20 & 3,67 & 0,06 & 10,50 & 18,38 & 21,105 & 18,29 & 5,61 & 16,74 \\
\hline DP & 8,2 & 396 & 2,96 & 0,15 & 0,06 & 1,15 & $\mathbf{0 , 0 1}$ & 2,18 & 6,39 & 7,2945 & $\mathbf{7 , 6 7}$ & 2,69 & 8,69 \\
\hline
\end{tabular}




\section{Quadro XIX. Percentagem do erro de previsão}

\begin{tabular}{|c|c|c|c|c|c|c|c|c|c|c|c|}
\hline $\begin{array}{c}\text { Grupo CEC } \\
\text { Paciente }\end{array}$ & $5 \mathrm{~min}$ & $15 \mathrm{~min}$ & 30min & $60 \mathrm{~min}$ & $120 \mathrm{~min}$ & $240 \mathrm{~min}$ & Fim.Cir. & $5 \mathrm{~min}$ & $15 \mathrm{~min}$ & 30min & $\begin{array}{l}\text { Fim da } \\
\text { infusão }\end{array}$ \\
\hline 1 & $-25,72$ & $-47,72$ & 50,74 & $-44,22$ & 45,71 & $-21,78$ & $-14,52$ & 38,73 & $-21,50$ & 20,92 & 35,67 \\
\hline 2 & 48,94 & $-30,09$ & $-13,19$ & $-25,24$ & $-100,00$ & $-56,39$ & $-83,84$ & 20,85 & $-57,46$ & $-42,14$ & $-38,55$ \\
\hline 3 & $-12,50$ & $-44,51$ & $-1,93$ & $-22,70$ & $-55,36$ & $-71,20$ & $-18,09$ & $-0,09$ & $-36,69$ & 53,74 & 16,95 \\
\hline 4 & $-52,16$ & 7,57 & 38,04 & 44,21 & 105,34 & & $-2,05$ & 7,47 & 14,47 & 37,28 & $-40,84$ \\
\hline 5 & 63,24 & 47,89 & 129,34 & 16,30 & 53,83 & 194,65 & $-14,03$ & 32,91 & 26,93 & 10,01 & $-5,94$ \\
\hline 6 & 31,57 & $-48,08$ & 54,60 & 31,32 & & & $-41,66$ & 33,75 & $-15,85$ & $-31,32$ & $-3,08$ \\
\hline 7 & 59,32 & 1,84 & $-0,64$ & 17,03 & $-4,47$ & & $-17,67$ & $-7,44$ & 21,40 & 13,00 & 74,22 \\
\hline 8 & $-10,69$ & $-43,93$ & 45,00 & 85,41 & $-2,29$ & & $-45,76$ & 8,47 & $-57,77$ & $-17,69$ & $-19,69$ \\
\hline 9 & $-64,67$ & $-31,04$ & $-68,64$ & $-47,33$ & & & $-89,74$ & 79,47 & $-70,15$ & $-79,47$ & $-49,39$ \\
\hline 10 & $-52,51$ & $-9,55$ & $-24,50$ & $-46,67$ & & & $-85,01$ & 70,03 & $-38,30$ & $-42,69$ & $-31,46$ \\
\hline Média & $-1,519$ & $-19,8$ & 20,88 & 0,81 & $-25,72$ & $-55,47$ & $-41,24$ & $-5,66$ & $-23,49$ & $-7,836$ & $-6,21$ \\
\hline EP & 15,45 & 9,94 & 17,28 & 14,26 & 24,16 & 29,03 & 10,63 & 13,01 & 11,03 & 13,15 & 12,33 \\
\hline $\begin{array}{l}\text { Grupo sem } \\
\text { CEC } \\
\text { Paciente } \\
\end{array}$ & $5 \mathrm{~min}$ & $15 \mathrm{~min}$ & 30min & $60 \mathrm{~min}$ & $120 \mathrm{~min}$ & 240min & Fim.Cir. & $5 \mathrm{~min}$ & $15 \mathrm{~min}$ & 30min & $\begin{array}{l}\text { Fim da } \\
\text { infusão }\end{array}$ \\
\hline 1 & $-18,69$ & 51,33 & $-51,87$ & $-32,58$ & 20,94 & $-42,50$ & $-35,74$ & $-1,78$ & $-23,41$ & $-45,85$ & $-54,49$ \\
\hline 2 & 36,21 & $-27,28$ & 71,20 & $-60,12$ & 77,22 & 156,69 & 20,05 & 66,50 & 21,85 & $-19,97$ & $-36,99$ \\
\hline 3 & $-44,58$ & 83,18 & 78,25 & 227,00 & 57,33 & $-11,02$ & $-38,48$ & 45,17 & $-67,20$ & $-8,81$ & $-8,81$ \\
\hline 4 & $-15,83$ & $-23,83$ & $-59,05$ & $-46,13$ & $-26,07$ & & $-51,74$ & 26,04 & $-19,97$ & $-9,18$ & $-24,04$ \\
\hline 5 & 29,54 & $-50,41$ & 127,34 & $-21,69$ & 80,54 & $-66,28$ & $-40,53$ & $-8,02$ & $-34,81$ & 126,32 & 49,72 \\
\hline 6 & 129,84 & 29,50 & 58,35 & 173,74 & 280,94 & $-16,60$ & $-16,60$ & 26,36 & 16,13 & $-20,75$ & 26,85 \\
\hline 7 & 31,60 & 87,26 & $-23,75$ & $-44,12$ & 4,66 & 54,14 & $-52,09$ & 41,41 & 1,11 & & 1,11 \\
\hline 8 & $-38,84$ & $-14,72$ & 37,39 & 11,42 & 127,87 & $-54,02$ & $-35,85$ & 5,79 & $-42,02$ & $-3,26$ & $-3,26$ \\
\hline 9 & 5,44 & $-31,33$ & 1,64 & $-19,92$ & 33,80 & 254,20 & $-4,05$ & 2,16 & 18,11 & $-20,16$ & $-0,45$ \\
\hline 10 & $-10,42$ & 51,74 & 33,93 & 25,74 & 3,25 & 283,02 & 16,23 & 59,76 & $-12,66$ & 18,47 & 31,52 \\
\hline Média & 10,43 & 15,54 & 27,34 & 21,33 & 66,04 & 45,76 & $-23,88$ & 12,03 & $-14,29$ & $-8,319$ & $-1,88$ \\
\hline EP & 16,05 & 16,11 & 19,04 & 31,19 & 27,82 & 43,56 & 8,387 & 11,44 & 9,20 & 17,98 & 10,08 \\
\hline
\end{tabular}


Quadro XX. Temperatura mínima durante a CEC e Hematócrito mínimo durante a CEC (Grupo CEC)

\begin{tabular}{|c|c|c|}
\hline & $\begin{array}{l}\text { Temperatura mínima durante a } \\
\text { CEC (o C) }\end{array}$ & $\begin{array}{l}\text { Hematócrito mínimo durante } \\
\text { a CEC }\end{array}$ \\
\hline Paciente & & \\
\hline 1 & 31 & 23 \\
\hline 2 & 30,6 & 28 \\
\hline 3 & 33,5 & 21 \\
\hline 4 & 31 & 26,4 \\
\hline 5 & 31 & 22 \\
\hline 6 & 31 & 25 \\
\hline 7 & 30 & 29 \\
\hline 8 & 28 & 28 \\
\hline 9 & 28 & 23 \\
\hline 10 & 31 & 25 \\
\hline Média & 30,51 & 23 \\
\hline DP & 1,68 & 1,16 \\
\hline
\end{tabular}




\section{HOSPITAL DAS CLÍNICAS}

FACULDADE DE MEDICINA DA UNIVERSIDADE DE SÃO PAULO

\section{TERMO DE CONSENTIMENTO PÓS -INFORMAÇÃO}

(Instruções para preenchimento no final deste)

\section{I - DADOS DE IDENTIFICAÇÃO DO SUJEITO DA PESQUISA OU RESPONSÁVEL LEGAL}

1. NOME DO PACIENTE.

DOCUMENTO DE IDENTIDADE $\mathrm{N}^{\circ}$ :

SEXO : .M $\check{Z} \quad$ F $\check{Z}$

DATA NASCIMENTO: ........................

ENDEREÇO $\mathrm{N}^{\mathrm{o}}$

APTO:

BAIRRO: CIDADE

CEP.

TELEFONE: DDD )

2.RESPONSÁVEL LEGAL

NATUREZA (grau de parentesco, tutor, curador etc.)

DOCUMENTO DE IDENTIDADE : SEXO: M ̌̌ F $\check{Z}$ DATA NASCIMENTO.: ...................... ENDEREÇO: $\mathrm{N}^{\circ}$ APTO:

BAIRRO: CIDADE:

CEP: TELEFONE: DDD (

\section{II - DADOS SOBRE A PESQUISA CIENTÍFICA}

1. TÍTULO DO PROTOCOLO DE PESQUISA Efeitos da circulação extracorpórea sobre a farmacocinética e farmacodinâmica do propofol em pacientes submetidos à revascularização do miocárdio.

PESQUISADOR: Ricardo Antonio Guimarães Barbosa

FUNÇÃO: Médico Assistente INSCRIÇÃO CONSELHO REGIONAL No 65594

UNIDADE DO HCFMUSP: Anestesiologia

3. AVALIAÇÃO DO RISCO DA PESQUISA: (probabilidade de que o indivíduo sofra algum dano como consequência imediata ou tardia do estudo)

$$
\begin{array}{rcccc}
\text { SEM RISCO } & \check{Z} & \text { RISCO MÍNIMO } & \mathrm{X} & \text { RISCO MÉDIO } \\
\text { RISCO BAIXO } & \check{Z} & \text { RISCO MAIOR } & \check{Z} &
\end{array}
$$

4.DURAÇÃO DA PESQUISA : 2 anos 


\section{III - REGISTRO DAS EXPLICAÇÕES DO PESQUISADOR AO PACIENTE OU SEU REPRESENTANTE LEGAL SOBRE A PESQUISA, CONSIGNANDO:}

1. justificativa e os objetivos da pesquisa ; 2 . procedimentos que serão utilizados e propósitos, incluindo a identificação dos procedimentos que são experimentais; 3. desconfortos e riscos esperados; 4. benefícios que poderão ser obtidos; 5. procedimentos alternativos que possam ser vantajosos para o indivíduo.

\section{IV - ESCLARECIMENTOS DADOS PELO PESQUISADOR SOBRE GARANTIAS DO SUJEITO DA PESQUISA:}

1. acesso, a qualquer tempo, às informações sobre procedimentos, riscos e benefícios relacionados à pesquisa, inclusive para dirimir eventuais dúvidas.

2. liberdade de retirar seu consentimento a qualquer momento e de deixar de participar do estudo, sem que isto traga prejuízo à continuidade da assistência.

3. salvaguarda da confidencialidade, sigilo e privacidade.

4. disponibilidade de assistência no HCFMUSP, por eventuais danos à saúde, decorrentes da pesquisa.

5. viabilidade de indenização por eventuais danos à saúde decorrentes da pesquisa.

V. INFORMAÇÕES DE NOMES, ENDEREÇOS E TELEFONES DOS RESPONSÁVEIS PELO ACOMPANHAMENTO DA PESQUISA, PARA CONTATO EM CASO DE INTERCORRÊNCIAS CLÍNICAS E REAÇÕES ADVERSAS. 


\section{OBSERVAÇÕES COMPLEMENTARES:}

\section{VII - CONSENTIMENTO PÓS-ESCLARECIDO}

Declaro que, após convenientemente esclarecido pelo pesquisador e ter entendido o que me foi explicado, consinto em participar do presente Protocolo de Pesquisa

São Paulo, de de 19

\section{INSTRUÇÕES PARA PREENCHIMENTO (Resolução Conselho Nacional de Saúde 196, de 10 outubro 1996)}

1. Este termo conterá o registro das informações que o pesquisador fornecerá ao sujeito da pesquisa, em linguagem clara e acessível, evitando-se vocábulos técnicos não compatíveis com o grau de conhecimento do interlocutor.

2. A avaliação do grau de risco deve ser minuciosa, levando em conta qualquer possibilidade de intervenção e de dano à integridade física do sujeito da pesquisa.

3. O formulário poderá ser preenchido em letra de forma legível, datilografia ou meios eletrônicos.

4. Este termo deverá ser elaborado em duas vias, ficando uma via em poder do paciente ou seu representante legal e outra deverá ser juntada ao prontuário do paciente.

5. A via do Termo de Consentimento Pós-Informação submetida à análise da Comissão de Ética para Análise de Projetos de Pesquisa -CAPPesq deverá ser idêntica àquela que será fornecida ao sujeito da pesquisa. 